\title{
Aubrey Lewis's Report on his Visits to Psychiatric Centres in Europe in 1937
}

\author{
HOLLAND ${ }^{1}$
}

\begin{abstract}
Amsterdam
I visited Van der Horst's clinic. He struck me as much more alert than Bouman, and is, I gather, more popular with the students. The researches of which he told me were concerned with electrical reactions in cats that were being treated with insulin, and the neurological findings in their hypothalamus; also the effect on neurotics of air of different ionic concentration, humidity etc. I gathered that in both of these researches the work had not yet really begun. I think he is also proposing to observe the electroencephalogram in monkeys poisoned with mescaline. I got the impression in many places that a great deal of research is arrived at by the process of saying to oneself, "A investigates B or uses method B; $X$ investigates $Y$ or uses method $Y$ : I will investigate $B$ and $Y$ together or use B and $Y$."

His chief psychologist, Van Essen, who succeeded Grunbaum, is an enthusiastic young man, whose training had been at first in comparative psychology under Van Boutdendyck [sic] and thereafter in Vienna under Karl Bühler for 3 years, where he wrote his thesis on "The psychology of decerebrate birds." He seems to have a free hand in his psychological researches on time relations of motor performance, and is to assist Van der Horst in proposed investigations of the Berger Rhythm ${ }^{2}$ and in other electro-physiological work, though he seemed to me to have little intimate knowledge of the technique and principles.

Van Essen though without medical training also runs a pedagogic child guidance practice, to which children are referred by doctors. He is also working on reaction time in three tempos, following on some of Van der Horst's earlier studies on cyclothymia and schizophrenia and American tapping tests. He and Van Hasselt in the histological department are, as far as I could gather, the only two assistants who have remained

\footnotetext{
${ }^{1}$ Psychiatry in Holland experienced the reforms occurring in other countries over the course of the nineteenth century somewhat later. In the second half of that century, there were fewer asylums in Holland than elsewhere, and rather than constructing new buildings, older urban buildings were renovated. Administrative bodies held much more power over asylums than doctors, and there were limited reforms in treatment and management. In 1884 a law restricted the maximum number of patients within each institution, leading to the construction of new buildings. Throughout the nineteenth century and into the first half of the twentieth, there was a strong religious component to the social efforts to improve care of the mentally ill.

${ }^{2}$ Hans Berger (1873-1941) was a German psychiatrist who made original observations on the changes in electrical potential which could be recorded through the intact skull and which led to the development of electroencephalography (EEG), which records the electrical activity of the brain.
} 
working in the clinic for years; the others have gone off into private practice. Similarly psychologists give up their work in order to go in for school teaching which is rather better paid. The rest of the laboratory staff at the clinic are relatively inexpert I should think, though Feitscher has had adequate training in psychometrics in Vienna. Feitscher discussed with me the psychological testing of children, which he does using Charlotte Bühler's methods. His original training was as a philologist; he is still interested in speech disorder in organic brain disease, though as far as I could gather he had not done much about it as yet; he was poorly informed about foreign literature on the subject.

Van der Horst told me he spent 4 to 5 hours a week in routine teaching, apart from his ward rounds. He has 150 beds, with five assistants on the clinical side and five in the laboratory.

I was told that the "Free" university is relatively poor in numbers and financially in danger of losing its privileges, unless certain requirements can be met. Of course, the Chair of Psychiatry and Directorship of the Clinic were not held by the same man until recently. I got the impression, not limited to this clinic nor indeed to Holland, that more research would be done if almost the whole staff were not engaged also in private practice, and so much time were not taken up in conducting university examinations. It seemed to be even truer of Bouman's Clinic in which the Professor spends relatively little of his time because of journeys abroad etc. Van der Horst's assistant, Wientjes, an alert fellow, interested in the somatic aspects, took me round the wards of the clinic. There is a fairly active child OP [out-patient] department, and as at Bouman's Clinic they take children into the wards. They have not time to do psychotherapy any more than at Bouman's Clinic.

At the Wilhemina ${ }^{3}$ Clinic I saw first Bouman's chief assistant, Van der Waals, who runs the psychological laboratory. He has also psychoanalytical interests, chiefly in his private practice. In the psychological laboratory he is able to get most of his apparatus constructed by an excellent mechanic-carpenter he has, and apparently he can also get adequate funds for instruments, for example, a Michotte tachistoscope. ${ }^{4} \mathrm{He}$ is working on the apparent movement of successively exposed objects and does it well, I think, though without applying any strict mathematical way of determining the relationship between the period of each exposure and the intervals between them, or as to the rate of movement and effect on the apparent duration of the experience. His research would lend itself very well to an enquiry on time appreciation, from the point of view of external factors which influence it.

Van der Waals also has some interesting work in optokinetic nystagmus, especially its influence on after-images. There seems to be a complete gap between his psychological researches, which are of the academic sort, and his clinical work with patients; though he spoke rather vaguely about some perceptual studies on cerebral lesions. I had an impression that it was only to organic cerebral disease that he thought experimental psychological study applicable; probably he is influenced by Bouman's point of view. Van der Waals's psychoanalytical views seemed moderate.

\footnotetext{
${ }^{3}$ The Wilhemina Gasthuis in Amsterdam was built in 1929; with its modern laboratories and a neurosurgery section, it was a milestone for Dutch neurology.

${ }^{4}$ Albert Michotte (1881-1965) of Louvain University devised, in the late 1940s, an elaborate mechanical apparatus that allowed him to manipulate the animation of two objects on a projection screen, thus enabling experiments on the attribution of causality.
} 


\section{Aubrey Lewis}

Bouman professes to be well-disposed towards psychoanalysis and told me that most of his staff had been analysed. I had the impression, however, that this had had very little effect on the general conduct of the clinic's work, and that psychotherapy of any sort in the OPD [out-patient department] is hardly practicable because the doctors cannot give the time to it. The same is true of the Valeriusklinick. Professor Bouman struck me as more interested in the cells of the cortex than in anything else, apart from travelling. He seemed convinced, in accordance with his earlier work, that cerebral cell changes in schizophrenia were constant and important. He has a dilettante interest in comparative anthropology, working in loose association with Kappers.

As in the other Dutch and the Belgian clinics, the buildings, equipment, space, libraries and so forth seemed excellent. Bouman's clinic is particularly well arranged in the provision for excited women, who are kept in large rooms, ingeniously arranged so as to appear open and very light. His continuous baths, however, have, like nearly all the European ones, either boards or canvas covers (with a hole for the patient's neck), which are really a form of constraint.

The provision for excited men was not so good. The cases Bouman showed me as interesting ones were nearly all of organic cerebral disease, and he told me he was working on the histopathology of Pick' $s^{5}$ and Alzheimer' ${ }^{6}$ diseases. He struck me as pleasant, and clinically very experienced, but old-fashioned and not stimulating.

The clinic which functions as a reception unit for the city is so arranged in the general hospital system that cases of cerebral concussion are all sent to him; his assistant Katt wrote a fairly comprehensive thesis about it last year. Evidently the compulsory writing of theses for a doctorate has this advantage, that it brings a fair number of people around the Professor, who do work which he suggests to them, or which he himself would like to do but has not the time for. Later these people drift away from the clinic, but at least it results in there being an interest in research and some activity.

The way in which cases are admitted to the various hospitals is part of an admirable system of health administration in Amsterdam. I heard about it from several sources but mainly from Arie Querido who is in charge of the psychiatric section. The arrangements are unified, covering at any rate $98 \%$ of the people of Amsterdam. The city is independent, and owns the Wilhemina Gasthuis and University, and employs under its

\footnotetext{
${ }^{5}$ Arnold Pick (1851-1924) described pre-senile dementia with focal cerebral atrophy in 1892. An assistant to Theodor Meynert and also to Karl Westphal, Pick later worked at the Wehnen County Asylum, and then became doctor at the Prague County Asylum in 1877. In 1878 he was made lecturer in psychiatry and neurology at Prague University. In 1886 he was professor of psychiatry and head of the psychiatric clinic at the German University in Prague. His work on the cortical localisation of speech disturbances won him international acclaim.

${ }^{6}$ Alois Alzheimer (1864-1915) worked at Frankfurt's asylum, collaborating closely with Franz Nissl, on the pathology of the nervous system. Alzheimer became director of the asylum in 1895, and from there conducted the research forming the basis of his description of pre-senile dementia now bearing his name, first describing in 1906 his observations on an unusual disease of the cerebral cortex. Emil Kraepelin suggested that the condition be named after him. In 1902 he went to Heidelberg, and then Munich where in 1908 he was a professor at the Psychiatric Institute and director of the clinic's anatomical laboratory. In 1912 he went to the Psychiatric and Neurological Institute in Breslau. Between 1906 and 1918 he edited, with Franz Nissl, Histologische und histopathologische Arbeiten über die Grosshirnrinde, 7 vols, Jena, G Fischer, 1904-1921.
} 


\section{Report}

Chief Medical Officer a large staff of doctors, nurse-social workers and secretaries who supervise the distribution and aftercare or out-patient care of all illness. The system arose out of the situation that hospital beds were getting choked up with chronic or unsuitable material. So now, whenever anyone is sick the panel doctors calls in the city doctor (the system also covers schools, defectives etc.) who goes and sees the patient and decides whether he needs hospital treatment, and if so, to which hospital and which department he ought to go. Consequently a man like Snapper can get all the bone diseases, for instance, that he wants for research or teaching - he can get indeed all that there are in Amsterdam; in fact any recognised teacher or investigator has only to say the word and his material is obtained for him. On the psychiatric side the public health doctors decide what patients shall go to what psychiatric departments, if at all, and can keep in touch with them in the mental hospitals (which are, however, not under the city's control, though the city pays 300 guilders a year for each patient and can get the patients discharged from hospital much sooner than was formerly the case because it undertakes to supervise them).

The way in which the psychiatric section keeps some control over the movement of the mental hospital population is by its power of deciding which patients it will send to any particular mental hospital. If the superintendent is active and cooperates with the public health psychiatrists then more cases are sent to him. If not, he is embarrassed by not having many patients and therefore not receiving the sustentation pay for each, which would help the finances of the hospital.

The social workers visit the patients and interview them in their own homes after discharge from hospital, as they recognise it is useless to wait until the patients come to them. It is very much more efficiently done than in the corresponding arrangements in Moscow and Leningrad. Querido has, as his social workers, experienced nurses, (it would probably be an advantage for them to have more specialised training on the psychiatric side, but they do their work very well as it is). I was told that they get a good type of nurse in the mental hospitals because there is much unemployment among teachers and the pay is good. I was able to go out with Querido and his nurse and social worker to a particular call that came in when I was there, and to see how smoothly the system worked. This public health and aftercare service is excellently organised not only on the administrative side, but also as regards records, though they do not seem yet to have availed themselves of all the statistical opportunities which they system provides.

The legislative and administrative details are complicated, though it is clear that the system has saved the city much expense and has facilitated the early discharge of schizophrenics, for example. The city organisation, as a whole, almost seems to have been worked into the scheme and influenced by it, e.g. policemen report to Querido's department any instance of a man behaving oddly; sometimes he has even to check over-enthusiasm, as when a policeman would be inclined to take into custody some person who is behaving oddly, whereas the patient in question is a harmless paranoid or defective who is being quite adequately cared for extramurally. Querido's background is in physiology (which he did with Cannon in 1924 on a Rockefeller fellowship) and then public health work and moderate psychoanalytical interests. He is justly proud of his department, and enthusiastic. Some effort has been made to bring the child 


\section{Aubrey Lewis}

guidance movement in Amsterdam into the ambit of this public health activity, but there are difficulties in the way.

The psychoanalysts are less strict in their orthodoxy than the London ones, and seem still to be outside the official circles; thus, for panel purposes one cannot get recognised as a specialist in neuro-psychiatry unless one has done three years in a psychiatric clinic, and few of the analysts have done this. As elsewhere, it was clear that conditions of private practice and work were one of the chief factors in determining the direction of people's interests towards analysis. The more they are dependent on private practice and work is one of the chief factors in determining the direction of people's interests towards analysis. The more they are dependent on private practice for their clinical material or their research material, the more are they inclined towards analytical inquiry and treatment.

Carp in Leiden struck me as a good instance of this. He has latterly had to give up 10 of his 20 beds to a neurologist and has no control over the nature of the cases admitted to his beds, consequently he has to use the out-patients of his private practice for his clinical material, and so his likings and interests have turned from organic diseases of the brain, which occupied him formerly, towards psychopathology and more or less analytical enquiries only.

Child guidance seems to have got further from psychiatry in Amsterdam rather than closer to it. Dr Tiebout seemed to be torn between the desire to be more analytical in her approach to the children, and the manifest economic obstacles to that. The clinic anyhow seemed to be limited by its small income. I gathered however that the analytical trend had led to the raising of the question whether the training of social workers should take the form of personal analysis in Vienna instead of a regular Psychiatric Social Worker's Training course, as at the London School of Economics, but this proposal had not got any further than getting ventilated.

Mrs Querido, who is also a doctor, works in the child guidance clinic, so that there is a loose connection of a personal kind between it and the public health organisation of the city; possibly the connection will become closer.

At Revesz's psychological laboratory I found there was also considerable interest in children. A woman who is his chief assistant has been working on problems of co-operation, i.e. seeing how much better a child performs a task if another child is set on to it with him: they have examined children over the age of seven. It seemed a well-controlled experimental approach to the question. Revesz himself seemed very stimulating and eager, especially about his research on haptic perception; his work covers a wide field and is applicable, I should think, to some problems of organic brain disease. Like so many other people working in fields that have not so far in their experience touched closely on psychiatry, he expressed a keen desire to get on to psychiatric material. I should think he would certainly, given the free run of a psychiatric clinic, attach some of the questions in a fresh and productive way. He said half-jokingly that he would jump at the chance to spend 6 months in a clinic like the Maudsley. I suspect though that he may be a difficult man to work with, because of his variable temperament and impulsive frankness.

Similarly when I saw Snapper and discussed with him the work he was doing, he agreed with me when I remarked on how relevant some of his investigations were to 
psychiatric problems, and he told me that although he himself had not the time nor the opportunity to tackle these, one of his men had been appointed internist at the university clinic, and it was now the rule in each mental hospital to have one trained internist to deal with general mental problems; I gathered though that this full time appointment involved routine work much more than research.

From some of the people in Snapper's clinic whom I met, I gathered that there is a closer association between Brouwer's and Snapper's clinics than between Snapper's and Bouman's; Bouman is generally rather isolated from the rest of the Wilhelmina Gasthuis.

I went over to Brouwer's clinic, but he was ill, so I saw de Jong. He seemed preoccupied and sensitive about his position. He was very kind and showed me the effects of bulbocapnine. Most of the objections that have been urged against his work seem to have some validity, but certainly he is carrying on steadily and systematically with the observations on motor phenomena in cats and mice, chiefly, produced by various drugs. He seemed painstaking and tenacious but depressed, dull, and to my surprise unfamiliar with some investigations that had been published and touched closely on his work. Some of the more or less obvious investigations (for example, sympathectomy and the effects of curare or insulin) he had not yet undertaken; but he told me he was proposing to go to the Heymans in Ghent to prepare himself for studying electrical phenomena. His work seemed to be interesting as a pharmacodynamic study of motility, rather than as one shedding light on schizophrenic catatonia. His collaborators did not impress me much in the little I saw of them. De Jong is of course fairly well aware of the weak points of his work and theory but seems to shut his eyes to them. I went to Kappers' Institute, but he was away in America. I did not learn about researches bearing even remotely on comparative psychology etc., perhaps because I was shown round by a dry, highly specialized zoologist, Addens, interested mainly in the nucleus of the spinal accessory nerve.

\section{Leiden}

In Leiden I was not able to see Carp or Gorter as they were both away, or Van Hemmelen, however, I saw Wiersma. The arrangement there is fortunate for a child guidance clinic in that the chief assistant of pediatrics and Professor Carp's assistant both work in it; the social work is done by a medial woman. The clinic seemed comparatively small (they have an average of 2-3 new cases a week). They are probably not having all the material, though of course the cases with a somatic basis are weeded out at the beginning. Wiersma seemed keen on doing as much as possible of the psychological examination of the cases himself, but seemed hampered in research work by the smallness of his material; in his investigations on some psychometric tests he was contentedly taking the problem children as capable of giving him his general norms, and I thought his statistical methods were hardly refined enough for his small samples. He lives rather under the shadow of his father. He seemed likeable and sensible in his child psychiatry. I also saw Gorter's chief assistant, and discussed with the physicist there - Van Ormondt - the investigations they are doing on mono-molecular layers. The methods do not yet seem applicable to clinical work, though they might soon become of use in estimating albumen-globulin proportions and quantity of electrolytes 


\section{Aubrey Lewis}

in CSF [cerebrospinal fluid] etc. I don't know whether there is any important difference between what Gorter is doing with it and what Langmuir in America and the men in London and Cambridge are doing.

Rademaker I also saw. He told me of his interesting work on the striate area in the dog, and the effects of extirpation on the movements of the legs of the animal; also of his work on nystagmus etc. He seems much occupied with clinical neurology at present.

In Holland, as elsewhere, I found the oddest gaps in people's knowledge of work that was close to their own, going on in other countries. This was true even of people who knew the literature of their subject apparently well otherwise; often they would admit they had only just heard of so and so, but did not know the value of his work or the details of it. It seemed as though there was a need for two things (a) all-inclusive abstracts such as the Zentralblatt used to supply in neurology and psychiatry, and (b) reviews by competent people of work in all sorts of scientific departments, so that people in individual fields should not be unaware of work touching on their own in other fields. The existing abstracts and reviewing journals obviously do not meet the need, for various reasons.

I also found in Holland, as elsewhere, that clinical psychiatrists were doing little in the way of research that would commend itself to any of the research workers accustomed to modern physiology, etc. They seemed neither to take up other people's methods precisely and intelligently, nor to originate any of their own; of course, there were exceptions to this.

\section{Utrecht}

In Utrecht I saw Ziedses des Plantes who explained to me his ingenious X-ray methods. Like Feitelberg and von Muralt, he seemed to illustrate very well the advantages of having had a special training, (for example, in physics or engineering) beforehand.

I also went to Rümke's clinic - he has just obtained the chair. Silvies Smitt showed me around the wards; I gather he has great hopes of getting the neurology chair which is now to be separated from the psychiatric one. He seemed a balanced fellow with strong, candidly expressed views. He runs the child guidance clinic; it is not in a very satisfactory state financially, I gather, and they may not be able to continue to pay a social worker. A private donor may again supply the money. The question of the neurological chair seems a ticklish one with a political background. In Utrecht they have a large number of students in the medical school who take up a good deal of the teacher's time; Rümke was examining students when I was there.

I also went round to Professor Noyons. He showed me his wealth of apparatus and his laboratories, and told me of the various researches he was doing in basal metabolism, skin reactions in varying temperatures, sound, smell, disturbances of consciousness during rotation etc. If only one could enjoy his extraordinary richness of appropriate and ingeniously devised apparatus, some of the metabolic problems of psychiatry could be tackled with much greater precision than at the present time. He apparently has no contact with the psychiatric clinic himself. 


\section{BELGIUM $^{7}$}

\section{Brussels}

In Brussels I saw Bremer. His work has an obvious application to psychiatry; although Bremer is in private practice and sees some psychiatric material, I gather he has not the opportunity particularly to carry over his physiological researches into the clinical fields. He surprised me rather by saying that he had obtained some promising results in the treatment of depression by photodyn - which is now generally discredited. I thought his work on the brain very stimulating.

I also saw Rodolphe Ley. He was extremely kind and helpful, in arranging visits for me, etc. He suffers from lack of material to work on, owing to unsatisfactory arrangements, and has to rely on brains sent him by others, like Van Bogaert. There are problems also about getting scientific papers published in a reasonable time. His histological work seemed sound rather than enterprising, though of course this could be accounted for by the somewhat difficult conditions under which he works.

From him I went to Laruelle's neurological institute. He showed me his "repèrage" method of neurological diagnosis (bubbles of air introduced by lumbar puncture), and the attempt he is making to benefit anxiety-neurotics by periods of continuous oxygen administration. I was not much impressed by the assistant, Andrée, who was carrying this out, but I was not there long enough to form an opinion. The best thing at Laruelle's clinic is his technique for cutting serial longitudinal sections of the cord instead of the usual cross sections. I gather that the whole of this work depends on his technical assistant, Mdlle Reumont, who is obviously very skilful and intelligent. It is a pity that as I heard elsewhere, there were obstacles in the way of her finishing her medical course. Laruelle seemed a man with plenty of ideas of a fruitful kind, but he does not publish much, apart from little things, and dislikes the hack-work of research. I could not find out whether it was a lack of funds or other reasons that had so far prevented him for applying his technique to the study of ascending and descending degeneration in animals; nor why he had so few collaborators. Although his institute is not official but lives on private funds, it seems to have an important influence on neuro-psychiatry in Brussels.

I visited the Dispensaire d'Hygiène Mentale, conducted formerly by Auguste Ley and now by Vermeylen, who sees only the children; all the adults being seen by Alexander who visits about four or five times a week in an honorary capacity. It seemed surprising that there was no regular paid official provision for the carrying out

\footnotetext{
${ }^{7}$ In the early twentieth century in Belgium there were fifty-four closed psychiatric establishments, belonging variously to the State, public administrations, individuals or religious organisations. From 1873 asylum directors had to be nominated by the Ministry of Justice; and in 1931 a jury was formed to check the qualifications and expertise of candidates; until then the head doctor could simply be the one living nearest to the asylum. From 1874 the law also required frequent inspections of establishments and the recording of any use of constraints. A system of open services for patients presenting no danger developed at the beginning of the twentieth century against the wishes of the judicial authorities; as a result of the controversy over this issue it developed illegally. In 1920 the law regarding inspections was extended to institutions for abnormal children. While demented children had to be held in asylums, they were, however, subject to laws on child protection. After the First World War, the mental hygiene movement led to the opening of numerous dispensaries for adults and children amidst an increasing concern with prevention of mental illness.
} 


\section{Aubrey Lewis}

of some of the work which is entrusted to the centre, for example the supervision and treatment of cases referred from the prisons under the "Loi de la Défense Sociale". 8 The treatment at the Dispensaire is mainly social, I gather, and is carried out by a competent sister in charge and her trainees and voluntary helpers: the number of cases is such, that I should think Alexander must be overwhelmed with them. The children's department is organised separately so far as the five or six doctors go, and here too the treatment is mainly social. It is the only child guidance clinic in Brussels, except a Catholic centre which is practically limited to the diagnosis of mental deficiency amongst Catholic school children. Here, as in most of the other institutions which I came across in Belgium, the question of rivalry or partisan appointment in respect of sectarian and political influence cropped up. The work at the Croix Rouge Centre seemed to me to be well done, within their limits.

Professor Vermeylen's psychiatric clinic is, of course, excellently constructed, and combines a purely voluntary university clinic - like the Maudsley or the Henri Rousselle - with another independent building for "colloqués", i.e. a sort of observation ward. He has a disadvantage in that he is not able to keep his patients longer than two months. He is energetic and positive, though not profound or impressive from the research point of view. In the development of mental hygiene in Brussels, however, he seems an important influence. The research he told me of at his own clinic included some studies in reaction time in GPI [general paralysis of the insane] before and after treatment (which he thought might have a prognostic value); and an enquiry which he was just beginning into the effects of a compound allied to dinitrophenol upon the absorption of vitamins; also some work on the haemato-encephalic barrier - it did not sound very valuable. He is rather more interested in social developments and administration than in pure psychiatry; he has, however, the advantage of having done some work in applied psychology. His work on mental deficiency seems to have been somewhat original but based on inadequate experience.

I saw Louis Vervaeck at the Prison de Forêt. It is a pity that the enormous amount of work which he has done in the way of collecting anthropological and other data should never have led to any conclusions; he has a mass of material, but I couldn't discover that he was going to apply any statistical analysis to it, or otherwise study it. It looked like an unrivalled collection of data for research in criminology.

I was struck in various places I visited in Belgium by their keenness on social work, and yet their relatively inadequate training for psychiatric social workers; they were

\footnotetext{
${ }^{8}$ This law (of 9 April 1930) instituted a new juridical system for "abnormal delinquents", not only for those whose responsibility was completely annihilated, but also for those with diminished responsibility, on the condition that this diminution was permanent. The law provided for the placing of the accused under observation in a psychiatric annexe of a penitentiary centre for one month - this could be renewed monthly for a period of up to six months. Psychiatric experts would determine whether the accused suffered from dementia or a serious state of mental disequilibrium or debility rendering him or her incapable of controlling his or her actions; if so, the accused would be interned in a special establishment, initially for five years, raised to ten years if the crime required punishment by forced labour, or fifteen if it was punishable by death. (Decisions were susceptible to appeal.) Each case was re-examined every six months in the light of medical observations. Upon release, a magistrate and psychiatric doctors would determine whether freedom of the accused was on a trial basis or definitive. If there was no cure, the internment could be prolonged. In 1964 various amendments were made to the law, making internment, whatever the gravity of the act, by default of indeterminate length. This was felt necessary due to the inability to predict the duration of a treatment.
} 


\section{Report}

for the most part unaware of such training as that given at the School of Economics in London to which the Scandinavians and Dutch come. It would probably be a good thing if one at least of their people could come and see what the training is.

\section{Louvain}

In Louvain I visited d'Hollander's out-patient clinic where he sees the patients rather cursorily and such of the ex-prisoners as are referred to him under the "Loi de la Défense Sociale". It seemed to me, however, that this law cannot be working satisfactorily because one of the patients, whom d'Hollander saw that morning while I was there, had killed his mistress and was now married to a woman among whose immediate relatives four had committed suicide; moreover d'Hollander had not heard of this before though it was not the first time the man had attended the clinic. D'Hollander is old and will probably have to retire fairly soon. Though he is energetic he looks as though he will presently be physically incapable of going on. His chief interest in is histopathology, especially of sympathetic ganglia and fibres. He is attached to some theories abandoned elsewhere, e.g. the tuberculous nature of schizophrenia. He has clearly had a great influence in Louvain and has obtained extraordinarily good buildings for his laboratories and wards. I gathered that he had his own way nearly always, and plenty of money at his disposal for his work; and that his nominee - a tall young man whom I met at the out-patient clinic - would almost certainly succeed him.

I saw van Gehuchten in his out-patient clinic, where he suffers from having practically no one to help him. His, I think, is the only neurological chair in Belgium; it is because of his father's prestige that it still exists. He is working on the effect of lesions of the locus niger in animals. He is only just beginning his experimental work. It is a pity he has no better facilities. He is also interested in acute infective encephalitis.

\section{Liège}

I went to Liège to see Divry but unfortunately did not manage to meet him. I saw his out-patient clinic which is not well equipped; his research work is, as far as I can discover from his publications etc., concerned with histopathology and he is more of a neurologist than a psychiatrist. Fredering I could not see.

\section{Antwerp}

In Antwerp Van Bogaert showed me the Institute Bunge. Van Bogaert finds it an advantage to be independent of the University because of the rivalries which he thus avoids; he gets his pathological material from many sources. Van Bogaert has with him Scherer who is working on the different cellular structure of gliomas in serial sections, and on comparative pathology, as well as routine work. He has a plenitude of material, and excellent facilities. The atmosphere of the institute seemed very agreeable. The comparative studies are being done also in an interesting way in the chemical department where they are working out the normal serum and blood chemistry of monkeys, preparatory to studying the pathological changes. They seemed particularly fortunate in their relationship with the zoo in Antwerp; whenever one of the animals is ill, Van Bogaert examines it clinically and when it dies he gets the central nervous system; 


\section{Aubrey Lewis}

part of it he passes on to Scherer and the other part to de Wulf, the superintendent of the Corbeeloo at Louvain, who is studying microglia by Hortega methods (which he learned in Madrid). I did not meet him. I also met the other people in the Institut Bunge, including an American CRB Fellow interested in neuro-surgery. A proportion of their time is taken up with routine work on the patients, but it is mostly research they do.

Van Bogaert seemed keen on enlarging the research activities of the institute: for example, I gathered that he felt that the physiological work was not being as well done as it might be owing to the incomplete training of his brother who looks after it. Van Bogaert distributes his interests so widely that, as he himself recognises, he does not go tenaciously and profoundly into any topic, but he struck me as an admirable man for directing a clinic because of his wide contacts and interests, his productivity in collaboration with others, his keenness and freshness of ideas, and his amiability.

In Antwerp I also saw the tropical diseases hospital and teaching school which seemed unduly magnificent for its main purpose. I gathered that in spite of the splendid appointments little research is done, though they do a lot of clinical pathological tests.

Van Bogaert also told me of the various more or less isolated problems which had been interesting him. There is no doubt as to his freshness and receptiveness. He had met with a number of infections and toxaemias of the central nervous system in monkeys and other animals; and endarteritis obliterans in the artery of the kangaroo's tail, confirmed by plethysmographic studies which he had been able to do; various forms of epilepsy, including one amaurotic one in animals. He is also very interested in fat metabolism, giving the patient butter and cholesterol, and then every half hour or so for the next 12 hours estimating the cholesterine, lipoid, non-saponifiable fat and phosphatides of the blood: he had had a case with cholesterol deposit in the cerebellum, xanthelasma, cholesterol in tendons and yet no change in the blood cholesterol. His interest in this latter problem was linked up with Epstein's work in Vienna.

\section{Ghent}

I also saw Professor Hyssen of Ghent whose chief interest is in reactions to pain (blood pressure, electrical changes etc.). He has practically no clinical facilities - no beds, etc., and he was very frank about the general conditions. Like some of the other professors in Belgium he has a policlinic only, and has to get his material for teaching from a mental hospital nearby, which in the instance of Ghent is very badly appointed.

I saw de Busscher in Ghent and he showed me the material which he had been able to collect as the result of his extremely energetic, almost excessively industrious activity. He has been able, partly through his experience and training, and partly because of his father who is head of the Department of Gynaecology in the "Byloque", to get a precarious attachment in that hospital, but without beds, out-patients or control of treatment: he was called in as a consultant. He is in consequence naturally discontented, and contrasted the conditions of work which he met with in America during his period as CRB Fellow, with the opportunities allowed him now. It seems very likely that his frankness is criticising and his hypomanic temperament would have stood in his way as much as the political bias in university circles. He has not refrained from telling the doctors publicly and plainly how gross the deficiencies are, for example, 
in the provision of neuro-surgical treatment for cerebral tumours. Although he has the position of chargé-de-cours in the teaching faculty in Brussels, where he is an exponent of very mild psychoanalysis to the Flemish-speaking students, he is unpopular with the strongly national Flemish who control the faculty in Ghent. It is proposed, I gather, by these people, to build a big hospital in rivalry to the "Byloque", (which is certainly badly provided with such things as $\mathrm{X}$-ray, and where the pathological department has settled somewhat into a rut, so that the findings sent back from these departments cannot be trusted). De Busscher is the only neurologist in Ghent, and so in his private practice gets a lot of material as well as the "Bonne Maison", where he sees cases. Fortunately, de Busscher is on good terms with the professor of surgery, de Beule, who would be glad to co-operate with him in starting a brain tumour centre in Ghent: he has already more than 50 cases that have come his way. De Busscher has so much energy that if such a unit could be started it would certainly be productive on the neurological and pathological side, I should think. De Busscher is also on very good terms with Thomas, the pathologist, and would probably get on very well with anyone who was fairly young, and even half as energetic as himself.

Thomas took me to his department of forensic medicine and showed me his interesting and very painstaking work on the normal structure of the thyroid and the changes which occur in it in general toxaemia etc., as well as his work on artificial cancer in mice and rats. He took me round to Professor Gormaghtigh, who told me about his work on suprarenals and on kidney lesions and changes in blood pressure induced by excess of vitamin D. I also saw Heymans who described his experiments on sympathectomized cats and the factors influencing the circulatory distribution: we discussed the application of some of these points to psychiatry, particularly the difference between the sympathectomized cat with and without adrenalin; the outstanding manifestations of emotion in the former instance cannot be central; it raises interesting questions regarding peripheral influence in affect, and links up with some of Bremer's work on his cats with isolated encephalon.

\section{Gheel $^{9}$}

At Gheel there were the obvious features, such as Kilgour describes, and which Pollock goes into from a wider point of view in his recent little book. The chief points of interest, otherwise, that occurred to me were (1) the attitude of the people of Gheel. Every psychiatrist stresses the importance of environment for mentally ill people, and the desirability that they should be surrounded by normal people and influences, of child guidance; what then is the reverse aspect? i.e. in this case, what is the influence upon the children and people of Gheel of having these lunatics and

\footnotetext{
${ }^{9}$ The origins of Gheel lie in a legend concerning Dimphne, the daughter of a king of Ireland, who in the seventh century clandestinely fled the country with her confessor, the priest Gerebernus, wishing to escape from her father who wanted incestuous relations. The fugitives were found by the king and his police in Gheel, on the path of a pilgrimage to Rome, and both killed. The legend tells of miraculous healings of mentally ill patients by the tomb of the girl; Gheel became a place of pilgrimage and inhabitants used to welcome and house the ill. Dimphne and the priest were canonized, and a church built in the eighth century had a "patients' room" where pilgrims prayed, and where Dimphne's relics lie. The welcoming of the mentally ill continued despite the construction in 1862 of an infirmary and then a psychiatric hospital, and after the colony became the property of the State.
} 


\section{Aubrey Lewis}

defectives all round them, living always in their houses; and what is the effect of taking lunacy as a matter of course? Of not having the customary attitude of aversion to it, but living in a rather topsy-turvy state of acceptance of it as more or less normal? Actually by all accounts it makes very little difference at Gheel; in other words, growing up in a partly insane environment has there very little effect on normal children or adults, so that presumably a relatively well-endowed person is not a penny the worse for being frequently in contact with mentally unhealthy or unstable people. However, this question, so frequently raised in genetic studies, needs more investigation and seems to offer some interest as a research possibility. There is, for example, also the question as to what form hysteria takes among the normal peasant population of Gheel. Do theyrimitate psychosis and defect rather than physical forms of illness? Gheel supplies, as it were, the obverse of the psychiatrists' insistence on the desirability of a normal and healthy environment for the development of normal mental health.

Then there is the important point that according to Dr Raemaekers they have no sexual delinquency among the patients, no assaults on children etc., and no homicidal attacks. Seeing that there are so many defectives, this also seems a point for further investigation as to the social influence at work in bringing about such an excellent result. The children they have are all defectives, not delinquents. Among the adult women patients, however, I gather there is a case of pregnancy about once every 18 months, and they have had two homicides in the last 100 years.

Then there is the question as to whether a fair amount of what might be called ill treatment must be reckoned with. Some mild ill treatment there certainly is; the control is not close or constant and the doctors deliberately do not investigate trifling complaints of unkindness etc. It may be that that is an essential part of such a working scheme, and that, inevitably, living in a family in such circumstances will lead to some ill usage which should not be bothered about. It is true that in the Dutch colony there is stricter supervision and probably also in the French one but it is quite likely that one must strike a balance between licence and strict control. It may well be that for many of the patients it is less "normal" if they are not occasionally treated as they would be in any ordinary home of their class when they were troublesome. This seems reactionary, though there seems reason to believe that the application of mental hospital supervision to family care might defeat its own ends. On the whole there is probably scarcely any victimisation of the patients by the family guardians, but sometimes some of the patients do an excessive amount of work because their delusions urge them to; however, in a particular case which I came across when I went round with Dr Raemaekers I think the family were trying to dissuade the patient. The doctors, of whom there are eight to 3,600 patients, are not closely enough in touch with their patients to know them all well.

There is also the question of whether defectives do better if they are in homes with people of a rather low intelligence themselves, so that they "fit in", as it were, or whether that tends to result in quarrelling and stupid ill-treatment. I raised the point with Dr Raemaekers but he had not considered it particularly. The question really is whether understanding and care by intelligent people is better than a milieu to which the patient easily adapts and from which he is, in essentials, not far removed. 


\section{Report}

The selection of cases for Gheel does not seem to be satisfactorily carried out. They have to take all the overflow of the mental hospitals. Judging from the numbers of patients they have in the colony, four more such places would provide for all the insane of Belgium; and the colony is of course much less expensive than the mental hospital. But I gathered that vested interests, especially the religious bodies, which control the mental hospitals, would be opposed to such a scheme, even if it were practicable.

It seems, however, certain from present trends that in the US and many European countries, especially Switzerland, there will be more and more family care, if possible on the colony system. Gheel is therefore very valuable: it is the best experiment, and offers many opportunities for research which do not seem to have availed of at all. (The Swiss procedure, as developed in Zurich under Bleuler and Hans Maier, is much more scattered and less satisfactory economically, as well as in some other respects). It is, for example, quite impossible to say what proportion of the patients at Gheel are defective, and what proportion have mental disorders. Nor could it be discovered how the patients do under the treatment; what proportion recover, what types of illness do best, how the duration of illness compares with that in mental hospitals, and so forth. The records barely exist and certainly are not detailed enough to give a basis for diagnosis. It is therefore impossible at present to form any useful opinion as to the value of the Gheel Colony method therapeutically (as against its economic advantages), much less compare it with prognosis or decide on the applicability of such methods elsewhere, say in the rural parts of England. Everyone who writes about Gheel puts a lot of stress on the religious background etc., whereas it is doubtful how far these historic and traditional factors now weigh with the population. It has been possible, for instance, to extend the colony into regions which were outside the geographical range of these traditional influence; girls from the villages and hamlets which are now included in the colony used, formerly, if they married a Gheel peasant, to find the care of a patient disagreeable until they got accustomed to it, but afterwards they fitted into the system quite well.

There are a lot of points upon which it is impossible to obtain precise information; there is for example the question of duration of stay and factors which may prolong it; for example, I saw one girl who stayed there largely because there was no one who would take the responsibility of looking after her when she went out, as her parents were separated and she had been in trouble through having an illegitimate child before. In this case they are really detaining a mentally healthy girl who is a potential social problem.

From the point of view of financial and administrative aspects of social psychiatry, as well as for psychiatric theory (influence of environment), Gheel seems to offer excellent material for research which could be carried out by a psychiatrist and social worker; they could extend their investigations to the other colonies and family-care schemes in Europe. At present the people at Gheel make no research use of their material; they do not, for instance, compare the incidence of tuberculosis in their schizophrenia patients with that of the normal population of Gheel, yet here is a perfect case for studying it, without having the abnormal living conditions of the 


\section{Aubrey Lewis}

mental hospitals to confuse the issue. They could also study the duration of life of their patients as compared with the average population living under almost identical conditions: there were a lot of old women patients about, and chronic patients stay there until they die. I think Dr Raemaekers would facilitate any investigations, but it is unlikely he could make them himself, partly because of his administrative duties which would, at any rate under present conditions, prevent him from giving enough time to it, and partly because his interests do not lie in that direction; but he has a benevolent attitude towards it, has done research work in pharmacology himself with Sollmann in [the] USA and seems hopeful of getting laboratory work going. It is a pity that one of the Dutch, psychiatric social workers, cannot be roped into a research of this kind; she would have the advantage of knowing the language.

There were several general impressions I got about conditions in Belgium. It was not that they were particularly different from those in other countries, but they were emphasized by the people I talked to. The fact that most doctors have to do private practice has, besides various clinical advantages, many disadvantages. Plenty of people would like to devote themselves much more to scientific work but cannot afford to; and on the other hand there is a great deal of the individualist attitude among doctors, i.e. they would rather earn the varying income of a competitive profession than have the fixed salary of a full-time professor or research worker. Vacancies are usually filled by appointing one of the people already in the particular city, so that there is on the whole not much interchange between the various universities and medical faculties. The clerical domination of some of the universities and of the mental hospitals is generally thought to tend towards conservatism and to result in inadequate medical staffing, along with unduly imposing buildings and equipment. It is perhaps partly due to this that Freudian doctrines are scarcely considered in Belgium, though Vermeylen is mildly favourable towards such a point of view; strict Freudian views of the kind met with in London are reprobated by the few people who know about them. Apart from Vermeylen, the general trend is strongly neurological, and even he is less speculative than some of them suppose him to be, I should say. Their mental hygiene movement concentrates on social results, and seems to have accomplished a good deal; of course the social conscience in such matters is fairly strong in Belgium. Sterilisation of the unfit is not an issue among them, and their rule is to have a procedure for therapeutic abortion almost as strict as the English requirements for certification of the insane. The secular nurses in psychiatric clinics are pretty well trained. I was told they do three years general training and one year special psychiatric training. I did not find out how the nurses among the religious orders are trained; d'Hollander said they were excellent.

Vermeylen seems to be the only professor who is particularly interested in psychiatry; the others are mainly neurologists or anatomists. The influence of French neurology and psychiatry is, of course, strong; consequently, and partly also because there is in many instances a dearth of material, people use the "casuistical" method of publication, ie of single cases. Moreover, there are few pathologists in Belgium. Van Bogaert says he cannot find anyone capable of co-operating in a virus enquiry. 


\section{Paris}

In Paris I went to see L'hermitte in the Hôpital Henri Brousse, but he was away and I went round with de Massary, who is one of the senior people there. He seemed to me a poor clinician, examining his cases in a slipshod way and sometimes not knowing the essential factors about a patient. His treatment seemed of the blunderbuss kind, in the children's OP department. His clinical material, however, was very interesting. I later saw L'hermitte, who is still very active, and better informed about foreign literature than many of the other people I met in Paris. He seems to stimulate his people in various directions (e.g. I have just received, since I came back, a thesis by a Persian doctor whom L'hermitte had put on to a clinical and psychopathological investigation into disturbances of the body-image). His chief interest is, of course, in histopathology. At the Fondation Déjerine I saw many sections illustrating his studies of the changes in the dentate nucleus in myoclonus epilepsy; also the cell changes in the cords of rabbits in which he had injected anti-tetanic serum. He was interested in the latter problem because of some cases of paralysis in human beings which had followed injections of anti-tetanic serum. He seemed a little bold in the way he argued from rabbits to men, rabbits being, I think, particularly untrustworthy for such a comparison. He has with him a very good technician, Frln Kirchner, who had much experience of microglia and macroglia work with Bielschowsky before 1933.

I was interested to meet Paul Schiff, who belongs to the "évolution psychiatrique" group, and is particularly interested in applications of psychiatry to delinquency. He has had a good background in neurology and psychiatry and is also a psychoanalyst, but his present work is in the prisons chiefly. He has an official position examining and reporting upon the new prisoners. His appointment followed legislative action in which he had a large share behind the scenes. It will probably develop further, I understand. I read some of the reports he furnished to the courts, and it seemed to me that Schiff was doing the job very well so far as one man could cope with the amount of material. He is a rather melancholy, quiet man, but enthusiastic about his work. I learned from him that in Paris there is the same problem as in London - so many societies that one can spend every night going to meetings of those which have some connection with one's work.

In Lapicque's laboratory I saw Monnier, who showed me his work in recording simultaneous action-current at two points on a nerve and so calculating the rate of

\footnotetext{
${ }^{10}$ The primacy of French psychiatry in the first two-thirds of the nineteenth century had gradually been occluded by German psychiatry in the 1880 s and 1890 s. In the twentieth century, French psychiatry did, however, enrich the understanding of delusional states and contribute towards their classification, partly through the work of Gaétan de Cléraumbault and Joseph Capgras. And, as can be seen here, there were some highly influential psychiatrists in France, especially in Paris, at the time of Lewis's trip. Building on a heritage of studies in neurology, hysteria, and neurosis, French psychiatry was significantly organicist in bent - assimilating the recent physical therapies, which gained much ground in the $1930 \mathrm{~s}$, researching epilepsy and GPI, and searching for infectious causes of mental illness - but was also incorporating psychoanalysis, which in the 1920 s made inroads in the form of organizations such as the Mouvement Psychanalytique Français and the Revue Française de Psychanalyse. The mental hygiene movement had taken off in 1920s, and in the 1930s there was a move towards modernization of services and a focus on prevention.
} 


\section{Aubrey Lewis}

conduction, and he told me also of the lessened excitability and rate of conduction in motor nerves which he had found as the central effect of the injection of pyrethrine. I heard him give a lecture (to an engineering society, I believe) in which he showed an excellent capacity for expounding the matter clearly.

I saw Guillain at the Salpêtrière and attended his clinical demonstration. It was neatly and dramatically done, but on a superficial level; the examination was very brief and the commentary limited to one or two points of practical importance. I also met Mollaret, Roussy and Oberling - very briefly, and Ivan Bertrand with whom I spoke several hours. Bertrand is of course not entirely contented, and like most people in Paris does not see where the young men are coming from who are going to continue in research, the claims of private practice being imperative. Although he has the necessary apparatus etc., he seems at the moment to lack collaborators. His own investigations on the rate of regeneration of peripheral nerve when the spinal cord of a rabbit is used as a temporary substitute seemed an interesting piece of research applied to reparative surgery; he had done it in conjunction with Gosset. His other studies in conjunction with Guillain etc., were fairly straightforward pathological and anatomical ones. He is anxious to get Fessard to work with him and also to get some work going on comparative pathology of the nervous system.

The group that surrounds Eugène Minkowski seems to have scarcely any contact with the neurologists and holders of official chairs in Paris; not that there is enmity, but only lack of contact. Laignel-Lavastine is on friendly terms with this group, but is somewhat contemptuously regarded by the more neurological group. Minkowski's group "L'évolution psychiatrique" consists mainly of people interested in psychopathology, but there are also people like Guiraud in it, and a number of Claude's assistants as well as people at the Hôpital Henri Rousselle. Most of the more progressive people now seem to be associated with this group, for example, Heuyer, who has started a child guidance clinic (Minkowski also visits a children's home for behaviour problems, which is being run on sensible lines). Henri Ey who has done interesting work on hallucinations, Rubenovitch etc. Of course some of the members are psychoanalysts, but the French Freudians are not orthodox according to Vienna, and are certainly much less extreme than in London. They have their own society for discussing points of analytical technique. In Minkowski's society they take a broad psychiatric view. Minkowski himself seems still to be the most potent influence in maintaining this desirable emphasis on the broader medical aspects of psychopathology, and his strong philosophic bent gives depth to the general studies carried on by the group. In respect of psychopathology this small French group seems to me on the whole to be superior to many of the English and American workers who are either wholly psychoanalytical or inclined to be naively superficial and objective.

Guiraud, who wrote the textbook with Dide, ${ }^{11}$ is chiefly insistent on his extraordinary findings in fresh foci in disseminated sclerosis. Certainly the things which he regards as parasites are visible in his stained preparations, and his Achucarro method seems safe enough, though it is surprising that so few people whom I have questioned

\footnotetext{
${ }^{11}$ M Dide and P Guiraud (eds), La Psychiatrie du médecin practicien, Paris, Masson 1922; 2nd ed. 1929.
} 


\section{Report}

about it even knew of the conclusions he had reached; certainly they (the conclusions) seemed hard to believe. He had with him, the day I was there, a young man, Delmond, who has written an interesting thesis on schizophrenia, and seemed quite alert and keen. I was surprised to find that although he works next door to Guiraud he had never seen Guiraud's preparations before. There doesn't seem to be as much communication as there might be between the various people and departments in Paris; of course the gulf between the "médecins des hôpitaux" and the "médecins des asiles" is wide. Guiraud I also saw in his OPD, where he is in his element because of his lively and plastic temperament. He struck me as a good clinical psychiatrist, and he must be a most amusing teacher. Although he knows the literature of psychiatry well, he seemed a bit behindhand in some respects; for example, he would tell commonplace things abut the result of malaria treatment in GPI as though they were fairly new.

The Hôpital Henri Rousselle seems to have fallen away from its original achievements and potentialities. Génil-Perrin is apparently a good clinician, but not particularly interested in research and progress and change of any kind. Of course he has only just taken over, but it is hard to picture him developing the place much; Mme Lebas, the secretary of the hospital, who has been there for a long time, seems to be chiefly responsible for the organization of it. They have a fairly busy OPD but from what Montassut told me there is not an adequate supply of doctors interested in working there, because they have to spend most of their time earning their living in private practice, and it is hardly worth their while. Moreover, there is no teaching there because it is all concentrated in the official hands of the Faculté. I gather they had no full time staff, but only part time people like Montassut, Schiff and Minkowski (though the latter hardly go there now), and house physicians. The doctors are former "médecins des hôpitaux" and psychiatrists without asylum experience; in other words the "médecins des asiles" have very little opportunity of getting into touch with the more psychological side of therapy etc.

In the laboratories at Henri Rousselle there did not seem to be much going on. The chemistry which was being done by Tscherniakovsky seemed old fashioned; they were doing out-of-date things like tryptophane, the Boltz reaction, but I understood that Tscherniakovsky had been away with Charcot on one of his polar expeditions and so perhaps had not been able to get things going. The younger Delaville - I did not see the elder one - was doing work on interferometry which seemed also out of date. They did not seem well up in the literature. In the psychological laboratories Lahy seemed more interested in psychotechnics and educational problems than in anything that had reference to the patients or psychiatry generally. Simonet, the director of the physiological laboratory, was away on the two occasions when I called. It seemed odd that the laboratories of the hospital should be quite independent from those of Claude which were only a few yards away.

I made repeated attempts to see Rubénovitch but he seemed in a dreadful hurry and passed me on to Lagache, who is the successor of Baruk and Rubenovitch as chef de clinique for Claude. Lagache is a Freudian, but fairly well equipped also on the somatic side. He will probably, however, drift into private practice, of which he already does a little. He seemed intelligent, and, like Delmond, keen on doing scientific work if he 
can get the chance. At present he is studying the psychopathology of jealousy, but the investigation did not seem likely to lead to anything particular. I could not find that much advantage was taken, at present, of the fact that Georges Dumas's laboratory is situated on the floor above the clinic, to bring about any application of psychology to psychiatric problems.

Fessard I found more original and very interesting. He has poor facilities at Piéron's laboratory - his wife has had to come in to wash up his vessels for him at times - his application of the Berger rhythm to problems of attention (studying the latent period) offered several possibilities. Unfortunately he is so shy and has in a mild way a feeling of inferiority and resentment towards doctors so that he rather distrusts them and fears that they will treat him as a technician, as though he had only some special skill. This made him dubious about falling in with Bertrand's invitation to collaborate; he knew of some of the common, rather unimportant, objections to Bertrand. He was actually eager, however, to work on clinical problems. He regrets the shortness of his stay with Matthews, and he would jump at the chance to get a further period in England, during which he might also find an opportunity of seeing clinical material and getting a working knowledge of clinical problems. The difficulty is, of course, getting spared from his teaching work.

\section{Strasbourg}

In Strasbourg I first saw Stahl who is continuing the work that he was doing in the USA. He is obviously very thorough and conscientious, and unhappy because he is unable to give all his time to research. His assistant and he are studying carefully the metabolic aspects, phosphatase, sodium, etc. of adrenal extirpation. The younger and more energetic people in Strasbourg seem to cooperate very well with each other. I met Keyser, Ginglinger and a number of the young people working with Leriche. Leriche's more or less experimental surgery struck me as bold rather than well-based. The originality of his ideas is very attractive but sometimes seems to depend on lack of familiarity with the relevant facts. Whether his therapeutic claims for sympathetic operations are justified, I had no means of judging. Surprisingly, he has not carried his operations into the psychiatric field, e.g. he has not treated anxiety cases surgically. I gathered, though, that Pferrsdorf is distinctly conservative. It must be stimulating to work with Leriche, but difficult if one is sceptically inclined. Keyser's studies on heat regulation were of interest and could, I should think, be carried over into the human field and applied to catatonic stupor etc., with some advantage, but he told me that the work is so exacting of time and patience that he would not like to have to repeat what he has already done (with pigeons etc.). His many other ideas were not particularly relevant to the problems of neurology and psychiatry. Ginglinger I also saw, but unfortunately Ancel, Bouin and Wolff were away on holiday, as it was Easter. Pferrsdorf seems to be mainly occupied, as he as been for years, with aphasia, and does not particularly welcome any fresh developments, though he is of course a good clinical psychiatrist. 


\section{Report}

\section{Lyons}

In Lyons, at Easter, I had difficulties - as also in Marseilles and Geneva - in seeing the people I wanted to, because of the holidays. Dechaume, the Agrégé to Favre, took me round the medical faculty, and the neurological department at the Hôpital Edouard Herriot. Dechaume works a good deal with Hermann. From what Dechaume told me, the collaboration between the people in the different medical departments is fairly close; of his own papers, most seem to have been written in collaboration. He told me that they had no trouble there in getting satisfactory young people to do research, partly because it is the road to a career in Dijon, Grenoble, etc. He showed me the laboratories of Policard and Hermann, but unfortunately I could not see either of these as they were away.

\section{Marseilles}

In Marseilles I did not see Cornil because he was ill. Mosinger told me that Cornil has to spend some months every year in bed, and his heart is getting worse. Mosinger is very energetic and his enthusiasm seems to equal his output. It is hard to understand how he could have found time to write his big textbook on legal medicine, and his monograph in collaboration with Roussy, and at the same time have done his teaching and have got his various researches under way. He carries his interest in the hypothalamus as a secretory organ to considerable lengths, but the specimens he showed me suggested interesting lines of work. I had the impression, though, that he is inclined to pin more faith, and inferences as to function, on histopathological observations than one should. He is, however, quite aware of the more or less conjectural nature of some of the links in his chain of reasoning. He was full of ideas, especially regarding psychiatry; besides his interest in the prolan content in women with dementia praecox. He told me about his studies of vitamin A content in the livers of individual guinea pigs, in whom no difference of species or of diet could account for the difference of chronaxie which according to him corresponded to the lack or presence of vitamin $A$ in these animals. If confirmed, it sounds a promising line of investigation, but as the administration of vitamin $\mathrm{A}$ in their diet raised the chronaxie, it seems surprising that diet can have had no part in determining the initial differences. Another and more interesting study that he was making in conjunction with Chevalier was a spectrophotometric investigation by means of which he would be able to analyse both quantitatively and qualitatively substances of relatively simple molecular structure, for example vitamins $\mathrm{A}$ and $\mathrm{C}$ and folliculin. In so far as it is a potential method of studying simple proteins in various tissues, it has some similarity to Gorter's study of monomolecular layers, though probably more practical at present.

Although Mosinger has not had training in psychiatry, he seems alive to its interest and importance and especially to the medico-legal implications. He struck me as overconfident, but certain to get a lot of interesting work done.

Neither in Lyons or Marseilles, as far as I could discover, does psychiatry really exist as such in the University. The professor, e.g. Lepine, is a neurologist and for his psychiatric teaching uses the material of the local asylum. 


\section{Aubrey Lewis}

\section{SWITZERLAND ${ }^{12}$}

\section{Geneva}

In Geneva I saw Claparède who looks older than his years now, tired and unhappy because of the political disturbances; his family troubles too have been great and seem to have told on him. His teaching duties are heavy at the Institut Jean-Jacques Rousseau, and his assistants are so much taken up with routine that they cannot give him much help. He was one of the few psychologists I met who had had a medical training and recognised its value for research. His chief interest, as for many years, is in sleep and in speech; the latter has led him to a general interest in the question of cerebral localisation and he is in close touch with the most recent literature. I gathered that Bovet has also found it difficult to devote himself solely to his academic work because of his concern about the trend of political developments.

I also saw Piaget who discussed the opportunities of research in child psychiatry; he was not very ready to talk, however, but preferred to refer one to his books. He has a few people round him like Rey and Meile. He is at work on the development of mathematical ability in children which he finds is present surprisingly early.

\section{Bois-Bougy}

At Bois-Bougy I saw Löewenstein: he has resumed his work on papillary reactions and the study of movements in hysterics etc. In regard to the former he gives the impression that he will carry it to all possible lengths; he quoted cases where he had been able by its means to diagnose syphilis of the central nervous system long before there were any neurological signs, and when the Wassermann in the blood and CSF were still negative. In view of the data he gave and other things I have heard, some of his studies of this kind seem to require confirmation. There can be no doubt, however, as to the excellence of his ingenious and accurate method within its limited scope. His studies of motility by the well-known apparatus he used in Bonn, and by moving pictures, were of less interest. He is very enthusiastic about his two methods and draws unjustifiably wide conclusions from them, I thought; his skill seems to lie more on the technical side than on the interpretative. Of course, he is very much limited as to clinical material now. It is a pity because his papillary method needs to be applied to

\footnotetext{
${ }^{12}$ Psychiatry developed later in Switzerland than in other countries, and was initially linked to German psychiatry (three of the first four directors of the Burghölzli were German). Two individuals in particular helped place it on an independent footing: Auguste-Henri Forel (1848-1931) - who had fought for the pre-eminence of the head doctor as opposed to the financial administration in asylums - and Eugen Bleuler (1857-1939) - under whom a wave of therapeutic optimism emanated from the Burghölzli. Asylum directors were ipso facto professors of psychiatry in the corresponding university. The five most significant university clinics were Bel-Air, Cery, Burghölzli, Waldau and Friedmatt. From the days of Bleuler's direction of the Burghölzli, psychiatry began to be located in a wider territory than just the asylum. A move towards placement in families developed a little; while in Cery, in Waldau, a colony of patients was established. From the 1930s onwards, psychiatric policlinics - corresponding to the dispensaires d'hygiene mentale in France - developed significantly. Instead of making a rigorous distinction between closed and open services, and voluntary and obligatory placement, Swiss psychiatry tried to give establishments the air of a service libre. Acknowledging the significance of both hereditary and environmental factors, Swiss psychiatry was also fairly receptive to psychoanalysis; the Swiss Society of Psychoanalysis was founded in 1919. Binswanger's existential and phenomenological views were also influential.
} 
neurological material (disseminated sclerosis etc.). Löewenstein is also rather limited in his outlook, it seems to me; he had not followed some of the lines of investigation by his method which seemed obvious, and he knows only the German literature. At the Bel-Air Sanatorium he has charge of a house where psychopathic children are looked after.

\section{Geneva}

I saw Friedheim in Ashkenazy's laboratory. He had had a preliminary training in psychiatry with Bleuler (and Kraepelin I think) before he took up bio-chemistry and pharmacology. He has collaborated with Meyer (the son of Hans Horst Meyer), but finds little support from Ashkenazy who apparently dislikes any complicated apparatus or new fangled methods. His idea that dyes act as catalysts for cellular respiration and might therefore be used therapeutically in malaria and trypanosomiasis opened up an attractive line of investigation. It struck me that it would be a good thing if he were to extend his studies to GPI. We talked of work done on these lines also which might be applied to continuous narcosis. I could not judge whether the latter line of work would be productive or not: he had not yet been able to make the preliminary experiments.

I tried to see Walthard and de Morsier but they were both away on holiday. I also did not see Ladame, but I was told in Geneva that since he had the chair he has been more or less swamped by administrative work, and had not undertaken any research.

\section{Lausanne}

In Lausanne I saw Steck (the successor of Preissig) who was rather annoyed with himself for not having carried further his experiments with insulin as a form of treatment for schizophrenia, which he proposed years ago. He still thinks that insulin is efficacious in smaller and less drastic doses than Sakel advocates (though when Steck advocated this method years ago, it was a death which resulted from it that put him off continuing with it). He is critical and like most people has come to the conclusion that insulin can bring social benefit, e.g. by making the patient quieter or by bringing about general improvement in the state of some chronic or hopeless cases, and that sometimes it is prompter in cutting short an attack than other methods. However, he had had one case of status epilepticus due to it, and a number in which the treatment had done no good. Cardiazol he dislikes. Like most people, he has seen a number of relapses after temporarily successful insulin treatment.

\section{Yverdon}

I saw Georgi at Yverdon. He has built up this private mental hospital (which was very badly run and had a bad reputation before) very successfully; but it is necessary if he is to get on at all that he should get a Swiss qualification, and the preparation for his examinations is now hanging over his head. He works very hard. It is a pity that Grünthal did not welcome the proposal that Georgi and he should work together in one place. Georgi has managed with his modest equipment and his one technical assistant to do a remarkable amount of chemical serological research on the patients who he had treated with insulin and cardiazol. I saw his method and clinical material and discussed 


\section{Aubrey Lewis}

with him more or less controversial points. He has obtained a remission in $70 \%$ of his cases, some of them after four and even six months' treatment by the method. He also has observed social improvement in long-standing cases - making them quieter. $\mathrm{He}$ is combining cardiazol with insulin. He believes that epileptic convulsions occurring during the treatment are an advantage whereas Müller does his best to avoid them by giving luminal. He is making a study of the blood electrolytes, the permeability of the "barrier" to bromide, etc., in his case.

Wherever the insulin treatment was being carried out it was clear that one had to separate the three aspects of the matter (1) immediate outcome of the present attack, (2) outcome of a case in the long run, (3) theoretical and research possibilities offered. Hardly any of the people who carried out the treatment in the places I visited were aware of the American work on sodium amytal, nitrous oxide and other substances which temporarily produce a dramatic change in catatonic stupor. When I told them of it they seemed almost abashed, because so much emphasis has been put on the dramatic immediate effects of insulin as indicating that it is something quite different from what has previously been tried in the treatment of schizophrenia. Naturally in discussing the treatment most of the people who were using it a good deal said nothing about its making any patients worse; I gathered, however, that this sometimes occurs.

\section{Landeron}

I went off to Landeron to see Bersot; his hospital seemed rather haphazard in its organization but he himself keen in a slightly dilettante way; he has worked on the development of children, and published a paper on the excretion of vitamin $\mathrm{C}$; he is interested too in insulin treatment and cardiazol, which he has employed. However, his main merit seemed to lie in his advocacy of mental hygiene, and his statistical efforts. For the former he writes many pamphlets, worthy and well-intentioned but curiously old-fashioned in tone. For the latter, i.e. statistical work, he struck me as having the necessary industry but lacking in any critical attitude towards the figures he was offered. He seemed to regard the diagnostic and other data compiled from the official Swiss sheets as quite reliable, though I learned from others that the doctors hate filling out these compulsory sheets, which are rather detailed, so they do it carelessly; and in any case even if they took trouble with it, there would be the question of varying standards of diagnosis. I could not find that Bersot bothered himself about sources of error. He did not know how to work out percentages and movements of mental hospital population in a statistical way; he does not know the literature of this subject as well as is desirable if he is going to continue with his task of collecting the mental hospital statistics for all Europe. Still, the task is so formidable that, unless one were blind through enthusiasm or lack of criticism to the certain deficiencies in any figures obtained, one could hardly make a beginning in such as task. When I enquired in other countries less advanced psychiatrically than Switzerland, it was clear that their figures were of varying degrees of unreliability and that very few were in a state in which they could be analysed with profit. In Italy, for example, the only person who seemed to have any data collected was Modena; I tried hard to see him but did not succeed, and in any case people told me that he had not yet got trustworthy data. 
Similarly, or more so, the Russian statistics were very much to seek [sic]. Bersot is, at any rate, doing his best to collect such data as he can obtain; it is necessary as the first step - there will be plenty of people to point out how unsusceptible of useful analysis such figures are. Perhaps the time is hardly ripe for attempting to get general European figures when the standards of public provision for mental disorder and deficiency and the standards of diagnosis etc., vary so much, not to speak of the difficulties of ascertainment.

\section{Berne}

In Berne I saw Klaesi who showed me the many improvements he had made in his mental hospital. He is so self-centred and talkative that I found it difficult to discuss any matter with him. He talked a great deal but mostly about administrative matters - the private rooms he had built and so forth. He is ill-disposed to the use of insulin though he is using cardiazol, which, along with continuous narcosis and psychotherapy, seems to him to provide everything in the way of treatment which insulin could. On occupational therapy he has strong views, believing it to be greatly over-rated. He has altered the organisation of his hospital so that there are now three divisions. In the clinic, which is the admission section and main university teaching department, he has made the rooms rather comfortless and removed all reminders of home on the theory that the patient should not have anything to make him so satisfied with being in hospital that he would be willing to stay indefinitely; similarly he will not let them work in the garden as it would be too agreeable. Of course for the chronic patients these Spartan regulations are not imposed. Though he claimed extraordinarily good results in avoiding noise in the wards of his hospital, I could not discover that herein it was different from any other modern psychiatric hospital either in its methods or the success attained. He is so positive, that one was forced to doubt some of his conclusions; for example, when I asked if he had the impression that the special colours on the walls of the rooms in which manic and depressive patients are treated had proved effective, he said, "We have no impression about it, we have certain proof that it does"; the evidence was not forthcoming. He is a very skilled clinician, especially in dealing with schizophrenics. It is difficult to form an opinion about his work because so much seems to depend on the phase in which one comes across his variable and forceful personality.

One of his assistants (Brieben, I think) showed me the new children's clinic, actually an old inn which they are converting for the purpose. They will use it as a reformatory and observation centre for up to thirty difficult children, to judge their conduct, psychiatric condition, etc.; they will not keep the children longer than six months. The children, I gathered, will be sent there willy-nilly, but defectives will not be sent; parents will not have any say as to whether or not their children are to go to a place situated, as this is, in the grounds of the mental hospital.

I met some other assistants of Klaesi and the superintendent of a cantonal mental hospital who was visiting him: the latter told me that he used family care for his patients, roughly up to $50 \%$ of them going into families, mainly the families of the female nurses of the hospital. The nurses have, as throughout Switzerland, a pretty 


\section{Aubrey Lewis}

thorough training and there is a fair supply; Klaesi has come to the conclusion, incidentally, that ugly nurses are less beneficial for the patients, especially the depressed ones, and regulates his staff accordingly (it was difficult, with all his statements, to make out if they were considered opinions).

I was told that there are about 100 medical students; there seem to be more universities in Switzerland than the population of $4 \frac{1}{2}$ million people require, and it seems doubtful whether they can go on getting enough suitable men to teach and do research in their departments, now that they are reluctant to take anyone from outside as they used to.

Schizophrenia seems to be the aspect of mental disorder that very much colours Klaesi's outlook; his interest has, of course, always been on that side of psychiatry.

Grünthal and his technical assistant were busy. He showed me his comparative studies on the thalamus, and told me how he found the ontogenetic sequence in his mice-embryos reflected in the phylo-genetic series he has accumulated. He is proposing to study the function of the thalamus by the use of the electro-cautery. He is also continuing his Würzburg studies in brain volume and brain swelling. He has an interesting programme of further studies to deal with the anatomical basis for what is specifically human instead of seeking in the usual way for what is common to human beings and other animals. I went with him to his Policlinic too. He seems very satisfied with his present situation and opportunities (he has the chronic organic cases under his care in the hospital, which suits him because of his longstanding interest in such cases).

In Berne I also saw von Muralt, who was excited about the discoveries he was just then making about the chemical changes in the nerve fibre. He was right in the middle of it, working very hard, and hoped to be able to report to the Royal Society in June that he had found that a cholin ester is produced for very short spaces of time in the nerve fibre itself during stimulation, instead of only at the synapse of where there is an interruption of lipoid continuity. He had not so far been able to test the influence of eserine, etc., because of the difficulty of getting through the lipoid barrier in the nerve sheath. His work seemed to raise a lot of possibilities as regards time relations in nervous transmission and their chemico-physical basis. He is still busy reorganising his department, and has been successful in getting an arrangement working by which one of the more promising people in the department of internal medicine comes to him for a year; he has a man from there studying blood volume by a new method which von Muralt had devised. Although he is thus collaborating with the Department of Internal Medicine and is proposing to apply some of his methods to studying the blood volume of anaemias, emotional excitements, etc., he is not sanguine about the possibility of getting collaborators from the clinical side as he finds them so often vague in thought and unprecise in technique. He makes ingenious use of optical methods for studying the respiration in a frog's heart preparation, basal metabolism, etc. There is also a man studying the influence of pyruvic acid, etc., on haemolysis. Von Muralt also told me he was going to study the changes in metabolism of cretins at high altitudes at the station on the Jungfraujoch, carrying the cretins up and down by the funicular railway, while the estimation was made by his interferometric method. 


\section{Münsingen}

I went to Münsingen and saw Müller and the people who are working with him on insulin and cardiazol treatment. He had 20-odd patients at the time under the treatment, which was directly under the care of a German woman doctor, called May - an émigré working there voluntarily, I gathered, who would soon have to leave. They were treating several patients in one room and did not seem to worry about one patient seeing another in the throes of the treatment. Müller, however, feels strongly that one must individualise as regards dosage, etc., after one has acquired some experience with Sakel's original method. It was significant that he was not treating with insulin the large number of schizophrenics that one found in the hospital when going round. It wasn't that he thought it would harm them, but he didn't believe it would do any good either, except to a few of the noisy ones who might be quieter after it. He did not believe that there were ever any physical ill-effects, but this is probably due to his doing only the more obvious laboratory investigations; Georgi has found cylindrical casts and albumen after the insulin treatment. He does not take quite the same precautions as Georgi does in regard to cardiazol, but on the other hand thinks it would be a little dangerous to combine the two treatments. He mentioned also that he had known a patient whose recurrent depression had been cut short by insulin, but who complained afterwards that the recovery was not so satisfactory as when it occurred without such treatment on previous occasions; he also finds that he gets better results with catatonic and paranoid forms of schizophrenia than with those in which psychogenic and reactive features are obvious. I found, however, that many of the cases which had done well with insulin in this hands, particularly the paranoid ones, were such as would be diagnosed as mainly benign depressive ones at the Maudsley, and, I think, at the Phipps or Boston Psychopathic. I could not find that he or anyone else had made an investigation into the effect of insulin on the duration of recurrent benign attacks, i.e. mainly manic-depressive forms. Müller had once tried the treatment on an old obsessional case which was almost schizophrenic but it did no good. This question of diagnosis and type of case benefited seems to me one of the central points of the whole matter, and then there is the question of what they mean by good results: often in Müller paranoid cases it was a recovery without insight, which is, after all, a dubious kind of recovery.

Müller is very honest about his cases though, of course, inclined towards enthusiasm, but I think that he is disposed to put undue emphasis on the single case, which proves little or nothing. He is very ready to concede the provisional nature of any conclusions reached. If the contention of most of the insulin therapists as to its efficacy in early cases comes to be accepted, then people may come to have much the same attitude towards schizophrenia as towards cancer, namely that it needs to be diagnosed early and treated drastically, and even then the results are rather unsatisfactory. Obviously, at present, no one can tell whether the apparent good effects last. One interesting thing about this wave of interest in the physical mode of attack on schizophrenia, by insulin or cardiazol, is that psychotherapeutically-minded people, like Müller, Kronfeld and young Forel, take up the method enthusiastically. It is interesting that Müller, who identified himself a few years ago with psychotherapy in schizophrenia, does not do any psychotherapy on his insulin cases after the treatment. 


\section{Aubrey Lewis}

Müller seems to have organised a sort of little training course in insulin treatment, and gives some certificate to those who have worked with him for three months or more. He is certainly very careful in some directions; for example, he takes electrocardiograms on every case; this, no doubt, follows on the work which he did in conjunction with Hadorn on the subject. Using such precautions he thinks the dangers of the insulin treatment have been exaggerated, but from what I have seen elsewhere, I doubt this; at any rate for the average psychiatric clinic or hospital. There are, of course, a lot of other points with regard to insulin which strike one, not only at Münsingen by also in Vienna, and in many other psychiatric clinics I visited, but they resolve themselves, apart from technique, into questions of standard of accuracy in diagnosis and reliability of statements about recovery. Nearly everyone who has used it agreed that some cases will benefit by it which they would not have expected to be benefited by anything; that it is not a panacea; that it is no good for chronic cases; that no one can say how long the good effects will last, and that animal experiments suggests the possibility of cerebral damage (which would, however, be a small price to pay if in fact it arrested for good a progressive schizophrenia). The research possibilities which it opens are very many and seem to be pursued fairly widely at one or other clinic - Georgi on the bio-chemical and permeability side, Angyal on the motility side (in Budapest), etc. It looks to me as though in the long run the chief merits of the treatment would lie (a) in the research opportunities for studying bodily reactions in schizophrenia, and (b) in the fillip it has given to the therapy of schizophrenia on the physical side.

At Münsingen I met also Rittmeister and some of the other assistants. Rittmeister was formerly a pupil of Minkowski in Zürich and is now carrying out an investigation on finger tip patterns in schizophrenics (which Katzenstein suggested to him).

It seems that a fair number of German schizophrenics come for treatment into Switzerland to evade sterilisation. I was told that although the diagnosis in the case of German patients referred to Münsingen may, in Germany, have been given as something that does not call for sterilisation under German law, nevertheless, when the patient returns to Germany, sterilisation will probably be carried out whether the patient has recovered or not, the diagnosis of schizophrenia being either inferred from the fact that he has been at Münsingen or from the history given by his employers, etc., in Germany.

\section{Zürich}

In Zürich I spent some time with Hans Maier and was much impressed by his quiet and competent way of examining patients, and by the extraordinary amount of work he gets done both personally and in the clinic as a whole. It was the first European clinic I came across where records were kept fully, more or less in the manner customary in the United States and England; the contributions from the social agencies to the history were remarkably full. The chief thing that impressed me about Burghölzli ${ }^{13}$

\footnotetext{
${ }^{13}$ The Burghölzli - the Psychiatric University Hospital in Zürich - was founded in 1875, with Bernard von Gudden as its first director. Other directors included Julius Eduard Hitzig, Auguste Forel, Eugen Bleuler, Hans Wolfgang Maier and Manfred Bleuler. Karl Abraham, Franz Alexander, Ernest Jones, Carl Jung, and A A Brill were among those who spent portions of their careers at the Burghölzli.
} 
was the way the clinic was organised on social lines, research taking a second place. Alcoholism is, of course, still one of the most important psychiatric problems for them, but court cases, where women referred for a recommendation as to whether an abortion is appropriate or not, and other such issues, take up a great deal of their time as well. As far as alcoholism is concerned, it is interesting that they will not take cases on for a cure in a Heim for anything less than a year.

The organization of the policlinic, which I also visited, was explained to me by Glaus, the senior Oberarzt at Burghölzli, he sees special cases but the test of the work is done by three assistants; they do not reckon to treat the cases psychotherapeutically, but there are a few people who come regularly for "control" - mostly drunkards, I gathered. If a case needs psychotherapy they refer it to some trained therapist in private practice, of whom there are so many in Zürich that their charges are relatively small and the insurance may pay for it. The bulk of the cases at the policlinic were would-be abortions referred by private doctors, by gynaecologists in private practice, or by the gynaecological department of the university hospital for an opinion; a few of the cases come spontaneously. It is expected that in the projected legal code for Switzerland there will be a paragraph on the practice of abortion, which at present varies from canton to canton. In Zürich the psychiatrists are more generous in their interpretation of what justifies therapeutic abortion than in England, for example, though in principle the difference is not great. I was surprised that they were not overwhelmed with applications, but this apparently is avoided because the patients do not regard the psychiatric clinic as either the first or last point in the arrangement, but only as an accessory intermediate step between their private doctor or the gynaecological clinic at the beginning, and the gynaecological clinic at the end. There are a lot of other details in regard to the carrying out of the procedure and concurrent sterilisation which were interesting as bearing on the developments in other countries. It is interesting also that as a routine contraceptive they now recommend the Knaus-Ogino safe period. I gathered that nearly all the time of the doctors is taken up with examining these cases in the afternoon, and writing reports on them in the morning, so that the Policlinic and the doctors in it see little of the actual psychiatric material such as one would see at the Maudsley Outpatient Department, for example, and the policlinic does not feed the hospital itself. The whole situation seems bound up with the "psychiatrization" of Zürich by Forel, Bleuler, Jung, etc. so that there is a plethora of trained psychiatrists and psychotherapists; partly also it is due to an increased demand for social services from the doctors of the clinic which leaves them little time for OP work of the general kind. The bulk of the doctors exercise in a large measure the functions of the German Amtsarzt. ${ }^{14}$ Another aspect of the "psychiatrization" is that doctors cannot practise as psychotherapists unless they have an adequate training in psychiatry; consequently, apart from pastors and lay therapists, there does not arise the situation that exists, for example, in London, viz, psychotherapists without any psychiatric background. The situation is somewhat like that in Holland, though of course more highly developed.

Owing to the thoroughness with which the social responsibilities of the psychiatrist are undertaken by the clinic and the methodical way in which patients are examined from many points of view, and records made, there is little time left over for

${ }^{14}$ Public health officer. 


\section{Aubrey Lewis}

independent research. They have been studying continuous narcosis, as formerly; also Huntington's chorea, ${ }^{15}$ Rorschach's test, ${ }^{16}$ and the effects of castration. The laboratory research is chiefly looked after by Wespi, who did not have anything particularly interesting to show or tell about; the laboratories seemed little used except for routine investigations for which they are well equipped, and which seem to be done thoroughly on all the patients. Hans Maier told me of an unusual investigation he was doing on the irradiation of the liver in schizophrenia; they are also working on alcohol.

Besides the clinic itself, I saw the separate house for children, similar to the one I had seen at Klaesi's hospital in Waldau; Lutz, who also runs a children's policlinic in the town, is studying juvenile schizophrenia. In the most acute wards of the hospital I was surprised, as in other Swiss clinics, to see that mechanical restraint is still used not infrequently.

Binswanger, the other Oberarzt (a half brother of Binswanger of Creuzlingen) who is leaving shortly, I believe, explained the family care arrangements which are in his charge. He goes out and inspects at least once a year every farm where they have a patient, which is a difficult task because the farms are scattered over a wide area. As in Gheel and elsewhere it is mainly a peasant population that takes the patients. The cases are selected, and include a large number of defectives; there are of course also schizophrenics, in accordance with Bleuler's views on the advisability of early discharge from the mental hospital. The troubles they have, arising out of family aftercare, are accusations of exploited labour and a very infrequent case of suicide or arson; brutality or ill-treatment hardly occurs at all. The system works moderately well and is growing, but its applicability to other countries, and particularly to England, seems doubtful, perhaps because of the lack of a corresponding peasant population here. They do not as a rule put their alcoholic cases out in family care. Binswanger explained the various provisions, including an intermediate home to which they send difficult cases. They lack adequately trained social helpers in the Inspektorat, which is an important defect. Their social workers have been trained in a general way, not specifically for psychiatry.

At Minkowski's brain institute and neurology clinic I saw Minkowski and Katzenstein. Katzenstein is much under the influence of Monakow's doctrines as one would expect, but singularly fertile in out-of-the-way ideas for investigations, for example, crystallo-graphic studies in the CSF. He seems much more active minded than Minkowski. They are working on the minute cerebral changes after head injury; their specimens, showing rapid infiltration of the cortex by proliferating strands from the

\footnotetext{
${ }^{15} \mathrm{~A}$ rare disease of the central nervous system characterised by progressive dementia with grimacing, gesticulation, ataxic movements, finger twitching, speech disorders and other involuntary movements. It was named after George Sumner Huntington (1850-1916).

${ }^{16}$ Hermann Rorschach (1884-1922) studied psychiatry at the Burghölzli university clinic under Forel, Bleuler and Jung; he graduated in medicine in 1909 and took a position in the psychiatric hospital in Münsterlingen. He became interested in Jung's word association tests, as well as in psychoanalysis and reflexive hallucinations. In 1913 he went to the Waldau psychiatric clinic near Bern; and in 1915 was made associate director of the Herisau asylum in eastern Switzerland, where he stayed until his premature death. In 1918 he had resumed his previous experiments with inkblots as a means of accessing associations, and published his work in 1921, in Psychodiagnostik. After Rorschach's sudden death, Hans Huber published the book anew and the work received increasing attention. An institute was founded in Rorschach's name in New York in 1939.
} 


\section{Report}

pia, the collapse of blood vessels, presumably through shock to their innervation, and cellular changes in this perivascular territory, were very interesting. Katzenstein has also been looking at the furrow across the palm usually found in mongoloid idiots, and is inclined to think that whenever this is present in a normal person one will find in other members of his family epicanthus and other mongoloid features, and that if a mongoloid idiot has not got the furrow other members of his family will have it. It is a new and surprising observation.

$\mathrm{He}$ is also studying camptodactyly and related digital anomalies which he says he has never found except in families with an accumulation of mental degenerative features; I don't believe this can be right. In collaboration with Rittmeister at Münsingen he has been testing Poll's opinion that there are average finger tip formulae for each sex; Rittmeister thinks that the majority of schizophrenics have formulae of the feminine type; this also sounds improbable. Katzenstein has been studying the heredity of some rare neurological conditions, but like Hans Maier doesn't seem to know some of the literature on these matters, e.g. Julia Bell, Sjögren. He doesn't seem to be going on with his earlier studies on the effect of extirpating parts of embryos. He is also interested in the spontaneous drawings of patients, of which he has an interesting collection. (It is surprising in how few psychiatric clinics I found any interest in the spontaneous products - artistic or otherwise - of the patients.) Minkowski is rather taken up now with clinical neurology, so that he has very little time, he told me, for detailed researches, like his famous earlier ones on the movements of the foetus. He has, however, recently done his investigations of the olive in epilepsy, and is working with Katzenstein on brain injury. He is also examining methodically Monakow's brain.

In W R Hess's Institute, I found Jung from Freiburg, who was just finishing his studies there; it seemed a good thing that someone should apply strict histological study to Hess's work. Hess will not use any anatomical distinction or criterion for his notions of "vegetative" and "animal", so that the lack of precision in these terms, which is not noticeable so much if only functions, hierarchies and purposes are under consideration, becomes evident if one tries to get Hess to correlate his ideas with what can actually be observed in the central nervous system. He would like to apply his point of view to psychiatry, but in its present stage it looks as though it would merely add another to the various psycho-biologies already existing. I put some psychiatric problems in connection with sleep to him but he could not offer suggestions as to how to tackle them, though he could offer interpretations in terms of his functional views. His explanations of psychiatric problems were all plus and minus explanations, which is the usual functional way of looking at psychiatry, but conceivably a bad way. Hess's method is, of course, far from being exhausted; he is carrying on interesting further investigations himself, and it is being applied elsewhere in Zürich by Krayenbuhl, and in other countries. Hess seems to ignore unduly the endocrine influences. I also saw in Zürich von Wyss who keeps up with the literature but doesn't seem to do much original work.

With Oberholzer I had an interesting talk about the position of the psychoanalysts in Switzerland. Although Oberholzer is a Freudian, he and his group are not members of the International Psychoanalytic Society. This is partly an outcome of the fact that nearly all these Swiss psychoanalysts have necessarily to have a psychiatric training 


\section{Aubrey Lewis}

which seems to have interfered with their full acceptance of the Freudian doctrine. Of its development in England, as influenced by Melanie Klein, he, like all the analysts I met abroad, was distrustful, if not derisive. Oberholzer and the group with him use all psychotherapeutic methods - hypnosis etc. - and he expressed what seemed to me sensible views about the suitability of psychoanalysis for psychiatry, and its possibilities. On the organization of an out-patient service he had views essentially the same as those held, for example, at the Maudsley. Oberholzer is also very interested in the Rorschach test; he knew Rorschach well. He considers that this interest has prevented him from getting one-sided and being only psychoanalytical in his outlook instead of having a broad psychiatric viewpoint; in short, he acknowledges the perils of a private practice in psychotherapy. Rather surprisingly he did not know the work of Vernon, Beck or other English and American writers on the Rorschach method. Indeed apart from the physiologists there were few people I met in any country who were as well acquainted with English and American work as they were with German. Knowledge of French literature was very variable, and on the whole poor except of course in France and Belgium.

Krayenbuihl, the neuro-surgeon, (his brother does the pathological work for Hans Maier, and runs a private hospital), is keen on studying the psychological effects of frontal lesions, but as he himself knows, he does not grasp the psychiatric intricacies of the matter, e.g. release of preformed tendencies, etc. More interesting is his proposed investigation (using Hess's method on the exposed brain) into the depth at which one must stimulate to get a motor or other response, especially in the frontal region. He is keen on using Hess's method still further, but has to go cautiously.

It is surprising how little cooperation there is among the various very good people working on or around the CNS in Zürich. It is also surprising, in eastern Switzerland particularly, to find how little influence Bleuler's psychopathological approach to psychiatry has had. It is true that notes are kept more fully here than in other European clinics and approximate to English and American standards of detail, and that the teaching is thorough and sound, but apart from the analysts, psychopathology is not studied. Jung has very little influence on or contact with the medical circles now; I gathered that he would like to, but only on conditions which are unacceptable.

\section{Basle}

In Basle I visited Verzar's Institute. The work there on the relationship between adrenal cortical activity, vitamin $B_{2}$ and $B_{6}$ and reabsorption seemed applicable to some of the nutritional problems of psychiatry, also to fatigue. Their attempts to apply their findings to clinical problems seemed somewhat unorganised. Laszt, Verzar's assistant, did not strike me as particularly intelligent, though he is apparently industrious and expert in animal operations; perhaps he is so preoccupied with individual investigations that he cannot see their general purport. Verzar's work on fat and carbohydrate metabolism has led to a linkage with general medicine - coeliac disease, Gaucher's Niemann-Pick ${ }^{17}$ disease, though not so far with the psychiatric clinic. I also learned

\footnotetext{
${ }^{17}$ This was named after Albert Niemann, a German paediatrician (1880-1921) and Ludwig Pick (18681944) a German pathologist. It is a disturbance of sphingolipid metabolism characterized by enlargement of liver and spleen, anaemia, cherry red spot of the macula with progressive blindness, lymphadenopathy, and progressive mental and physical deterioration.
} 
of their work on compensatory increase in the lung when aeration is inadequate, as in asthma, and also on the metabolism of parts of the body, e.g. different perfused muscles, and their diminution in size with various poisons.

In the psychiatric clinic, unfortunately Staehelin was away, but young Manfred Bleuler took me round. There, too, there was a quite extraordinary ignorance of any but German literature, in spite of young Bleuler's having spent a year in the United States. They have done a fair amount of genetic work (Brugger's etc.) influenced by Rüdin (probably because of his formerly having had a chair there). They seem to hanker after compulsory sterilisation; the ostensible basis for it seems to be the prevalence of deficiency, but young Bleuler admitted that there were no statistics on which to base their views, and that it was rather a matter of principle. The clinic seemed well run and quite active, but a little behind the times, e.g. they are studying the use of Sodoku, and are thinking of introducing tryparsamide in the treatment of GPI. Anatomical and chemical researches are not bothered about much, though Staehelin's interests are chiefly on the pathological side.

Also in Basle I saw Demole at the Hoffman La Roche works, ${ }^{18}$ and Professor Rotholin at Sandoz. ${ }^{19}$ Demole seems to have got quite away from his former neurological and psychiatric clinical interests, and to have concentrated on vitamin problems.

\section{ITALY $^{20}$}

\section{Pavia}

In Pavia I saw Margaria. He has only been there a few months, and has very little assistance and most of the routine work to do, e.g. 4 lectures a day on 3 days a week. His laboratory, which was built by his predecessor, Gayda, is on an unduly generous scale considering that Margaria has only two assistants. The pay is so small that it is clearly impossible for most people to undertake such work, for example, Margaria, as professor, gets the equivalent of $£ 3.10-£ 4.00$ per week and his assistants get half or three quarters of that until they themselves obtain a chair, say at the age of 45 . Some of Margaria's work he can get his students to do. He is energetic and is starting a

${ }^{18}$ In 1896 Fritz Hoffman-La-Roche founded F Hoffman-La Roche as the successor company to Hoffman, Traub and Co. It became one of the largest and most successful pharmaceutical companies in Europe.

${ }^{19}$ Sandoz Ltd (now Novartis Ltd), in Basle, was set up as the Chemical Company Kern and Sandoz in 1886, by Dr Alfred Kern (1850-1893) and Edouard Sandoz (1853-1928).

${ }^{20}$ Several influential figures in the second half of the nineteenth century - Camillo Golgi, Augusto Tamburini, Eugenio Tanzi and Cesare Lombroso - put Italian psychiatry on the map. By the second decade of the twentieth century, psychiatric work was shared between a minority of public asylums, neuropsychiatric divisions of general hospitals and private asylums. Teaching, in university clinics, was dependent on the Ministry of National Education. Psychiatry, however, took a downhill turn after the work of the founding fathers; teaching tended to privilege neurology and the asylums went into decline, partly due to indifference amongst the administration as well as doctors, who preferred private work, and of course to the cultural isolation of fascist Italy. Although Italy did not instigate purges and repression to the same extent as the Soviet Union and Germany, and there was not a similar move to create a purely Italian/fascist science, certain textbooks by Jewish authors were proscribed (mostly after 1938), and in the fascist period racial laws accounted for significant losses of professors, particularly in the sciences, medicine and law. Of the 1,200 -odd professors with chairs, 98 had to leave because they were Jewish - almost one in twelve (a higher number than that leaving due to voluntary emigration or forced resignation for political causes). (Edward $\mathrm{R}$ Tannenbaum, Fascism in Italy: society and culture 1922-1945, London, Allen Lane, 1973, p. 338.) 


\section{Aubrey Lewis}

lot of studies, influenced by Meyerhoff, A V Hill, Bancroft and others - (metabolism of the red cells, pyruvic acid influence, and particularly lactic acid studies in work and fatigue). I had the impression that his lactic acid work is somewhat concerned with the present interest in sport physiology, of which Donaggio is the most extreme instance. (Like most of the other reputable people, he is contemptuous of much of Donaggio's work which has, however, received a great deal of official support.) In his study of carbohydrate metabolism he was applying the method used by Verzar (moniodoacetic acid).

I also saw Riquier, the professor of psychiatry in Pavia. He also has only been there a few months, having come from Padua to follow Rossi. Rossi had put all the emphasis on neurology, and was evidently a dominating figure in neuro-psychiatry in Italy. He had organised the clinic on research lines, but it does not look as though under Riquier this will be continued to any extent. Riquier is a much smaller person, and knows little of conditions outside Italy, $\mathrm{He}$ is very proud of the open wards which he had in Padua, and proposes to introduce them in Pavia. The Pavia Clinic, which is derived partly from private benefaction (a rare thing in Italy), is fairly well constructed. The women nurses are nuns here; the men have little training. They have a ward for encephalitics, as have most of the other university clinics that I saw; it is the outcome of the advocacy by their Queen of a Bulgarian quack remedy which she had heard of in her native Montenegro and which has turned out to contain belladonna. They are treating patients with insulin and proposing to take measurements of metabolism, blood pressure, etc., but without much realisation, apparently, of the snags in doing so; when Margaria, who was with me, pointed these out they seemed surprised. Riquier is anxious to develop neuro-surgery, and would like one of his men trained in it. He favours sending him to Olivecrona or Clois Vincent. He is anxious to link up surgery of the central nervous system with pathology and neurology and would probably provide good facilities when his man had been trained. The clinic is the admission hospital for the town, but can draw material from the local mental hospital or send cases there; there are about 60 psychiatric beds. As regards the teaching of the students, I learned in Pavia that De Vecchi, the former Secretary of Public Instruction, had ordered the Professors to teach clinical neurology and psychiatry in 25 set lectures, to be given to the students in two batches, i.e. twice over. This had made an unnecessary amount of work for the professors, and indeed Lugaro told me that when he received orders to teach by set lectures instead of by clinical demonstrations as he had always done, he ignored it because it was so impracticable. Margaria was spoken of elsewhere in Italy always with respect as a sort of white hope of Italian physiology, and it became clear from conversations that there are few promising men coming on; an academic career does not attract the more brilliant younger men because of its lack of rewards, and such of them as go in for it tend to be diverted into more or less practical applications, e.g. sport physiology, aviation physiology, psychotechnics. The older men of established reputation, like Giuseppe Levi and Lugaro, are tolerated but not encouraged; they get no financial support from the authorities, whereas the younger people or men like Pende often do. 


\section{Milan}

In Milan I found little to see. I visited Gemelli's laboratory in the Catholic University, but it is notorious that he does hardly any actual work himself there, is almost entirely occupied in his semi-political activities as Rector of that University, and in planning a similar university in Rome, where I believe he is President of the new Pontifical Academy. Gemelli still publishes interesting psychological studies but it is generally said that all he contributes to them is either the original idea or the review of the literature; he reads enormously. The actual work is done by Padre Galli and Dr Pastore. He has also had with him people working on electro-physiology, e.g. Rohracher and on animal psychology, but phonetics is his chief subject. He writes excellent orientating reviews also e.g. in Scientia. The laboratory is extravagantly equipped with instruments, but it looked as though there was no one there particularly trained to use them intelligently.

In Milan I also called on Prof. Medea who is mainly a neurologist, but is President of the Italian Mental Hygiene Society. They have a good school for abnormal children in Milan, but they have so much leeway to make up in these matters, that what is particularly good there, would not be so in more advanced countries. Medea is not the full professor; the man who holds the official chair, Besta, has no beds, and is not interested in psychiatry particularly, I was told that neuro-surgery under Clivio had been the main interest of the clinic latterly.

\section{Turin}

In Turin I saw Levi and his assistant Jablonsky (from Albert Fischer's laboratory in Berlin) and Fräulein Mayer. Levi has to work under some unsatisfactory conditions, but is carrying on his cytological studies very thoroughly. He has neuro-fibril cultures that have been alive for 14 months, and which show the anastomosing of the network that forms, so that the strict theory of neurones can scarcely be sustained. The possible clinical application of what he is doing seemed to lie in his study of the resistance of neuro-fibrils in artificial conditions: and one of his assistants is studying the ageing process in peripheral nerves, which might have a bearing on senile psychosis. Levi is also investigating the rate of growth of the new (or rather the regenerating) fibrils. Levi reads enormously, and is au courant of almost everything physiological and neurological.

I also saw Herlitzka. He said that he had been diverted into the physiology of aviation and submarines after the war, and could not get away from this field, though he would prefer to be doing electro-physiology. Whether because of his annoyance over sanctions (about which he feels strongly), or for other reasons, he said nothing about the research he does. He talked, however, about other people - Donaggio, Pighini and Pende (all of whom are well-in politically, but are regarded as scientifically negligible).

Lugaro, whom I also saw, is no longer so active, but is still one of the few really well-informed psychiatrists in the country. Everyone speaks of him respectfully, and from his writings it seems likely that if he had published in some more widely diffused language than Italian he would have had a considerable European reputation. He had anticipated Kappers in regard to neurobiotaxis, and Bleuler in regard to dissociation 


\section{Aubrey Lewis}

phenomena in schizophrenia. The width of his interests and his detailed work make one feel that he is an outstanding figure, but conditions have become unfavourable to him, and he is no longer productive, though still, I should think, capable of it in better circumstances.

In Turin I asked particularly about any people doing psychiatric criminology and genetics; the connection with Lombroso occurred to me, but neither here nor elsewhere in Italy is there any satisfactory research in this field, so far as I could discover. There is a woman, Gian Ferrera, carrying out twin-studies rather incompletely along the usual lines, but I could not discover any of the current work on forensic psychiatry or constitution which, for example, Kinberg so praises. I asked after di Tullio, who has written a textbook, but they said he was not connected with psychiatry in any way. Pende, of course is keen on constitution studies, but without any bearing on psychiatric or neurological problems.

It is of interest that Lugaro is almost alone in holding the view that the chairs of neurology and psychiatry in Italy should be separate, instead of as at present combined. Certainly as Lugaro pointed out, the effect has hitherto been a neglect of psychiatry. Insulin at the moment is resulting in a slight revival of psychiatric interest, but not a very intelligent one; for example, Cerletti treats schizophrenics in this way, but his methods and opinions struck me as ignorant. The poor state of affairs in psychiatry seems to be partly due to the fact that all the clinical professors do private practice and are dependent on it chiefly for their income. This, with all the teaching they have to do, leaves little time for such detailed work as psychiatric research actually demands. Then, of course, there is the political aspect. Moreover, all the professors are dependent for their clinical material on a smallish admission hospital, largely devoted to neurological beds; their contact with the mental hospital is a permissive one, since they have neither administrative control nor any privileged position, apart from the right to borrow cases for teaching.

\section{Genoa}

In Genoa I was able to see a large mental hospital. I was taken round by Rieti, one of the doctors who had been trained in French psychiatry a little and also in psychoanalysis: (there are very few psychoanalysts in Italy and they exert no influence). The superintendent of this hospital, Alberti, has the title of professor because he has passed the appropriate examinations, but he has really no university position. He had a political pull, at any rate, to the extent of getting a great deal of money from the authorities of the Province for his hospital (his brother is a Senator). He obtained roughly $£ 200,000$, I was told, to build his new admission hospital, and managed to spend all they gave him and more, but the upkeep has proved so expensive that the authorities have regretted their generosity. The money has actually been spent extravagantly on a hospital for $\mathbf{4 0 0}$ patients containing every conceivable apparatus, many of the most expensive ones never having been used, nor likely to be, it seemed, (great X-ray apparatus, electro-cardiograph, diathermy, short waves and other electrical apparatuses for this form of treatment, which is so popular in Italy). The patients, however, in the wards are, many of them, senile and advanced chronic patients for whom the splendid surroundings are quite inappropriate and pointless. There is neither 


\section{Report}

segregation, occupation, nor proper nursing as far as I could see. There were private wards but the patients in them seemed, from the way they were dressed etc., to belong to the poorer classes. Moreover, in the wards the sanitary and other arrangements were at a surprisingly primitive level from the point of view of privacy, etc., but Rieti and others clearly regarded it as the last word in modern mental hospital provision.

In the laboratories they have a physiologist and histologist, Massazza, in charge who has various doctors doing histological and pathological studies under his direction, but I did not hear of anything of importance. The "libero docente" degree which entitles one to be professor and so is valuable in private practice, has hitherto been fairly easy to obtain if one had published a number of papers and could pass the necessary examination; hence everybody feels that it is important to publish research papers, but the standard attained is low, (while I was in Italy the regulations for obtaining the "libero docente" were tightened up by an administrative decree). From this probably springs the bulkiness of their periodical literature. At this Manicomio, for example, which I visited in Genoa, they publish independently the researches carried on by their own doctors, and a lot of other clinics and hospitals do likewise; there is no editorial sifting of all this stuff, except what is submitted to the two or three journals which have standing. Certainly a great deal of work published has been badly done, without personal competence or competent direction by others; it is sometimes the experimental animals that have to suffer most, in futile and amateurish experiments.

As far as the clinical work in this mental hospital was concerned, I was surprised in looking a their books to see what an exceptionally high proportion of GPI they have there, perhaps it is due to the fact that Wassermann is done as a routine and so is X-ray of the chest of every new patient, but I could not find any that they had made any particular use, so, far, of the data so obtained. Rieti does a psychological examination, which really amounts to a full mental status plus a Rorschach and perhaps a Rossolimo. ${ }^{21} \mathrm{He}$ is enthusiastic, but suffers from lack of training which he proposes to remedy by going to New York; he ought, however, to improve himself in straight clinical psychiatry before he goes in for research in clinical psychology, as he proposes.

In contrast to the absurdly grand admission hospital, was the other part, the old, much larger section of the Manicomio. The conditions under which the patients were looked after there were definitely out-of-date. It seemed to me that if they had spent their money on proper nursing, occupational therapy, rearrangement of the available buildings (built in 1860) so as to permit of proper grading of patients, etc., and on purchasing their apparatus and building their laboratories at a scale on which they were likely to be used, it would have been more to the point than building this admission block of which they are so proud. In keeping with their general outlook is the fact that here, as in many other Italian clinics, they have a keen nose for anything new. They

\footnotetext{
${ }^{21}$ Grigorii Ivanovich Rossolimo (1860-1928) became a lecturer in Alexis Yakovlievich Koshewnikov's neurological clinic in Moscow in 1889. He then became head of the department of neurological disease at the internal disease clinic run by Ostroumov. In 1911 he founded an institute for child psychology and neurology, and in 1917 a department for child psychoneurology at the State University in Moscow when he became professor of neuropathology there. He is most famous for the experimental psychological methods he devised. His name is associated with several of these methods and instruments; these include a brain topograph, a diadochokymograph, an orthokynometer, an orthostatometer, and a dermografometer.
} 


\section{Aubrey Lewis}

had, for example, discussed the propriety of introducing Moniz's method of treatment by destroying tissue in the frontal lobes, ${ }^{22}$ at the Psychiatric Congress in Naples the week before I was there. They try insulin and all these other advanced methods, while in fact their general care and use of well-established methods of treatment are lagging behind those of other countries. It is not mainly a question of money, seeing how much they lavish on building and equipment, though actually they apologise for their deficiencies on the ground of poverty. Mental hygiene has a real field in countries like Italy where the level of treatment of mental disorder, judged by modern standards, both in hospitals and by means of policlinics, is bad.

Medea, who is President of the Mental Hygiene Association in Italy, told me he had been preaching better provision, on the ground that it will diminish through early diagnosis and prophylactic treatment the number of people in mental hospitals; this seemed to me a much less sound basis than would be an insistence on the fact that extramural care would be possible for many cases, duration of illness would be, in some cases, shortened, and a much better and more decent standard of adaptation and care obtained for the chronic cases. I was told everywhere in Italy that this new admission block in Genoa is regarded as a model which the others hope to imitate. Many people gave me to understand that the majority of mental hospitals were over-filled and very backward.

In Italy, as in Russia, one had the impression that a good deal was sacrificed to outward show - fine buildings etc., and that the political pressure on scientific people to work on problems that had an immediate relevance to daily affairs had, in fact, resulted here and there in some unsatisfactory work on problems not suitable for attack by the rather precise methods familiar to the experts in question. In Italy I gathered that some of the physiologists regarded their applied studies of this sort as a sop, so to speak, whereby they obtained funds for their more customary researches; one man told me he had got the money for an animal house on the pretext that he was going to use the animals for research in the physiology of aeronautics.

Also in Genoa I saw de Lisi, who has the university chair. The clinic is here, as elsewhere, predominantly neurological in its material. The laboratories are extensive, but de Lisi deplores the fact that he cannot use his surgical theatre because he has no surgeon; he hopes that a former pupil of his in Cagliari, who has studied in Paris and in Baltimore, will fill the gap. As in some of the other clinics in North Italy, their neurology is influenced by Paris more than by Germany; as for English neurology and psychiatry their knowledge of it often seems to be summed up in Kinnier Wilson's disease $^{23}$ and Hughlings Jackson's name, more or less.

De Lisi is an accomplished man, probably a stimulating teacher, very vivacious and alert; he can read English very well but won't talk it. He seemed one of the few men in

\footnotetext{
${ }^{22}$ Egas Moniz (1874-1955) is often spoken of as the discoverer of cerebral angiography and prefrontal leucotomy. He became professor at Coimbra in 1902, transferring in 1911 to the new chair in neurology at Lisbon where he remained until his death. He also worked for a time as a physician in the Hospital of Santa Maria, Lisbon. He served as a deputy in the Portuguese parliament until 1917 when he became Portuguese ambassador to Spain. Later in 1917, he was appointed Minister for Foreign Affairs. Moniz was awarded the Nobel Prize in 1949, although John Fulton is often considered prefrontal leucotomy's true father.

${ }^{23}$ Samuel Alexander Kinnier Wilson (1878-1937), a British neurologist, described, in 1912, "progressive lenticular degeneration", a familial nervous disease associated with cirrhosis of the liver. It is also known as hepatolenticular degeneration.
} 
Italy who was doing anything interesting in psychiatry; he has been working on motor constitution, in association with Pintus who was formerly with him in Cagliari. He is proud of his bound volumes of case records, representing improvements he made in record keeping when he came to Genoa: they seemed so average when one looked at them, though, that one could infer that previously the records had been deplorable, and indeed it seems that in all the clinics and mental hospitals the records are bad on the whole. He followed Cerletti in Genoa about a year ago. De Lisi has encouraged Rieti in his psychopathological enquiries and they are now writing an article together. I also learned in Genoa a little more about the Milan Clinic; Besta, the professor, had a clinic for soldiers who had had head injuries in the war (like Isserlin's one in Munich) and had as his assistant, Clivio, who now works independently as a neuro-surgeon, and is said to have good results.

I also in Genoa met a German lawyer, now practising in Italy, and asked him about forensic psychiatry in which he is interested, but it seemed to be a quite stagnant subject.

\section{Rome}

In Rome I visited Cerletti's clinic. After the death of Sante de Sanctis the combined chair was again broken up; Cerletti became professor of neurology and psychiatry, and Ponzo, a former pupil of Kiesow and associate of Gemelli, became professor of psychology. Cerletti has an adequate enough clinic from the structural point of view, but seemed very ashamed of it, and is apparently shortly going to have a much grander building. He is mainly a neurologist, but is concentrating somewhat on insulin treatment at the moment. He seems incapable of recognizing the clinical condition of his patients; for example, he showed me one young man as a "cure" following insulin treatment, who in fact revealed himself quite obviously as a dissembling paranoid schizophrenic and indeed, when I talked to him for a little time, he disclosed that he was still having hallucinations and delusions; Cerletti had accepted at face value his statement that he was now quite well and quite rid of his morbid disease. Similarly Cerletti said that he did not think that a woman in the ward was schizophrenic because she didn't satisfy Kraepelin's test obeying the command to stick out her tongue so that a pin could be stuck in it. However, Cerletti has working in his clinic a German refugee, Kalinowski, who has had a good psychiatric training, so that probably corrects the deficiency. They are also using cardiazol and observing the effects of this substance and insulin upon the behaviour and the cerebral structure of the dog. One dog to which they had been giving cardiazol and producing fits regularly, behaved as though it were now demented in consequence. The pathologist at the clinic showed me brains in which structural changes had occurred following insulin administration. The histopathology seems to be well done in Cerletti's clinic. He is said to be a good neurologist and to have had a good training in neuroanatomy. He talked of some interesting work he had done earlier on the effects of intoxication with morphine in cats etc., but he doesn't seem to have been pursuing anything of that sort of late years.

I went to Ponzo's laboratory but he was away and I was shown round by his associate Professor Banissoni, who is actually an Austrian from Trieste. It is clear that 
the greater part of their time is taken up in lecturing and teaching; all sorts of people have to be given semi-popular lectures. The research they do seems to be concerned mainly with psychotechnics, and did not strike me as very advanced, though Banissoni himself is very knowledgeable. Ponzo works in collaboration at times with Gemelli and the other people in Milan.

I also visited Pende's institute. I did not see him, but was taken round by one of the younger men, who showed me all the apparatus which is used for testing the school children and workmen who come there for examination of their constitution. A great deal of what I was shown struck me as eye-wash. In one laboratory I was shown a lot of apparatus for testing special senses: I asked my guide what purpose this served, and he said that it was essential for making typological examinations, but when I asked him how the tests were done, he hesitated and admitted he did not know. On several of the instruments in question, when we took them out, the rubber was quite perished so that they had obviously not been used for some time. My guide then admitted that they had discarded this particular set of investigations.

In the large laboratory where reactions are measured there was a great display of special apparatus for measuring various professional aptitudes, etc., but again it seemed designed for show rather than for any scientifically justified end. My informant said that there had been no exact statistical examination of any of the data collected, but showed me lots of charts, including some which correlated Pende's constitutional types with the particular occupations to which they were suited. It may be, of course, that my informant was ignorant, and so misled me as to the work done, but he assured me that he was actually in charge of the largest and most used of these laboratories for vocational testing, and what I heard in other places about Pende's work confirmed the impression I received here. He has, of course, wards in the same building but I could not discover that he did any special research on the patients in them. Altogether I had the impression that the work on constitution for vocational selection is badly done and is mostly for outward show. Bastianelli made a very different impression. $\mathrm{He}$ is extra-ordinarily well-read in the literature of neurology and physiology, but his main interest is, of course, in malaria. He usually has a small number of beds occupied by patients with GPI whom he uses for his experiments with malaria. He mentioned several interesting observations which do not seem to have percolated into the literature of GPI therapy - largely, I suppose, because they have been published in malaria journals. He has, of course, no official university status, and judges fairly severely the value of a great deal that is done by the professors in Rome. His own institute seems to range further than malaria studies alone; for example, one of his men is doing interesting wok on electrocardiographic responses. His brother, I gathered, is doing a good deal of cerebral surgery in Rome.

I tried to see Modena, who, I was told by Kalinowski and others, was the man entrusted with the statistics of mental disorder throughout Italy. Although they are so proud of their statistical work generally in Italy, so far as psychiatry is concerned it seemed to be negligible. Modena, however, works at Ancona and is only occasionally in Rome, and I did not manage to see him. I have heard since from Kalinowski that Modena is conscious of how much there is to do and wants to start on it. 


\section{Naples}

In Naples I visited the biological station, and Dohrn told me of the various researches going on. At the moment, however, the only thing that has any bearing at all on the central nervous system was a study on tissue respiration; they were using the customary Warburg method. Fragnito's psychiatric clinic in Naples did not seem of any consequence.

\section{Florence}

In Florence I went to Zalla's clinic and was shown round by his "Aiuto", Roberti, a disciple of Lugaro, who is hoping to get a chair of his own within the next few months in the South of Italy. The university clinic is situated almost in the same grounds as the mental hospital and there seems to be a closer liaison between the two than in any of the other places I visited in Italy. Roberti, who is a lively, active-minded person, is pursuing some researches into hallucinations and the influence of "vegetative" drugs like physostigmine upon them. He talks quite intelligently about the matter until one questions him closely on any issue, and then - as in the rest of his conversation - one discovers that he is profuse and superficial, though undoubtedly with a widely-ranging mind. As so often in Italy, when I asked if they had such and such a department or did such and such research, I was given an affirmative answer which more detailed questioning showed to be unfounded; for example, Roberti talked about "insane art" and when I asked about any collection, said, "Oh yes, there is a good one", but when I asked to see it, it turned out to consist of one bad specimen done by a mental defective. His tongue runs away with him; when I asked him if he had seen any cases of peduncular hallucinations he said he had seen lots; which struck me as improbable. Roberti said that the nursing was done by peasants who had little or no training, though they were, in his opinion, none the worse for this; elsewhere I had been told that the nurses had training; presumably there are local differences. I was taken across to the mental hospital and met the superintendent, Simonelli, whose training had not been in psychiatry but in biochemistry. He seemed, however, no longer to have much interest in the latter subject nor any particular competence in the former, though perhaps he is a good administrator. (He had had to make a choice between turning into a mental hospital superintendent or remaining an "Aiuto" - he decided for the administrative job.) He was dull and loquacious; when I asked him about any biochemical researches on patients he was very vague and branched off into a discussion of Donaggio's work. There is no organised occupational therapy and the patients are left apparently a good deal to themselves.

\section{Padua}

In Padua I saw Terni. He is very active and has been particularly occupied with the preganglionic fibres of the sympathetic and their relationship to the intermediolateral tract of the cord and the white rami communicantes. He doesn't seem now to be so occupied with his anatomical work, e.g. the abducens accessory nucleus, though he writes critical general reviews, for example, of the relation of the vegetative nervous system to the endocrines and of the theory of surgery of the sympathetic. In his 


\section{Aubrey Lewis}

cytological work he is using ultra-violet rays mostly for damaging the cells, and his laboratory seems to be well equipped.

He has also modified Policard's method of micro-incineration; instead of incinerating he gradually increases the temperature to $400^{\circ}$ using a specially constructed microscope; as the temperature rises the colour changes, the fats etc., alter, so that he can detect proteins and fats, where Policard is concerned only with minerals. He is looking round for expert chemists for this work, he told me. One of his associates has been doing very patient work counting the number of fibres in cross section of nerves; he finds that the number of fibres is diminished in old age. Terni is obviously one of the most energetic people at the medical faculty and keen on furthering psychiatry and psychology as much as he can. He is collaborating with the physicist in Padua, Rossi, to see if there is anything in the influence of cosmic rays on cells, I gathered.

Terni arranged for me to meet Berlucchi, who was recently appointed Professor of Neurology and Psychiatry. Berlucchi has obviously been diligent, especially in neurological research, but seemed to have no independent ideas at all. He is, however, diffident and has no command of foreign languages so one can hardly compare him with a confident, voluble person like Roberti. Terni has a good opinion of Berlucchi and thinks he will do good work. His inaugural address reviewing morbid psychomotor phenomena had been stimulating. He does his best to obtain familiarity with foreign literature, but has some surprising gaps. He is more interested, he said, in psychiatry than in neurology, but in the past seems to have worked on the latter mostly, and he has now only about 10 psychiatric beds - (Riquier's former clinic, quite divorced form the mental hospital and not a pure admission unit). He had spent a short time with Gerstmann in Vienna. I gathered that they had hoped to get de Lisi in Padua and that Berlucchi is a second best. He doesn't seem to have any ideas for research in psychiatry at the moment. I also met Truffi, the Dean of the Faulty who, is, of course, mainly a syphilologist.

Terni also arranged for me to see Musatti who is at first a little unprepossessing, but is actually enthusiastic and intelligent and doesn't, like so many others in Italy, give a quick reply which he cannot support if questioned further. Musatti is a pupil of Benussi's and follows in his footsteps. In the "concours" for the chair in Rome he was one of the three candidates finally selected, but Ponzo got it because Gemelli and de Sanctis supported him; the third candidate is now in Ferrara and is a painstaking, dull man. Musatti is, from his training, interested in Gestalt and in perception of movement. He mentioned the work he had done on the efficacy of even minimal convergence or divergence on perception of depth and apparent movement; it linked up with the Frankfurt work on the divergence of hands as influenced by colour and some of Rademaker's work and Cerletti's studies on the movements of the eye muscles in cats in whom sight had been extinguished from the beginning. His investigations are not at any point in touch with clinical material, though he is a psychoanalyst and treats patients. Although he has never had a personal analysis he is accepted by the Italian Psychoanalytic Society, and is one of the judges who decide who shall be admitted to it: it is surprising how in each country the analysts cut their coat according to their cloth. Musatti has no established position, he teaches philosophy and history at the Lyceo to earn his living, and has a little apparatus in his rooms. 


\section{Report}

He told me that neither Benussi's chair nor Kiesow's had been filled: Gemelli is now mainly a politician: Galli is a man without ideas: Ponzo is busy with his applied work and teaching, as is also Bannisoni who also runs a general medical practice - so psychology is not much cultivated in Italy at present. The philosophers are opposed to it because of the prevalence of Croce's ideas and the trend towards idealism and against anything materialist or positivist. ${ }^{24}$ Educational psychology has similarly been displaced by semi-mystical and empirical methods of approach. So little contact has there been between the psychiatrists and the psychologists in Padua that, as Terni told me, Riquier did not even know of the existence of Musatti. So far there has not been contact between Berlucchi and Musatti, though probably Terni will be able to effect it. If Musatti were given the chance he would probably do good psychological work, I should think. It is surprising how neglected subjects like animal psychology are (though Gemelli has just written a review on it in Scientia). Psychopathology, genetics and social anthropology also seem to be neglected in Italy. It is also noteworthy that the difficulties they have in travelling have led to their being ignorant of much that goes on elsewhere; even Terni did not seem to know some of the things that are going on (though Giuseppe Levi from his reading was very well informed); Musatti had never heard of any mescalin studies.

In various places it was suggested to me that Reggio Emilia might be worth a visit, but actually it seemed hardly necessary to go there. It is still one of the biggest of the mental hospitals and one of the few where research is tackled on a large scale; the influence of Tanzi and Morselli is responsible for this (just as in Florence Tamburini or Mingazzini is responsible): but Pighini, who is the chief person there, is not regarded as in the least reliable by any of the people I met. Buscaino in South Italy is better spoken of, but more for his wide reading and remarkable memory than for the value of his researches, (which are mainly chemical, of course): this confirms the opinion one forms from reading his publications.

\section{HUNGARY ${ }^{25}$}

\section{Szeged}

In Szeged I saw Miskolczy. His psychiatric clinic, separate from his neurological one, is an old dilapidated building, but he has done his best with it, and in some respects

\footnotetext{
${ }^{24}$ Benedetto Croce (1866-1952) was an influential historian, philosopher, and senator. Although he never held a university position, he published widely (on Hegel, Marx, Goethe, history, poetry, and art), elaborating an idealism influenced by Hegel. He was Minister of Public Instruction from 1920 to 1921 , and during the Fascist era was one of its major opponents. After the war, he was a minister in the new democratic government, and from 1943 to 1947 was president of the reconstituted Liberal Party; he retired from politics in 1947 and established the Institute for Historical Studies in Naples.

${ }^{25}$ Psychiatry took off in Hungary in the second half of the nineteenth century. The National Asylum was created in 1868 in Budapest and, towards the end of the century, treatment improved and legal changes were effected. Between 1900 and 1916 the number of people treated in asylums or hospital services tripled, with treatment ranging from baths and diets to bromides and opiates, with psychotherapy available in private institutions. After the First World War progress slowed, however, despite the inauguration of some new psychiatric services attached to public hospitals, mostly in provincial towns. Gyula Nyiro and Fabinyi, in the 1930s, enabled the extension of psychiatric care to neurotics, as well as the first ambulatory care centre. Insulin and electroshock were increasingly used for the major psychiatric illnesses; and in psychotherapy, hypnosis, psychoanalysis and individual psychology were dominant. Sándor Ferenczi (1873-1933) had
} 


\section{Aubrey Lewis}

even (for example in the use of isolation) it seemed better than more pretentious clinics. Miskolczy struck me as sensitive, and justifiably proud of what he had accomplished there. He is determined to push on with his research, though handicapped financially. The neurological clinic is, of course, in much better condition than the psychiatric one, and there he has reasonable facilities for histological research and routine biochemical investigations. He has collected special cases systematically and so has an unusual number of brains of Pick's disease, etc., for the studies on the heredo-degenerative conditions which he has published in the monograph with Schaffer. He is Dean of the Faculty this year, which rather hampers his work; moreover, one of his men is away in America and another in one of the other medical departments in Szeged. He has, however, with him at present an assistant called Benedek who seems keen.

Miskolczy is about to make detailed studies of the brain in GOI [sic, presumably GPI], going further afield than previous investigators, who concentrated on the cortex; he has some interesting ideas in connection with this, bearing on the cause of remissions. He is also getting the cooperation of chemists in studying neurofibrils; one of his men, who is spending two years working with Szent-Gyorgyi, will soon be returning to him to cooperate in this. Also, when his colleague, who is now with Percival Bailey, returns, the neurosurgery will get under way. He impressed me as thorough and critical, and with original ideas on the structural basis of psychoses; his research has the advantage of collaboration with Szent-Gyorgyi, Raczyska, Jantschow, (the spirochaete man), and others at Szeged. Apart from his own qualities, he seemed to illustrate the advantages of working in a small university city where all the university professors know each other and may, if they are on good terms, collaborate with great profit, in contrast to a big city, where people in different fields seldom meet. Among the side lines with which Miskolczy is occupied are: the effects of various substances, such as adrenalin and other hormones and physostigmine, on the cells of the central nervous system; some work in comparative pathology in regard to a familial recessive disease of the central nervous system of fowls, probably cerebellar; the relation of the shape of neurons to their functions, e.g. Purkinje and pyramidal cells; the effect of Szent-Gyorgyi's new vitamin P on patients who bruise easily ("insane" ear, ecchymoses, etc.). As regards his views on schizophrenia, he is very well aware of the possible objections, but he refuses to follow the speculative lines which some of his critics prefer. Certainly what he reports can be taken as reliable.

He took me round to Szent-Gyorgyi's laboratory, where I heard of something of the recent work on the treatment of diabetic ketosis with succinic acid, the vitamin $\mathrm{P}$, and his more fundamental work on the chemical processes which are the essential sources of energy (the work similar to Keilin's). He professes to dislike the clinical application of his work; yet it seems to occur fairly promptly, anyhow.

Raczyska [Racesyska], in the Medical Clinic, told me of his interesting work on the use of histamine (by gradually working up the dose) to prevent surgical shock, and his blood pressure work.

been the main figure behind the National Psychoanalytic Association in 1913, becoming professor of psychoanalysis at Budapest University in 1919 and effectively the head of a Budapest psychoanalytic movement which saw Hermann and Michael Balint amongst its members. The Second World War put an end to these developments, with Balint, Sandor Rado, Rapoport and Franz Alexander pursuing their careers elsewhere. 


\section{Report}

\section{Budapest}

In Budapest I visited Bela Johan's Institute. He explained to me how public hygiene has been developed under his direction. He is not at the moment particularly interested in mental hygiene, but is pulling up the standard of the work in mental hospitals by exercising his power of selecting the doctors for them. There can be no doubt, judging from recent appointments, that good people like Meduna are now getting a chance, but Johan's power in this respect cannot really be complete because at the mental hospital, although the superintendent has not been there long, the place is badly run, and I was told that he is a lazy, incompetent person, who obtained his appointment only because of some family influence. I get the impression that Johan considers that the mental hospitals must be pulled up before social services and policlinics for mental disorder should be taken in hand; the state of the mental hospitals suggested that this is the desirable point of view. There is a great contrast between the excellence of the public health organisation and the model institute of hygiene on the one hand, and the mental hospitals on the other. I suppose when Johan decides to concentrate on the mental health field that, too, will become a very good service. He is so thorough and has been obviously so successful in organizing the rest of medicine.

I saw Meduna several times. $\mathrm{He}$ is ambitious, hard working and conscientious. $\mathrm{He}$ has a good book knowledge of psychiatry and some practical experience, of course, but as he has never been out of Hungary to study, his knowledge of practical arrangements and day-to-day clinical work is disproportionate to his abilities. He works in close association with Nyiro whom I also met; Nyiro is responsible for a well-run Sanatorium in the grounds of the hospital where patients are treated on a voluntary basis. Meduna is enterprising, as of course cardiazol shows, and has done good, if humdrum, pathological work under Schaffer. His material prospects at the moment are not particularly good. He is aware that cardiazol is not the beginning and end of schizophrenia, and would like to organise a wider scheme of research into the whole problem; it seems unlikely that he could alone direct efficient research, but he would certainly supply on the clinical side good cooperation and probably ideas too. As regards the cardiazol, he makes no extravagant claims for it, but clearly in his heart of heart has high hopes. There can be no doubt that some patients in whom the prognosis has seemed poor do well with cardiazol. He has the common weakness of calling every anergic patient catatonic, so that some retarded depressions are likely to be diagnosed schizophrenic. One of the points constantly urged against cardiazol treatment, especially in Switzerland, is that it is not only disagreeable to watch but unpleasant to experience, and certainly in the Swiss clinics many of the patients struggled against having another injection. At Meduna's clinic, however, where a number of patients were being injected, there was nothing of this; much must depend on the attitude of the doctors who give the treatment.

I also visited Benedek at the University Clinic. Many people seemed to be of the opinion that Miskolczy had had just as strong claims on the chair as Benedek, when Schaffer retired. Benedek struck me as very energetic and versatile, but not at all original-minded. He seems to pick up every new thing, and to do some work on it. He is said to give a great deal of his time to his private practice and to be a martinet in his clinic; his assistants seemed almost servile in his presence, and all complained of being 
overworked and looked it. Anyhow, it has the result that a lot of work is done in his clinic. His chief assistant, Angyal, is mainly interested in the motor phenomena during insulin shock, which he has analysed skilfully. He has worked with Gerstmann. Juba, the histopathologist, is working on the structure of gliomata and on some neurological problems, e.g. lyssa. He and another assistant came with Benedek from Debreczen; the latter assistant works in the cerebral tumour ward, making a great deal of use of stereoscopic radiography. They are not doing anything very remarkable but what they do is probably reliable. Most of the assistants look ill.

I tried while in Budapest to see atso Szondy, who works on endocrines, but he was out of town. Meduna showed me round two of the mental hospitals in Budapest; the patients in one were lying in rows along the stone corridors, elbow, to elbow, and altogether in a primitive state.

\section{AUSTRIA $^{26}$}

\section{Vienna}

In Vienna I visited Pötzl's Clinic. Hoff took me round. The organisation of the place seemed bad; in the OPD it was not so much the number of patients as the haphazard way in which they were seen that led to confusion. Hoff would no sooner start to examine one patient than he was called away to the wards to see someone else, and he was not able to give proper time and attention to the examination of any patient, as far as I could see. The level of routine work seemed bad, although individual patients are no doubt examined very carefully if someone is interested in them. Stengl, for example, is interested in the association of obsessional symptoms with diseases of the brain stem, Pötzl with the more neurological disorders, Pichler is doing some anatomical work, etc. and so on. Hoff who is the chief figure in the clinic, as far as I could make out, works very hard but gives some of his time to a semi-private clinic which he has near the hospital was well as to private practice. Wagner-Jauregg and others told me that it is really he who prompts Pötzl and runs the place. Of course insulin is their chief topic, but they don't do it as well as the Swiss do it now, and are far too interested in the publicity aspect to be able to view it dispassionately. They are

\footnotetext{
${ }^{26}$ Before the Second World War, Austrian psychiatry was concerned largely with the foundation of psychiatric institutions and the improvement of conditions for patients. Research was primarily practised in university clinics, while psychotherapeutic schools were being developed in private societies. The law on admission and length of stay was reformed in 1916, making public establishments, university clinics and private institutions subject to the same regulations. This reform led to the requirement that the situation of an individual being kept in an institution against his or her will had to be examined within a month by a judge-led commission, advised by an independent psychiatric expert. In the universities, neurology and psychiatry were taught together from the beginning at Graz and Innsbruck, and in Vienna from 1911, until relatively recently. This led to a priority being given to organic research, which led to three strands: new treatment methods (Julius Wagner-Jauregg and Manfred Sakel); legal and clinico-descriptive psychiatry (Richard von Krafft-Ebing, Josef Berze, Erwin Stransky), which itself led to contributions in the nosology and psychopathology of schizophrenia and the manic-depressive psychoses; and cerebral psychiatry (Paul Schilder and Otto Pötzl). Psychoanalysis was of course a hugely significant product of Austria, which was also incorporated into the more organic psychiatry by several figures, including Pötzl. Psychoanalysis and individual psychology became distinct fields after the separation of Alfred Adler from Sigmund Freud in 1911.
} 
also interested in trying out other therapeutic methods; for example, Hoff is trying out of the treatment of melancholia with a combination of thyroid extract irradiation of the thyroid and physostigmine, and some other substances. I do not recall the exact details but it sounded unlikely to be of value. He was also anxious to introduce Benzedrine. He seems to be dabbling in several fields, because he told me he was also working on a virus investigation in poliomyelitis and encephalitis. Kauders, I believe, is working on it in a more serious way in Graz. Pötzl has so committed himself that it is difficult to get an opinion about some aspect of the insulin treatment from other professors who have come in contact with it, e.g. Marburg, and Chiari; the latter has examined the brains of patients who died under the treatment, but was disinclined to speak of what he had found in these brains because Pötzl might not like it; Marburg has been afraid to do animal experiments with insulin for the same reason. I heard some conflicting statements; for example, Hoff said that in Vienna the schizophrenia group is much more stringently delimited and prognostically much more unfavourable than in other centres, diagnosis being restricted in the tradition of Meynert and Wagner-Jauregg; Wagner-Jauregg, on the other hand, told me that they are very loose now in their diagnosis of schizophrenia, and have quite departed from his own strict notions of dementia praecox. Hoff made the point to me that insulin treatment could still be advantageous even if the results were not lasting, because one might have thus given the schizophrenic four or five years of normality, but apart from the fact that there has been nothing to tell how many years of normality the apparently recovered cases have, his argument is weakened by the premise from which he starts, namely, that schizophrenics don't do any good at all except spontaneously. Of the possibilities of treatment on general lines, e.g. according to Adolf Meyer (whose merit he questions) he has no notion. Hoff admitted that Sakel, who started the treatment, has no knowledge of psychiatry and indeed no capacity for learning it. According to Hess, Sakel is enthusiastic about his work and cares nothing about fame and money, etc. It appears, however, that some of the early publicity which Sakel managed to obtain for himself caused a great deal of resentment among the more responsible people in Vienna, who felt that Sakel, and Pötzl's clinic incidentally, were almost starting "a racket".

I gathered from Hoff, Wagner-Jauregg and others that the quality of the doctors at the clinics is steadily and rather rapidly deteriorating now because many appointments are not decided by the medical faculty, but by the political authorities who override the latter's recommendations.

There have also been a number of dismissals on purely political and racial grounds. The responsible people who talk about it seem concerned at the way in which the level of scientific work is sinking.

Marburg told me of his investigations on experimental epilepsy in animals and showed me the reprints of studies done in the previous two years. Chiefly, however, he wanted to talk about the lack of resources, which he considered would hamstring his work. I gathered that whereas Wagner-Jauregg used to refer the neurological material to him and the brains to von Economo, Pötzl does not do so, and that Marburg is not on such good terms with the psychiatric clinic now. I was told that he was a poor clinical neurologist, unsystematic and variable in examining cases, but of course a good pathologist. Certainly he has collected an immense material. He does not give 
the impression of having any stimulating ideas, but he knows the literature very well, of course.

I got in touch with the psychoanalytical group around Freud. Anna Freud, who seems active and sensible, has working with her, amongst others, an American psychiatrist (formerly with Macfie Campbell) and Mme Laforgue, the wife of the psychoanalyst in Paris. They are doing at the Montessori Kinderheim an interesting investigation into the diet which children under the age of two years spontaneously choose; the direct connection with psychoanalysis was not obvious, but I was told that the object of the study is not only the children's choice but the extent to which they get back their primitive pleasure in eating; the physical side of the children is attended to also in that they are examined physically and weighed every time they come.

In talking to the various analysts I met - Kris, Wälder, Julia Deming, Sterba, Hartmann (formerly in Pötzl's clinic), etc. I got the impression that in Vienna the analysts treat character disturbances very much more than actual neurotic illness, i.e. they seldom get cases of straightforward phobias, obsessions, etc., but a great many people with sexual and other personality difficulties, yet no definite symptoms. Consequently they are not much interested in therapy and practical problems of the OPD or the clinic, and cannot understand the medical point of view. The group is not as coherent as one had thought; Nunberg has been spending some time in America, there have been secessions, Federn has never been analysed himself, and they have switched over towards the non-medical side. The Viennese analysts, however, distrust the line of development which psychoanalysis has taken in England under the influence of Melanie Klein's work with children. The analysts in Vienna have had less and less to do with the university clinic, so that Stengel is practically the only one working there now.

I spent some time with Pick in the Pharmacological Institute, where I met also Rössler and some of the other assistants. Some of Rössler's work on pharmacodynamics of the circulation seems to have a bearing on schizophrenia and corrects the notions of Meduna and others as to the mode of action of cardiazol. The most interesting work that I saw in Pick's clinic was being done by Feitelberg, a Latvian, working there. He had set about measuring heat changes in the brain as a direct way of determining the functional activity of different parts of it. His previous training as an engineer has enabled him to devise a very ingenious way of measuring the temperature changes, comparing those of the cortex with the brain stem in rabbits and cats, and with the temperature of carotid blood. He was using the method to test stimulants and depressants, e.g. narcotics, and to determine their site of action; (in accordance with the Meyer-Gottlieb theory). He stimulates the tissue by a method similar to Hess's. After an interval of 10 minutes or so the temperature of the separate parts of the brain under narcotics becomes the same, but in the meanwhile there are significant differences. He has found also that the temperature of the occipital lobe rises when there are slight stimuli; it would be interesting to test the effects of mescalin. His method is very ingenious and seems capable of yielding valuable results in several directions. He had, however, to interrupt his work for $1 \frac{1}{2}$ years to do his compulsory military training in Latvia last year and the year before. 


\section{Report}

Pick also discussed the prospects for pharmacological research in psychiatry, mentioning for example that he thought that nowadays much of the initiative in synthesising the new preparations must be left to the big manufacturing chemists because of their much greater technical facilities and experience. (This is not quite in accordance with what Supnieswski does, but seems to apply, except in very special cases.)

Chiari I found to be quite uninterested in the central nervous system, except that he has an assistant working on the changes in the brain in periarteritis nodosa. Their pathology seems to consist entirely in examination of clinical material, without regard to experimental work.

I saw Durig in the Physiological Department. He turned me over to Lippay who was busy with chronaxie studies and fatigue phenomena and excitability in denervated muscle preparations. Rudolf Allers, the Adlerian, works there also on sensory physiology, but has now little interest in experimental work of that kind. There seemed to be little contact between the different departments in the Physiology Institute: Lippay, for example, did not know what the others were doing.

I met some people who talked mainly on general topics, e.g. Wagner-Jauregg who was very informative about the present state of psychiatry in Austria, Kris who worked on the psychology of art from the psychoanalytical point of view, and Wäler, the sociologist, who edits the International Psychoanalytical Journal. Berze I did not manage to see; some of the others spoke disparagingly of him. Gerstmann's work is of course careful and painstaking; a contrast to Hoff. Eppinger and Hans Horst Meyer I met very briefly. Epstein who works in the Kaiser Franz Josef Hospital on the chemistry of fats, etc., seems to have no connection at all with the neurologists and physiologists whom I met; most of whom had never heard of him, and Pick seemed to know very little about him.

I saw Karl Bühler, who explained to me his views about the uselessness of collecting further facts about psychology, instead of bringing those which are now available into a coherent scheme. He has sketched out the lines upon which he proposes to formulate a more or less complete psychological system, having due regard on the one hand, to physiological and biological requirements, and on the other hand, to the complicated psychological phenomena which fall outside natural science. It is obviously influenced by his studies on language and development. He is very critical about the psychoanalytical theory and about the Gestalt writers, and Kurt Lewin and Spearman. He is much more alive and stimulating than the people I met in the clinical departments. Although Bühler thinks that more than enough piling up of data is going on, Brunswik is going ahead with some experimental work in his laboratory, and Bühler himself keeps well in touch with recent work.

\section{Prague}

In Prague I went to Gamper's clinic. He is chiefly interested in the brain stem and the analysis of symptoms produced by diseases in that region. His methods are the conventional ones. Surprisingly, he said that he did not find it difficult to distinguish the organic from the psychogenic symptoms: I told him how often we found it impossible to be sure whether an apparently extra-pyramidal syndrome was hysterical or not, and he said that he thought that might depend on the fact that different clinics had 
very heterogeneous material. He, for example, had scarcely any neurosis among his out-patients and very little introspective productivity on the part of the schizophrenics such as he was familiar with elsewhere, of the Heidelberg material [sic].

The person of whom I saw most in Gamper's clinic was Klein. Gamper has an arrangement by which his chief assistants alternate each year between the psychiatric and the neurological clinic; the neurological clinic is regarded as the heavier in its demands (which indicates their predominant interest). Klein is at present on the psychiatric side. He told me that as far as laboratory work is concerned, they do not go in for histological studies, limiting themselves to a determination of the site of cerebral lesions. Klein is interested in aphasia and apraxia; he seemed quiet, reliable, and well-informed in his own field; has probably few new ideas, but critical.

Both Klein and Gamper were very apologetic about the structure of the psychiatric clinic, but it is not so old actually, and it seemed to me airy and large enough if only the nursing were to be improved. There were lots of Gitterbetten [children's cots], apparently used as a substitute for supervision and nursing; on the women's side things were a little better than on the men's side, but there seemed little attempt to give the patients occupation, or to treat them as individuals. The clinical material is really that of an observation ward or reception station, there seemed few chronic lunatics and some neurological cases. They are situated just above the mental hospital, which similarly suffers from lack of nursing and occupation for the patients, etc. Patients lie about and look depressed and degraded. The corresponding Czech psychiatrists, Haskoveç, who has the university chair, and Mysliçevek, who runs the mental hospital, are more in touch with French psychiatry; they publish single cases and pathological studies in the French journals. I was not able to meet either of them, and was dependent on hearsay and articles of theirs which I have seen.

In the neurological clinic there is Kral, who is the other chief assistant to Gamper. We discussed the reaction which he and Gamper have reported as characteristic of schizophrenia and some organic diseases of the central nervous system; he is quite definite about its regular occurrence, and told me that he had carried out a small number of control investigations on non-organic, non-schizophrenic diseases, the results confirming his views. The number of investigations done, however, did not seem to warrant his conclusions; the work has not been adequately tested elsewhere. Kral seemed more lively and more energetic than Klein. They are also anxious to try the reaction which Lehman-Facius reported at Frankfurt a few months ago, but cannot get details from him.

In Rihl's Institute of Pathology I saw Reiss, who showed me his technique for removing the pituitary in rats, and told me of his work on that and on adrenalectomised rats. He is no doubt a good endocrinologist, but when it comes to clinical application, he seems a bit ignorant and credulous (for example, as to the effects of provirol on impotence). Like a number of people in these countries he is troubled by political trends, finds himself out of sympathy with the Germans and for various reasons is eager to publish his work in some English-speaking journals.

I attended a meeting of the Ärzteverein in which Knaus, the gynaecologist, and von Jaksch took part. There was an incidental discussion about contraceptive methods and population problems: Knaus was, oddly, rather ill-informed about the latter. In 
Budapest I was told by Meduna that deliberate abortion is quite a problem in some of the villages in Hungary. I did not have an opportunity of meeting anyone especially interested in eugenics. I was told that, apart from Benedek, (whose interest is fitful), and Somogyi, who is a school teacher, no one is much concerned about it at present in Hungary; and in Czechoslovakia I did not find out who were the authoritative people interested in the matter. The people I met seemed to regard eugenics as a simple issue between compulsory sterilisation in the German style and laissez faire.

At Tschermak's physiological institute I saw Schubert: Tschermak was away. Some of his work in optics and acoustics is certainly applicable to psychiatric and neurological problems, e.g. to depersonalisation and toxic states, but the methods are too complicated for the non-expert. Schubert has worked on aviation physiology, and on electrical phenomena in the stomach in normal subjects (using similar apparatus to that for electro-cardiography).

I gathered that one of the other men there is working on calcium metabolism in relation to muscular activity, but Schubert could not tell me the details. Although Tschermak's researches are so applicable to psychiatry, I could not find that there was any liaison between his department and Gamper's. As so often elsewhere, I was impressed here by the urgency and importance of their matter of collaboration or fertilisation within the university or city: people seemed to try out work of which they had only read in a foreign journal in preference to what was being done next door, or perhaps in ignorance of it.

\section{POLAND $^{27}$}

In Cracow I went to the Psychiatric Clinic which was shown me by Prof. Pienkowski and his assistant Godlowski. I could not find that the professor was at present engaged in research; he was not pursuing his former studies on the hand symptoms of extrapyramidal disease, and he seemed depressed and tired. He mentioned various additions to the work of the clinic, e.g. a children's department, and spoke of the research which he and others were trying to initiate on the inheritance of mental disorder, but in discussion he did not give the impression of being at all familiar with the problems, much less with the methods of attacking them; he spoke only in general terms of the need for a firm basis, thoroughness, etc. The clinic was apparently intended mainly by Piltz, when he designed it, for neurological cases, and it seems neither adapted for the treatment of severe psychosis nor to contain all the varieties desirable for

\footnotetext{
${ }^{27}$ The first psychiatric hospitals on Polish territory emerged in the first half of the nineteenth century, and from mid-century psychiatry courses began to be part of the medical programme. After Poland's independence at the end of the First World War, the Polish Psychiatry Society was founded in 1920 - although meetings of neurologists, psychiatrists and psychologists had been taking place since 1909 - and was principally concerned with consolidating therapeutic approaches and with juridical questions. Biological tendencies dominated, although Borsztajn and Forstig published psychoanalytic works. The Society's 1933 meeting dealt largely with heredity and the prevention of mental illness, and ended with a formal protest against the eugenicist use of sterilization for psychiatric patients, which had just begun in Germany. Polish psychiatry was to suffer under Nazi occupation; all universities were closed, and virtually all psychiatric patients were killed in the Nazi euthanasia policy. Sixty per cent of psychiatrists did not survive the war. (See Jacques Postel and Claude Quétel (eds), Nouvelle histoire de la psychiatrie, Toulouse, Editions Privat, 1983.)
} 


\section{Aubrey Lewis}

teaching, etc., in a university clinic. The nurses seemed poorly trained, and it was a little inappropriate that Prof. Pienkowski should put so much more emphasis on the structural arrangements of the clinic, of which he evidently thought highly, than on the standard of the nursing. There were many evidences, as I walked round, that this was well below what is now regarded as necessary. I was told that occupational treatment was employed, but during the round I saw no signs of patients working or of the customary facilities for it. Although lack of money was emphasised as responsible for some deficiencies, the more glaring ones, to the casual visitor, were such as could probably be remedied without much expense. Several of the laboratories which Piltz had set up were now unoccupied; the only research of which I was told was anatomical and experimental - chiefly by Godlowski, the Agrégé, who was doing careful work cutting the posterior commissure in cats and observing the effects on motility; his interests are on neurophysiological lines, and in conformity with a general trend in Poland (e.g. Rotfeld in Lvov and Orzechowski) they centre on the vestibular apparatus. In the museum of the clinic there were a lot of brains awaiting examination and I was told that they had all been collected there in the fifteen years since the clinic opened; the extraordinarily high death rate seemed to be partly due to their cerebral tumours not having been operated upon and to their having senile cases in the clinic. This is no doubt related to the neurological bias (there were only thirty odd psychiatric cases and these had to be together, e.g. a hysteric near deteriorated and noisy schizophrenics, etc.). There is a larger, more varied material at the reception ward in the general hospital, but their interests there are also mainly neurological. Prof. Pienkowski told me that he has four polyclinics, one of them for alcoholism alone, and that psychotherapy is employed, but as he said that there were $\mathbf{3 0}$ or so new cases at each session, it was clear that time and probably experience would be lacking for so much work of this sort. The physicians are occupied with their private practice in the afternoons. Their clinical outlook was not impressive, e.g. several cases of cryptogenic polyneuritis were shown to me, but the possibility of a vitamin deficiency was not mentioned, though a lot of less probable causes were; for a case of spontaneous hypoglycaemia they were going to irradiate the hypophysis; a rather popular therapeutic procedure in Poland at the time, without considering the possibility of pancreatic tumour. In spite of Cracow being such a small place, it did not appear that the people in the clinic had very close contact with the other research workers, e.g. physiologists, pharmacologists: Godlowski's scientific connections lay elsewhere. They were, however, in touch with recent literature, especially Godlowski, who seemed able and well trained, and the most active influence in the clinic.

In the Pharmacological Institute I saw Prof. Supniewski. He told me of his work on mescalin and allied compounds, and on synthesised substances related to acetylcholine. At the time I saw him he was much handicapped by not having any competent assistants; the lack of adequate pay or prospects in his department made it impossible to get people to take up the work. His incidental remarks on political and social matters showed that he was psychologically hampered in his productive worked by dissatisfaction with the general conditions prevailing in Poland and Europe. He seemed interested in pharmacological questions bearing on psychiatry, but to lack the nexus with psychiatrists; I was to try the effect of some of his cholinergic compound, which 


\section{Report}

he offered me, when I got back to London. He was disposed to reticence about the uses of mescalin now, as he had not worked on it for the last few years.

\section{Warsaw}

In Warsaw I first saw Opalski, the neurologist, who was then working in Prof. Masurkiewics's psychiatric clinic, in order to qualify for any vacant chair in the combined subjects. He was responsible for the insulin unit, which seemed, as in so many European clinics, to be conducted more light-heartedly from the nursing point of view, etc., than the risks require but his chief interest and research lay in straightforward histo-pathology.

Prof. Masurkiewics showed me round the clinic; the buildings are very old. He showed me some unusual cases of aphasia, etc., and explained to me his theoretical views of the pathology of mental disorder, in which the vegetative nervous system plays a large part; he makes a curious fusion of the views and findings of Orbeli, Hess and Bourguignon. One of his assistants, a woman, Madame Skrzypinska, had gone to Paris to work with Bourguignon, and the research was still going on. Prof. Masurkiewics struck me as unusual, in that he had developed an original point of view in psychopathology, without losing touch with practical clinical problems and concrete (as apart from speculative psychological) research.

I also visited Prof. Orzechowski at his neurological clinic; he seemed to have a heavy burden of cases there, and I could not discover that he was actually pursuing any research.

Chorobski, the neuro-surgeon, was working in a unit arranged for him in the "traumatological" hospital, which is directed by a military surgeon, though Chorobski himself is officially attached to Prof. Orzechowski. He could not resign himself to the material and personal difficulties which he met with in Warsaw; he contrasted it with conditions he had known during the years he spent in the United States and in Western European countries. Temperamentally he seemed rather ill-equipped to cope with adverse conditions. He was very busy, but could not get good assistants who would stay; he was just about to lose his excellent American trained nurse and his chief medical assistant, both of whom were very reluctant to go but could not afford to remain. Practical difficulties such as lack of money for equipment, the right to diagnose and select cases, etc., preoccupied him rather. Nevertheless it seemed clear that he was building up a sound neuro-surgical unit and that there was no effective hostility to this in Warsaw. His reputation as a good brain surgeon is high in Poland, and he seems to be educating the rest of the profession in regard to the possibilities of surgery of the CNS. His chief interest on the research side was in the sensory fibres of the sympathetic, and in the relation of arterial tension to brain conditions and the psychological evidences of impairment. It seemed a pity for his proposed work in the latter that he had not had a good training in clinical psychiatry. For the development of his department it would possibly have been better if he had been allowed private practice; he would then probably have been able to get and put more money into the surgical unit. At present they do not even take private paying patients into the unit. So that well-to-do people are operated on there without paying fees which could help greatly towards developing the unit along desirable lines. Chorobski's keenness and industry seemed 


\section{Aubrey Lewis}

to promise that he would not have neglected his main work, even though he had had some facilities for private practice; he would very likely have been able to get on with research more satisfactorily.

I saw Konorski and Stefan Miller and Mdlle Lubinska at the Nencki Institute. They showed me their conditioned reflex laboratory and discussed the special use of the motor response in their experiments. It seemed, allowing for the objections made by the Leningrad workers to this method, that it could be extended to the study of some psychiatric problems in children, especially in regard to inhibition. The keenness of these three workers and their interest in some of the applied problems arising out of their research were impressive.

\section{RUSSIA $^{28}$}

\section{Moscow}

In Moscow I had some difficulty in getting to see some of the people I was most anxious to visit. The first I saw was Dr Victor Minor, who did not appear to have any laboratory; I called on him at his home. He discussed with me his work on the distribution of the sweat glands, especially the importance of mechanical or physical factors, the relation of sebaceous to sweat over-activity and his interesting speculations in regard to the differences between sweating due to heat and that due to emotion. At present he seems to be one of the most active of the lecturers on medicine to the general public. I saw next Prof. Lina Stern, but on none of the three occasions when I saw her - twice at her laboratory and once at her home - did she seem inclined to speak in other than general terms of the current research work in her laboratories, evidently centred on the haemato-encephalic barrier as in her earlier Swiss days. She seemed always very tired and was working very hard. She, her friend, the daughter of the late Prof. Bach, discussed the question which I raised, of the efforts made to co-ordinate and direct scientific work towards specified ends in the USSR; Miss Bach repeated the theoretical and general arguments which I had read elsewhere, but Prof. Stern seemed to have little interest in or esteem for these arguments, and I gathered that in physiology, at any rate, she did not consider there was any real difference in the present Russian way of initiating and determining the trend of research and that followed in other countries, though there were manifestly considerable differences in detail.

\footnotetext{
${ }^{28}$ In nineteenth-century Russia, debates about psychiatric theory and practice were situated in a context of the wider opposition between Slavophiles and Occidentalists; there was, however, a keen interest in both French and German psychiatry. In 1861, after the abolition of serfdom, the newly created zemstovs assemblies of doctors, engineers, and statisticians - established agricultural colonies for the mentally ill The first psychiatry Chair was created in 1857 at the Medico-Military Academy in St Petersburg, held by I M Balinski. U M Bechterev held the post from 1893. Moscow's first psychiatry chair was given to A J Kojevnikov (who isolated continuous partial epilepsy). Grigorii Ivanovich Rossolimo and Vladimir Mikhailovich Kernig were two neuropsychiatrists who became well-known throughout Europe; figures such as S S Korsakov and V C Kandinski were also influential. Interest in psychoanalysis existed before the Revolution, but became more marked between 1917 and 1928; from 1928 onwards, however, a highly vigorous intellectual culture was repressed; only Pavlovianism was acceptable and indeed became State doctrine. All Western developments, psychoanalysis and existentialism especially, were condemned.
} 
I visited Prof. H Müller's Institute; he was away and his associate, Gershonson, showed me round. There seemed to be more original serious work going on here than in any other institute I visited in Moscow; several of the research workers explained the details of what they were doing: influence of X-ray dosage on mutations, splitting of the $\mathrm{Y}$ chromosome, estimation of the size of the genes in the metaphase chromosomes (by Raphael and another American), etc. Gershonson also told me of the ingenious research being done into the fixity of gene characters, by transplanting bits of growing germ gland on to a Drosophila's egg (other tissues from the larva were also being used); the bearing of this on "Penetranz" and other fundamental questions of heredity was discussed. They were also good enough to tell me of some of the research in applied genetics being done on sheep, rust-resistant wheat, etc. by the Institute. I asked also about Prof. Müller's views on artificial insemination in human beings; Gershonson implied in his answer that this was a private vagary of Prof. Müller's.

I next went to the Brain Institute, where they were occupied with four problems - variability of the different brain fields à la Brodman, "Entwicklungsmechanik" (observing the effect upon other regions when a piece of embryonal or growing brain is cut off), Berger rhythm, and very careful serial studies of the changes in Pick's disease. They were also busy dealing with "élite" brains, e.g. of Gorki, Pavlov. Undoubtedly their painstaking work in mapping the human cortex and in making beautifully accurate atlases is extremely useful; fortunately they seem to have experts who enjoy doing that as their permanent total occupation. Their work on the Berger rhythm seemed to be more fruitful of results than that of reliable people elsewhere, although technically they did not seem to be taking all the customary precautions to ensure accuracy; they were working on the changes produced by artificial tumours such as implanted myoma and on the effect of drugs such as chloroform and strychnine. Unfortunately the man who does all the work in this department was not available, and consequently I could not get any detailed information about his research.

At Prof. Levitt's Institute he told me of the work going on under his direction. Like so many of the scientists I visited, he spoke proudly of the large number of assistants he had, forty-six, I think - but they were scattered in different institutes, and I gathered from what he said that many of them can scarcely have any genetic knowledge, e.g. he has two men working on heredity of psychoses of whom one is a psychiatrist ignorant of genetics (the other is a pure geneticist): Levitt said that he knew of only one other man working on psychiatric genetics. He mentioned Ignatiev. He showed me the children's clinic, in which he keeps twins for six days' observation; some of the precautions taken to prevent infections seemed excessive. I had read and heard of his enormous collection of twins - 2000 pairs; but when I asked him about them I discovered they were mostly children under 10 and that he had occupied himself almost entirely with average children; he had few morbid twin collections of any size. The method of ascertainment of his twins would, it seemed to me, preclude their being used as a representative sample for psychological studies, since, besides those discovered by inquiry at houses by field workers, he accepts spontaneous applications (which might conceivably include an unduly high proportion of intelligent, enthusiastic or neurotic subjects). He told me that so far as psychiatric disorders were concerned he did not see that any other methods were applicable than the familiar ones, namely, family 
studies and twins. His collaborators were working on some two hundred schizophrenic pedigrees. An inquiry into a problem of educational psychology was being carried on by a woman in his department, who had earlier collaborated in this work with Luria (observing the extent and duration of improvement in performance and also in perception when a model is presented for copying in which the constituent parts are not separately visible). I was surprised to find, however, that they had not extended the investigation beyond the point which it had reached when it was reported on in their article two years before; possibly this was due to the withdrawal of Luria. Levitt also told me of his interesting studies of the incidence of achlorhydria in the immediate relatives of patients with gastric ulcer; the incidence of accentuated secondary aortic sound in the siblings of patients with hypertension; and other such work, looking for the early or premonitory signs of disease. It seemed to me, however, that at any rate in his use of the urinary concentration test on the relatives of patients with diabetes insipidus he was being unduly influenced by his notion of what anomaly would be a signal or a constitutional feature of an impending disorder; in the psychiatric field this difficulty would become of much greater importance than in the subjects he has so far worked on. His use of the twin method for histological correlations, e.g. correlating the height of the $\mathrm{T}$ wave in the electrocardiogram with the size of the heart seemed to me an interesting and new method, but more limited in its possibilities than he believed. He also spoke of the serological test he had been using and from which he had expected much. He seemed full of original ideas, e.g. he had taken pieces of skin from a patient with an atrophic skin disease and cultivated them in vitro to see if the atrophy persisted; if it had he would have supposed it to be a constitutional or inherent quality.

In view of the semi-political cloud under which Levitt was reputed to have been earlier in the year, it was interesting to notice with what energy and emphasis he interspersed his account of his researches with rather irrelevant or seemingly naive remarks about the superiority of Marxian arguments over capitalist science, e.g. he brought the Marxian arguments against natural selection into a discussion of this work on dominance, and he said that it was only in Russia that the capitalist mistake of anecdotal or "literary" selection of twins had been avoided; he is obviously so familiar with the international literature of his subject that one would hardly think he could have meant this seriously. ${ }^{29}$ It was also noteworthy perhaps that, after he had asked me to look over the English of an article he was sending to an English journal, the Voks guide, [he] made a point of asking me for the article and reading it forthwith, and of being present when Levitt eventually called at the hotel to get it back from me.

Next I saw Prof. Kroll, who told me of his histological studies with a functional background, i.e. secretory function of neuroglia, activity of sympathetic nervous system and adaptation of skin to temperature and other changes; his work on the thalamus was interesting. He showed me his laboratory and suggested various psychiatrists and other research people in Moscow whom I ought to see; for reasons that I could never fathom properly, nobody was able to arrange, however, for me to get in touch with

\footnotetext{
${ }^{29}$ These remarks suggest that Lewis was not aware of the extent of the anxiety that must have been felt by people in Levit's position and the extent of their possible persecution.
} 
these people. Among them were Lubitchev (or some such name) at "Viem", Gurolevsky and his associate professor, and Mark Serejski and Gilarowsky the histopathologist.

I saw Speranskii at his Institute. We spoke of his views, developed in his book, about the influence of the nervous system on somatic disease, and the converse. His observations and experiments were very interesting but when I asked him about the application of this theory to some concrete issues in psychiatry he would not commit himself in any way and referred me back to the book. He said that a number of clinicians were now applying his method to the treatment of their cases, but here again it was impossible to get any definite details or illustrations of how this was done; he had not yet attached any psychiatric problems but was reluctantly yielding to the solicitations of the psychiatrists to do so; I could not discover what he had in mind to do, although I raised such questions as: did he mean to collect more facts in the light of his theory or to rearrange the present ones? How would it apply to such a matter as the treatment of GPI? The neuro-psychiatric complications of pernicious anaemia etc.

I made several attempts to get in touch with some psychologists, but neither in Moscow nor in Leningrad was I able to do so. I had a letter from Dr O'Brien for Hellerstein, but nobody seemed to know what had become of him; ${ }^{30} \mathrm{Kroll}$ thought that he was working in Lina Stern's institute, but she told me that she knew nothing about him. I got an impression, rather than a definite statement, that he had been caught up in psychotechnics of "pedology", and after that their initial flourishing these branches of psychology had not justified expectation and had been more or less liquidated. Since then I have seen the account (in Sir E D Simon's book on Moscow) of how educational psychology, mental testing, etc., had been indicated as anti-Marxian and Prof. Blonksy had publicly retracted his alleged errors. I cannot imagine why no one in Moscow told me of this plainly when on the subject, since it was no secret, the decree of July 1936 had been published and the matter ventilated in the Moscow Daily News. Luria, Kroll told me, had taken up medicine, and was busy with his examinations so that I was not able to see him.

I saw Propper, who also suggested various people I ought to see, but nothing much came of it; he took me round, however, to Ivanov-Smolensky's laboratory in the Institute, Ivanov-Smolensky was in Leningrad, but I was told of their work on the sympathetic response to conditioning in children; as with many other interesting things, the work was at that time projected - "in construction" - rather than actually under way there.

Propper told me of his own work on epilepsy and on pain. He was stimulating the cortex diffusely by electrodes put on the skull and then observing the biological changes (effect of perfused frog's heart, etc.), and producing toxic effects by injecting an emulsion of brain tissue into animals of the same sort, i.e. more or less repeating Forster's experiments; he had done similar work with pain stimulation in animals, though there seemed to be a possibility that the BP and other effects he observed might be due to an adrenalin-like substance.

\footnotetext{
${ }^{30}$ O'Brien, in his letter to Lewis (O'Brien to Lewis, 23 February 1937, p. 8), describes Professor S G Hellerstein as the Director of the Psychotechnical Laboratory of Institute of Experimental Medicine, saying that his field is applied psychology.
} 


\section{Aubrey Lewis}

Kroll kindly took me along in his motorcar to the Institute Gannushkin where Serejski and Kronfeld work. The director unfortunately spoke only Russian and a few words of German, and did not (as I had hoped he would) just hand me over to Kronfeld (whom I had known in Berlin in 1928). They have treated a lot of schizophrenics with insulin, 250 in one year, under the direction of Kronfeld and another German exile, Sternberg. Schizophrenia is a diagnosis more generally applied in Moscow than in Western countries. Many cases we would call depressive, manic, or psycho-neurotic they label as schizophrenia, - especially schizophrenia mitis. Although this is a reception hospital, they said $80 \%$ of their admissions were schizophrenic (an extraordinarily high figure). I saw eight or nine recovered cases playing ball to music, under an instructor; apparently this recreational therapy is mainly for convalescent patients. In the occupational therapy department there were four rooms, mainly adapted for more or less skilled trades, e.g. making woodwork and toys, and for painting street rubbish-bins, and doing other socially useful work. I was told that a sixth or less of the patients work there. One or two of the men patients whom I saw there were, I was told, quite well now, but had elected to remain, and they continue their work in the shops while living outside; there seemed a good deal to recommend such a plan, but, on the other hand, I would have thought that therapeutically it would be more important to use these places and the work-rooms for patients who were still ill. In short, their occupational therapy is on the old plan - not so much to benefit the patients' health, as to benefit others by the work of a few, usually chronic or convalescent, patients. I was told that other patients work in the wards; I did not see this, as when I was there it was rest time. They also have an X-ray and electrical department of which they are very proud; young doctors from other places come there to learn the technique, but it was reminiscent of some Italian and other clinics I had seen where there was much equipment for giving static electricity and other forms of instrumental treatment either obsolete or of solely suggestive value. I also visited the histological laboratory where the pathologist (an elderly man who had evidently had a severe hemiplegia) showed glia stained by his own method. In the wards the nurses were people of little training. I was told that this would be remedied later on. The "disturbed" ward was very disturbed. Kronfeld had been given charge of a department and was extremely enthusiastic about Russian psychiatry and the treatment that he had received from Narkomzdrav. ${ }^{31}$ I was not able, however, to speak to him at any time except in a group of people, which I regretted because his praise was so excessive in some instances where the facts were quite obvious to anyone who knew psychiatric conditions outside Russia, that I found it difficult to believe it to be his genuine opinion. I asked whether he was still pursuing the work in psychopathology and psychotherapy, for which he had been so distinguished, but he and the rest of the doctors seemed embarrassed by my question, and I learned that psychopathology is not much pursued in Russia and that for psychotherapy there is either little time or little inclination; psychoanalysis is frowned on.

When the patients are discharged they come under the neuro-psychiatric specialist for their district. I could not, however, get any information about the numbers and organisation of these cases in Moscow, being always referred for details to someone

\footnotetext{
${ }^{31}$ An abbreviation of Narodny Komissariat Zdravookhraneniya - People's Commissariat for the Protection of Health.
} 
else whom I never discovered. I tried to get the figures about the rayon service also from Karanovitch, of the Narkomsdrav, but whether because of the language difficulty, or some other reason I could not get them. In Leningrad, however, I did get information to this point.

My last visit in Moscow was to Karanovitch who, I was given to understand, was their chief authority on the statistics of psychiatry. As he spoke only Russian it was unusually difficult to make clear to him what I wanted to know, and to the most simple questions as to the percentage frequency of this or that disease he would answer with a long statement. I gathered from him that there has been no marked change in the distribution of the various mental disorders, e.g. they have as many manic-depressive psychoses as formerly, but that they now hospitalise traumatic cases, which they did not do before, and this has apparently altered the hospital incidence of the other conditions. He said their statistics were still incomplete even for Moscow, that extramural psycho-neurotic cases were not yet included in them, and that differing criteria of diagnosis influenced them, as one would expect. He thought I would be able to get better information in Leningrad. From the figures available it seemed that they have still an enormous deficiency of beds (the present number being perhaps one-sixth of what are needed). They have little provision for mental deficiency per se; nor for senile and arteriosclerotic cases, hence the predominance of patients in the earlier decades of life. Moreover, cases seem to be discharged too soon, judging by the high figures for re-admissions. To draw conclusions, however, from their published statistics as to the frequency of particular disorders is to court error; one does not know whether, for instance, the high percentage of schizophrenics (nearly one-third of all admissions) may be a matter of diagnosis, or of factors determining selection for admission. The figures do, however, seem to show a great advance on the psychiatric provision available in earlier years.

\section{Leningrad}

In Leningrad I first saw Koupalov; he showed me the chambers used for the conditioned reflex studies and how he puts the food in fluid form directly into the dog's mouth, thus eliminating the secondary cause of salivation, e.g. chewing. He seemed almost entirely taken up with the physiological side of his problem, and therefore opposed to movement studies such as those of Konorsky because of their complexity and their variability. He seemed wedded to Pavlov's "cortical" theory of inhibition, etc., and unaware or unable to see how unsatisfactory this is found to be by psychiatrists, for instance; it seemed unlikely that the direction in which he was pursuing his researches would result in illumination of morbid psychological problems.

Next I went to Podkopaev, but he seemed indifferent or reluctant to see me, excused himself and handed me over to Gersuni who was studying action currents of the $8^{\text {th }}$ nerve (Wever-Bray, etc.) and observing the effects of other stimuli on this, the relation of loudness to intensity and chronaxy, also the noise phenomena produced by an electrical current through saline in the external ear. He seemed competent and keen. He was interested in the question of the influence of drugs which I raised with him, but had not so far studied it. 


\section{Aubrey Lewis}

At the Filatov Hospital Krasnogorsky showed me two experiments on conditioned reflexes which he was doing, one on a slightly neurotic girl, and another on a myxoedematous patient in whom the basal metabolic rate had fallen to -40 , and who, while in this condition, did not develop conditioned reflexes. His experimental rooms were much less well equipped than others that I saw in Moscow and in Leningrad; his apparatus was old and worn, though adequate for his purposes. Krasnogorsky is obviously energetic, original-minded and enthusiastic about his work. He told me about the various forms of research in paediatrics, nearly all of them concerned with original problems, usually of therapy, e.g. his method of treating enuresis by a planned salt control, which however might only be effective with those in whom the enuresis was due to an irritable spinal micturition-centre. He also told me of his work on sleep and of his reasons for giving up the notion of inhibition, speaking of more and less excitability instead. Although the pure Pavlov followers in Leningrad evidently regard Krasnogorsky's work in the field of conditioned reflexes as too uncontrolled, dealing as he does with human beings, he seemed to be the only one really attempting the necessary work of applying the method to clinical problems. Others seemed hampered by Pavlov's theory about the cortical happenings.

Gurevitsch, of the mitogenetic rays, showed me his laboratory and his method. In talking about his research he was fairly plainly on the defensive; he brought in A V Hill's contemptuous remarks about his work, and also Bateman's critical article in Biological Reviews, of which he spoke bitterly; this was perhaps understandable considering how devastating Bateman's article had been. I also saw his assistant, a psychiatrist called Braines (of whom Ossipov spoke quite highly). Braines made startling claims, and seemed very confident. He had found that in mania there was a great increase in the mitogenetic activity of the blood, but in depression no such activity at all, and by treating depressive schizophrenics with the blood of manic patients he had, he thought, brought about recovery; irradiated blood had exerted a similar good effect; also by the injection of a manic patient's blood, he got to take their food satisfactorily. It all sounded very improbable. I gathered elsewhere that Gurevitsch was likely to lose suddenly and completely the strong support that he had for his researches, as soon as the government, i.e. the political heads of scientific work, concluded that it had no real value; that this withdrawal of support was imminent; there had been no published criticism of his work in Russia because it would have been indiscreet in the circumstances, but that this had not meant that it was generally accepted. People thought Gurevitsch was honest but misguided.

I saw Ossipov at the Military Academy and at the Brain Institute, where Bechterev was formerly. The clinic at the Military Academy was, surprisingly, not full. The accommodation, which was generous, was for a hundred patients. They have laboratories but, apart from some research on mescalin and hallucinations, they did not appear to be doing much research there just then. In the Brain Institute, besides the morphological work there was evidence of there having been formerly considerable interest in psychology, especially the comparative psychology of apes, but here, as in Moscow, psychology seemed to have become rather a taboo subject; no successor had been appointed to Wagner, the last professor. In the electro-physiological department, the influence of Orbeli's views was evident. Mdlle Novikova, who had been in the 
USA, was investigating the effect of cutting the sympathetic rami on the nerve muscle response of frogs (stimulation of peroneus) which had had a hemisection of the cord. I also saw Petrov's work on the influence of electro-magnetic fields on nerve muscle preparations. I was impressed by the investigations in the biochemical department where they were analysing the calcium, potassium, sodium and magnesium in the grey matter of brains from the embryo onwards, seriatim, and the oxygen exchanges of the grey matter of rats. In decorticated dogs, the physiologists were observing the conditioned reflexes using the standard Pavlov technique; they told me that the decortication had been complete but it was evident that the dog they brought in was using its occipital visual cortex still. Ossipov gave the impression of a well-trained psychiatrist of the old school; his outlook seemed to be substantially that of Kraepelin, under whom he had studied.

At Ivanov-Smolensky's clinic (formerly Pavlov's) I found that continuous narcosis was their chief interest. Ivanov-Smolensky uses Cloettal on patients with catatonic stupor and considers that his 50\% remission rate represents a substantial therapeutic advance; he seemed to be unduly influenced by Kraepelin's $15 \%$ recovery rate. Walking through his wards, however, the cases that he showed did not appear to be severe catatonic stupors but looked more like what we would call melancholic semi-stupors. It was difficult to discuss psychiatric matters with him, partly because of the language difficulty and partly because he seemed to resent as criticism such questions as: what were the figures for a control series of his cases not treated by continuous narcosis; whether the good results obtained were regarded as supporting Pavlov's theory of overexcitability and need of rest in these catatonic cases, and if so whether the success of the treatment in manic-depressives did not indicate that the same theory would apply there; what criteria were used to determine whether the stuporose patients were narcotised continuously (he said he used response to pain and light reflex, which seem an unsatisfactory way). He was treating some cases with insulin in pursuance of his views as to the vegetative changes in the sleep treatment. He assumes that in schizophrenic patients there are toxic phenomena which must be attached. His other research, i.e. the examination of all new cases by a modified conditioned reflex method, seemed to have little to distinguish it from the familiar reaction time and learning experiments, but done in a Pavlov chamber; the results, however, were interesting. There was also the mechanical hypnotising apparatus.

From Ivanov-Smolensky and Ossipov I learnt that there are 10 rayons for Leningrad, with its population of approximately three million; each rayon has on its staff a neuropsychiatrist with two doctors assisting him. There are about 200 neuro-psychiatric patients in the rayon, the doctors spend $4 \frac{1}{2}$ hours a day on two days of the (6-day) week seeing patients who come to them, and three hours on two other days of the week going to see patients. In the $4 \frac{1}{2}$ hours each doctor sees about 20 patients. All the questions of commitment to a mental hospital are decided by the doctors; there is no legal aspect to the procedure. From what Ivanov-Smolensky told me the number of cases in the mental hospitals in Leningrad is small in proportion to the population; like every other psychiatrist I asked, he said he did not think that there were fewer manic-depressives in Russia than elsewhere, and said that the statistics were not as yet complete enough to permit one to say. 


\section{Aubrey Lewis}

Prof. Orbeli took me first to his electro-physiological department where interesting work was being done on Vedensky inhibition and on the autonomic fibres in mainly motor nerves, e.g. to gastrocnemius, rectus abdominis, artorius, (in relation to Orbeli's theory concerning the different stages of evolutionary differentiation). Orbeli. spoke of his views and observations on the regulation of reflex activity by sympathetic influences. He was studying the influence of sympathectomy on metabolism and on the mesencephalon investigated by the Hess method. One of his assistants was observing the trophic changes in the eye of the rabbit following excitation of the Casserian ganglion on that side. At another visit I saw Orbeli operate, cutting the vagus in two dogs and suturing it to observe the gradual effect of the regeneration on gastric and intestinal secretion; the other vagus had been cut three years before. He showed me various animals that had been operated upon (one had the impression in Moscow and Leningrad that more animal experiments are done there than anywhere else in Europe): cats in whom the posterior columns had been out high up with consequent disturbances of motor behaviour - some of their symptoms were exactly like those of a man with visual agnosia; the assistant, Pancratoff, working on this was also studying catatonic patients in the psychiatric clinic and comparing their motor disorder with that of dogs in whom the cerebellum had been removed. Other animals with experimental lesions of the cerebellum and the thalamus were also brought in. Orbeli spoke of the influence he believes the cerebellum to have upon intestinal and other forms of sympathetic activity. Also there were animals in whom the effects of labyrinthectomy could be studied.

I also saw Prof. London operate. Although so much less deft in his technique than Orbeli, he does his remarkable three-stage operation with surprising rapidity. The originality and wide applicability of his method to the study of bio-chemical problems made one wonder why it is relatively little employed elsewhere. It was a relief to be in the company of London or of Orbeli, who are so direct and clear, after having contended with other people who seemed more bent on impressing the visitor than on discussing their research itself.

Lindberg showed me dogs at various stages after ablation of one hemisphere, and of the pre-frontal region on the other side; it was surprising to see how little they used their smell to locate food thrown to them in their hemianoptic field. Having apparently heard from someone else before I came to him, that I had spoken of the difficulty of getting in touch with various people because of their working in several different institutes, he told me I had been misinformed on this point, and that most people like himself do all their research in the one place. (I gathered from others, however, that it is still necessary for many doctors, probably not the research men, to take up a number of jobs to earn a fair living.)

Rosenthal was also working on the effects of removal of the hemispheres, with particular attention to the effects of the removal of small pieces of cortex upon complex activities; he tests not only the ordinary conditioned reflexes as Lindberg does, but also such motor conditioned responses - or trained habits - of the dog as giving alternately first one paw then the other. He was also, like Lindberg, interested in seeing how far tactile disorientation was preserved after decortication (conditioned response to stimulus on one spot and not on another). He had a number of plans: he wanted to 
modify Dusser de Bareme's method, and test the effects of electro-coagulation of the top two or three layers of the cortex instead of all six; also by the "trace" conditioned reflex to attach the problem of memory, also "negative" stimuli. The question of the part played by sub-cortical mechanisms is little regarded; for example, it seemed that stimulation of the labyrinth by hot and cold water might be used to throw light on this; he said it had not been done. He stated his conclusions about the area striata and other regions of the cortex in such a form that it seemed he was finding that a conditioned reflex should be established as long as the area of cortex which received and dealt with the appropriate perception was intact, e.g. if all the cortex except the area striata were removed, visual conditioned reflexes could still be obtained. I discussed with him the bearing of this on Lashley's work and he said that Pavlov had believed that there were many centres of nuclei where specific "elements" were concentrated but that simple "elements" for some purposes were distributed throughout the cortex.

I next saw Prof. Osowsky who conducts one of the university clinics in an outlying suburb, and is chiefly responsible for the collection of psychiatric statistical data for Leningrad. He told me that what published statistics there were might be found in a book by Dr Persakoff (or some such name) which he would send me, but like some other books and papers promised me by people in Russia, it has not reached me. He said he had not the impression that manic-depressive psychosis was any less frequent in Russia than elsewhere (he had studied in Halle and knew German psychiatry well), or than it had been formerly in Russia; and that he would be surprised if it were so. He himself saw few psycho-neurotics because they did not come his way; his clinic, like most of the others, selected its material from the general hospitals, the dispensaries, etc., and therefore he and his university colleagues were not in a position to form a personal impression of the frequency of the various forms of mental illness. It is usually after a preliminary period in the clinics (evidently reception hospitals) where the patients can stay as long as the doctors wish, that they go on to the mental hospital if necessary; consequently a majority of the manic-depressive cases may recover in the clinic and never be included in mental hospital statistics. He did not believe that any figures were available concerning the patients seen in the rayon; he had not even the figures for his own district, though his clinic is in the locale of the dispensary of the rayon psychiatrist there. I asked him about the content and form of the usual groups and it seemed that there was nothing particularly different from what is found in other European countries, e.g. the hysterics have psychological rather than coarse neurological-looking phenomena; obsessionals look like masked schizophrenics; anxiety states, however, he said were more often discreet anxiety attacks than chronic states. Fortunately, also, he was responsible for the treatment of alcoholics - a subject on which I had been able to find out nothing except vague generalities from others. The arrangements for alcoholics, and indeed for all the outpatient specialist treatment by psychiatrists in the rayon, are still restricted to the big towns, the team there consisting of a neurologist, a psychiatrist, a "narcologist", a psychotherapist and, rather pointlessly it seemed, a neuro-pathologist (probably a man who does laboratory tests, as for syphilis, etc.). Cases of acute alcoholism are sometimes admitted for 24 hours to the hospitals in Leningrad. Severe alcoholics are sent to an institution, containing 25 beds, where they seldom stay longer than two months. On discharge there is no control of their 
drinking, but if they commit anti-social acts, they are punished according to the act and not for the alcoholism. Alcoholism is not accepted as an excuse of plea of lessened responsibility for delinquency. The treatment in the institution, which is too small to deal with all the cases, consists of work therapy and perhaps subcutaneous injections of oxygen, or some other fashion of the time, e.g. hydrotherapy. He said that after discharge the patients do not, as a rule, relapse and that new drunkards do not develop among the younger people because "unlike people in the capitalist countries" they have plenty to occupy and interest them. He attributed the improvement to the general social improvement and the milieu, and partly also to the lectures which are given in the factories and to children in school about the dangers of alcohol; this is not done "by private societies as in capitalist countries", but by the state. He did not mention this prophylactic side until specifically questioned on the point and did not seem very enthusiastic about it; when I asked him if the emphasis in these lectures was put more on the social wickedness or the physical ill-effects of the habit, his reply gave the impression that it was left to the individual lecturers to decide what they should say. He said that there was no control of the sale of alcohol to drunkards, nor, I gathered, when the alcoholic has come before the courts for anti-social behaviour, is the penalty greater for a second offence. He described the outpatient surveillance or treatment of the cases by the narcologist vaguely as social care (a nurse is trained to do the social work) psychotherapy and oxygen injections. Anything more precise was not forthcoming. A patient had to attend the dispensary if told to do so; the rayon doctor could ask a policeman to bring him by force if he did not come, this was, however, seldom necessary. Some of the things Prof. Osowsky told me seemed to have been more rosily presented than other evidence suggests. The most recent statistics I obtained from them showed alcoholics to make up nearly a quarter of the total male admission to mental hospitals during the year. There were almost as many alcoholics as male schizophrenics; the total alcoholic admissions included a considerable number of re-admission (about half of them as far as I could make out). Evidently alcohol is a very much bigger mental hospital problem with them than in England or the USA, though their figures may be swollen by the compulsion put on alcoholics in Russia to undergo treatment. In Moscow I noticed several men drunk, some of them in their twenties and thirties; one drunken young man who was causing a scene in the crowded restaurant of the Park of Culture and Rest, seemed to excite sympathy and amusement among the other people there, and was treated with extra-ordinary forbearance by the policeman who was called in (I was told by the people I was with that the young man was protesting that he had to work very hard and was entitled to sleep or sing at the table if he wished, and that people sitting nearby were taking his side).

I asked Prof. Osowsky about what is done for feeble-mindedness, and wayward or delinquent children. He did not regard these problems however as a matter for psychiatrists or even for doctors of any kind to attend to. I gathered from other sources that juvenile delinquency had been increasing in the last five or six years, and is causing much concern. He mentioned occupational therapy and educational measures but by the former is meant in Russia what has been the custom in the less energetic mental hospitals with us, i.e. getting such patients as can do useful work, rather for the sake of the work than of their own health. 


\section{Report}

Since the denunciation of "pedology" in 1936, the whole subject, and especially mental tests and psycho-technics, has been under a cloud, almost to the point of extinction; consequently I could not find that there was any special training for defectives on a large scale. As I did not, however, manage to get in touch with anybody who spoke with first-hand knowledge about the matter I was left uncertain. Although Osowsky had been specially picked out for me as the man who would know all about the statistics for Leningrad, he was unable to give data which one would ordinarily be able to get from official records, and altogether the statistical side of psychiatry seems unaccountably neglected. Even at Davidenkoff's clinic for neurological and neurotic cases (formerly Pavlov's clinic), when I asked what were the proportions of different types of illness at the clinic each year since its opening six years or so before, I got the only too common answer to any definite question, namely, "they were just getting it out", "it would be ready shortly"; and when I asked how many of the cases were neurological and how many neurotic, they could not even tell me that. I was eager to find this out because, according to Osowsky, a lot of the neurotics go to the internist, as in other countries, or to the neurologist, rather than to the psychiatrist.

At Davidenkoff's clinic I asked about the treatment of the neurotic; they emphasised that they did not use psycho-analysis but employed a little hypnosis and persuasion. I gathered that they do very little psychotherapy at all. Davidenkoff's chief assistant could not give any concrete illustrations, it seemed, of his reiterated statements that they studied and treated their patients by physiological methods and that through Pavlov, psychology had been superseded by physiology, etc., etc. When I pressed for details and method, they kept laughing and saying "Oh, something concrete he wants," and repeated their phrases about applying the knowledge gained from dogs to the study of human beings. In the long run what they do, as far as I could make out, is to give full doses of sodium bromide three times a day but with no control of the chloride intake (at first they said vaguely that they did and when we got into details said they had not done it yet, but they were just going to begin it). Similarly with the classification of patients into four types according to their temperaments, the only criteria apparently, apart from a rather subjective total estimate, were how the patient had responded when his life had been in danger and what were his responses to fatigue and work tests (Kraepelin - Schults, ergograph, dynamometer: chiefly the latter). They were doing some research on sleep, taking electrical records of eyelid movements in subjects who are falling asleep; the work was being done mainly on a "narcoleptic", whom I saw, but who seemed to me probably a hysteric. They were treating a "narcoleptic" by sleep conditioning and said they had "cured" him, though I found that he still had his cataleptic attacks. They work in a large hospital and can pick their cases to suit themselves. They were also doing some conditioned reflex work on motor reactions, on orthodox lines. I asked about Davidenkoff's genetic studies, of which I had known something before, and one of the assistants, who was responsible for that part of the work, told me she was studying the heredity of sleep in twins and ordinary siblings. Her results, however, will be a little unreliable, I think, because she gets the necessary data as to length, uninterruptedness, etc., of sleep from the children themselves whom she is studying and from their parents, rather than by direct observation. In the wards she showed me a number of myopathics and dystrophics 


\section{Aubrey Lewis}

and said that in various neuro-muscular conditions (including Myasthenia gravis) she had good results by giving "myelisat" which they use very widely for the non-cerebral neuro-muscular affections. There were a number of interesting cases, e.g. an epileptic, who had been conditioned to have a fit whenever light of a particular colour was turned (he had formerly had his fits on awaking from sleep, their onset being detected by the electrically recorded lid movements). On the other hand, in a woman with a remarkable tic beginning in her eyelids, they had not made any attempt to register these initial movements and analyse them on their apparatus. In the wards the doctors talked freely about the patients' neuroses in front of them, talking Russian to the interpreter quite loudly. The beds were a little crowded but the clinic well laid out for its purpose. As in other clinics, there seemed many more doctors about than would be expected in other countries, but since punitive taxation has practically killed private practice, these clinics may not be representative of Russian hospitals as a whole; probably the profusion of doctors has not quite the significance one at first attaches to it. It seemed clear at any rate that in the clinics the number of doctors is out of proportion at present to the amount of competent work done or even the number of hours spent at it (so many finding it necessary to work at several jobs). In the department dealing with vegetative anomalies, Dr Weinberg showed me a number of endocrine cases, some of them very rare, and a collection of patients with migraine. Apropos of the somewhat uncritical approach some of them showed to endocrine therapy, even Ossipov told me he had had great success in treating melancholia with an interior pituitary preparation given by the mouth.

Conditions in Russia, even for a visit so remote from political questions as this, were different enough from those in other countries to call for some general references to them. There was first of all the baffling difficulty in getting to see the people and places one wanted to. Though I repeatedly asked in Moscow and Leningrad to be allowed to visit a large mental hospital, this could never be managed. I had hoped to see Prof. Bronner early in order to get a general understanding of the organisation and line of development of psychiatric work, but this was impossible (I was variously told that he was ill, away at a congress, and on holiday); nor, though I asked if I could call on any of his assistants who could inform me on these matters, was I able to do so. Similarly, I was never able to see Prof. Astachoff, Prof. Uktomsky, or Prof. Davidenkoff; and, as the explanation varied, (e.g. one day Prof. Uktomsky would be too busy to see me, they said, another day his telephone had broken down, another day he had already been away for a week from Leningrad) one felt that it was easy to arrive at false conclusions from what one saw and heard. Moreover, it was impossible to spend the time as profitably as elsewhere, since far fewer visits were arranged in the time that I was accustomed to pay ordinarily, and some of those whom I saw seemed so bent on impressing the visitor and answering questions without consideration, or else defensively, as if criticism were implied that it was hard to form a clear picture of their work. A neutral inquiry was treated as though it were a statement containing objections out of which one was to be dissuaded. It was noteworthy that the senior people, like Kroll, Orbeli, London and Lina Stern, and some of the younger, abler physiologists and geneticists were free from this. They talked reasonably and did not keep trying to reply to some argument supposed to lie behind one's question. The 
psychiatrists, however, were prone to wander round the point, and to paint a diffusely rosy picture, on the details of which they would hedge. Some of them talked more like salesmen than scientists.

Although more or less familiar with main trend[s] in other countries, they seemed in psychiatry, and to a less extent in physiology, out of touch with the nuances of opinion elsewhere, e.g. the malarial treatment of GPI and continuous sleep treatment of psychoses were to [sic] as though they were recent and still highly disputable discoveries. Orbeli's attitude towards protopathic and epicritic sensation is an example of the same thing. No doubt it is due to the very limited contacts even the foremost men can have with their fellow workers outside Russia, and, though less significantly, to the difficulties in getting hold of foreign journals, (this is apparently not the case in physiology but is so in psychiatry). The younger clinicians, who have never been abroad, seemed to suffer most from this limitation and the ones I met at the Gannushkin clinic and in Leningrad seemed unpromising and ill-informed, judging from the very little I saw of them. Their notions of the outside world in its medical aspects are naive on some points; advances in Russia, which by our standards would be belated and fumbling, they presented as daring triumphs of Soviet thought in medicine. However, I feel particularly diffident about my impressions: what with the language difficulty, the delays in seeing people and their reticence or vagueness in some cases when I did get to them, I could not feel confident that I was finding out what I wanted to know. Moreover, I had extremely few opportunities of seeing anyone without the interpreter's company, even though in most cases there was no interpreting needed: where I did see people alone they talked much more freely and enabled me to see how misleading, on some matters, the interview à trois had been. I was enjoined not to publish what I had been told or indeed what I had seen, because it might rebound - as had happened before. I did not gather that the best scientific workers in this branch of medicine are happy, or that what is done in Moscow and Leningrad is representative of the rest of USSR, or even of RFSSR: the discrepancy is extreme. Criticism of scientific work may be hampered because of its political repercussions as with Gurevitsch's work; or suddenly whipped up by a political change of wind.

Psychiatry, even at its best, seemed on a much lower level than physiology and genetics, and probably than brain morphology. But I could not get to see enough people to judge fairly, and when I did meet someone like Kronfeld, who could describe the position fully, he hid his knowledge and opinions behind exuberant praises.

I had supposed I might find in Soviet psychiatry great licence of speculation and experiment, original points of view, and enormous development of the social side of this subject. But in this I was disappointed: I always asked what they were doing that was new or different from what is done elsewhere, but found that the work was mostly along familiar lines: as far as social psychiatry was concerned, I heard of no new sides and no enthusiastic progress. "Pedology" and vocational psychology had been dropped, with public repudiation of mental testing, because they conflicted with political views, or had been misapplied. Speransky and Braines certainly had unfamiliar things to tell but the one was unspecific and the other dependent on a biological theory that is discredited. The actual yield from original theories, e.g. of Speransky, or from formerly stimulating ones, e.g. of Pavlov, seems meagre. 


\section{Aubrey Lewis}

As regards the practical work in psychiatry I had the impression that the nursing is poor, though on the upgrade, and that of psychiatric social work, as understood in England or the USA, there is little: they seem to rely (understandably but, as things are, rather shakily) on large-scale, and not on individual, social measures. Of a psychiatric approach to delinquency I could not find evidence nor of any detailed sociological approach; I was told that the number of offences by children had increased in the last few years. There were many indications (e.g. in the Park of Culture and Rest) of the earnestness with which the people are instructed in medical, as in other more or less technical, matters. Except with regard to alcohol and syphilis, mental health appears to play little part in the popular education.

I had the impression that scientific congresses are long and unduly numerous and time-consuming. Teaching inevitably takes up a great proportion of the senior men's time too. The statements about the number of people engaged in research in this and that institute needed qualification; many of them seemed very much in statu pupillari, and the amount of serious work done depended on a few people, trained and competent. Like so much else in Russia, the significance of all this varies according to one's response to the assurance "it is in construction; come again in five years' time and you will see".

I expected that in psychiatry the Soviet insistence on research being directed towards practical and previously defined ends would be obvious and interesting. But it seemed doubtful whether such planning was really working, in the way one had read of, in the field of medical research, or whether there was much co-ordination of effort. The directors of departments had to submit budgets or indicate in advance what they were aiming at, but this was done, at any rate by some, perfunctorily and with a belief that in research you could not predict what you would have accomplished, or even what you would be working at, by the end of a year or two. I did not gather that the members of the party who meet regularly in each institution interfere with straightforward research. I was unable to meet people like Prof. Bronner who could have informed me of the lines of development planned in medicine. However, a casual visitor can see that the political and social background casts much light and much shadow on scientific work, and that broad statements about it cannot be taken at face value.

\section{FINLAND $^{32}$}

In Helsingfors I saw Prof. Fabritius. His outlook on psychiatry was considerably coloured by his earlier, predominantly neurological interests. He mentioned some of

\footnotetext{
${ }^{32}$ Psychiatric hospitals, such as the Lapinlahti in Helsinki, that near Kuopio and the Kakisalmi and Pitkaniemi hospitals, began to be built in Finland between 1835 and 1900 . From 1840 the management and care of the mentally ill became the State's responsibility. After the First World War there was much development in psychiatry; most provinces had their own asylum, or shared one with a neighbouring province, and psychiatric departments were established in general hospitals. German psychiatry had influenced Scandinavian psychiatry heavily until the Second World War, and many Scandinavians went abroad to study the subject. Freud's theories were not very influential until after the Second World War; until then Scandinavian psychiatry emphasized somatic and constitutional aspects. The concept of schizophreniform psychoses was much used (it had been elaborated by Langfeldt), and from the 1920s malaria therapy and the convulsive and shock therapies were increasingly used, a little later than in other European countries.
} 
the principal difficulties that arise in regard to staffing, through the prevailing nationalist feeling and the Finnish-Swedish dispute. He mentioned that his most promising assistant, Gordin, who had lately written the excellent monograph on torsion-dystonia, was being blocked in his advancement for reasons of this sort.

In Helsingfors there is the familiar problem of short-time workers, i.e. the doctors of the clinic are unable to keep adequate records, do scientific work, etc., because so much of their time is split up between a number of jobs in order to earn a living. His first assistant, for example, has a private practice, prison work, court work and some other jobs, so that he is able to spend only a few hours a day in the Clinic. The professor is himself apparently much occupied in writing expert reports and in teaching undergraduates. Gordin's work was interesting, though he seemed unduly influenced by the views of Muskens. Kaila (who had been in Heidelberg when I worked there in 1928) is apparently unable to give much time to research. Psychoanalysis and the related points of view are not favoured in the clinic.

Prof. Fabritius had been working on the effects of injecting separated leucocytes of schizophrenics subcutaneously into normal people, and he also told me of some studies on the cerebral spinal fluid, which had not been carried very far. He spoke critically of the work done by Brander, in Prof. Ylppo's Department, on premature children, and his extraordinary finding that the IQ of these children correlated with their birth weight. In Prof. Ylppo's Department there was apparently considerable interest in some of the psychiatric problems which children present.

I also saw Prof. Granit, who was good enough to show me his experiments on the eyes of decapitated frogs. It seemed that this was a field in which investigation into the effects of such drugs as mescaline, and also the changes that accompany visual hallucinations might be studied with profit; Granit agreed that there were possibilities, but the worker would obviously need some special training for a short time in his laboratory. It seemed also that his research into light and dark adaptation might be applied to a small corner of pharmacological investigation in psychiatry, but with far less profit than his work on the changes of retinal potential.

\section{NORWAY ${ }^{33}$}

\section{Bergen}

In Bergen I saw Dr Birkhaug. The bulk of his work is, of course, remote from psychiatry, centring around the relationship of immunity to allergy, in connection with tuberculosis. The exactness of his methods and especially the careful statistical checking were, however, illuminating and in striking contrast to some of the loose research in psychiatry which could be done with equal strictness perhaps. Some of

\footnotetext{
${ }^{33}$ See note 32 above for general Scandinavian trends. In Norway, a government-initiated inquiry into the conditions of life of the mentally ill in 1824 advocated opening four psychiatric houses, and led to a highly progressive Act in 1848 for the treatment and management of the mentally ill. The first psychiatric hospital, the Gaustad hospital in Oslo, opened in 1855, based on the Auxerre psychiatric hospital. Between 1855 and 1881 three more hospitals opened: Rotvold in Trondheim, Eeg in Kristiansand and Neevengarden in Bergen. The first psychiatric service began in 1917 and was part of general hospital Ulleval in Oslo; the second was the psychiatric service of the University of Oslo, built in 1926.
} 


\section{Aubrey Lewis}

his work seemed applicable in principle to infections like anterior poliomyelitis and encephalitis lethargica, which are of importance for the psychiatrist. Of the alleged association of schizophrenia and tuberculosis he was a sceptical as most authorities; he knew the literature of it.

The social aspect of his work on tuberculosis and the success of his attempt to concentrate the preparation of BCG [bacille Calmette-Guérin] in one place were also interesting in relation to comparable problems in social psychiatry, especially the widespread employment of potentially dangerous therapeutic methods. The remarkably unhampered conditions under which he is able to work perhaps account in part for the critical thoroughness with which he is able to apply himself to a concrete scientific problem. He also showed me the leper hospital and two of the patients who had advanced anaesthesias and amputations.

\section{Oslo}

In Oslo I visited the University Clinic. Professor Vogt had recently been ill for three months, but he showed me round the clinic and discussed the lines along which it had developed. His interests seemed administrative, social and psychological. But it was clear that in spite of his special interest in problems of the family, sexual life, etc., he was no great appreciator of psychoanalysis, (though in theory, like many people, more sympathetic to Freud's intelligent system and sincere work than to the obscure or superficial views of some of the related schools). Like other people in Norway he deplored the way in which Harald Schjelderup's enthusiasm for psychoanalysis had swamped his earlier studies and work. On the other hand, Prof. Vogt was not much interested in somatic studies, such as Langfeld had been pursuing in his clinic.

Langfeld told me of his own inquiry into the prognosis, not only of schizophrenics, which he has published, but also of manic-depressives and obsessionals. He is proposing to work on the vegetative nervous system; one got the impression that in these somatic investigations his brother, the professor of physiology, was prompting him. So far as his clinical investigations are concerned, he seemed not sufficiently acquainted with the literature, in spite of considerable effort. I also met his brother, who mentioned the objections that had recently been made by him and others to Gjessing's conclusions. It is surprising that there is so very little contact between Gjessing and the physiologists at the university.

The university clinic is still incomplete and is intended for the treatment of neurotics, and the observation, only, of psychotics. Like others who have in the last 20 years developed a clinic on these lines, i.e. voluntary admission, open doors, etc. Prof. Vogt, when speaking of his experiences and hopes in detail, showed that he had worked his way independently along the same road as others were following; the problems are clearly very much the same, impose the same self-discipline on the doctors concerned, and cause the same surprise in each country when it is demonstrated, for instance, that a large measure of freedom can obtain in a voluntary clinic without any considerable risk. Likewise he had aimed at a children's department. The impossibility of having enough doctors to carry out detailed psychotherapy, the unwisdom of keeping patients for more than a year at the most, the uselessness of treating drug addicts in the 


\section{Report}

clinic, and other points familiar for example at the Maudsley Hospital, came up in his conversation; his conclusions as to what is best were remarkably similar to those arrived at in London.

The problem of following up the cases after they have left the clinic is made difficult for him by the fact that they come from all over the country. For those who belong to the Commune of Oslo, Dr Lofthuis maintains a general supervision, and has a social worker to help him; he also had until lately been responsible for the recognition of defective children, etc.

The laboratories of the clinic did not seem to be in very active use. The psychological laboratory was empty, and in the chemical laboratories only routine work was going on. Langfeld, however, was doing blood sugar responses to insulin intravenously, in order to investigate why schizophrenics sometimes require such large doses before they exhibit the effects of hyperglycaemia. He did not, however, seem to know some of the recent work, e.g. that of Himsworth on sugar metabolism, and, as one so frequently found in the various countries, had been accustomed to rely on the German literature and had only latterly begun to read the English and American journals.

The buildings and equipment of the clinic seemed good, except for the occupational therapy [sic], which follow the old pattern of skilled carpentry, gardening and other useful or pleasant tasks, probably limited to the few who feel like it or are particularly trained for it. Recreational therapy, gymnastics, etc., are not organised. Making allowance, however, for the habits and outlook of the Norwegians, the arrangements probably work better than a more rigid system would. As elsewhere in Norway, much of the laboratory work is done by medical students waiting their turn to get on with their clinical studies. Apart from Langfeld, I heard only of one assistant - a young cand. med. - who was doing research (on histopathology under Prosector Jansen at the university). The clinic seemed on the whole good, but not enterprising, active or original.

The relationship between the clinic and the two neighbouring mental hospitals Dikemark and Gaustad - is friendly but, I gathered not intimate. The result, however, of the present relationship between the psychiatric clinic and the Oslo mental hospital is that the clinic mainly keeps the manic-depressive cases, whereas the schizophrenics, and other prognostically less favourable forms, are passed on; consequently Gjessing rarely receives at his mental hospital typical affective cases such as he would like to study along the lines he has employed for cyclical schizophrenia. As far as the doctors are concerned, there seems to be some interchange; but for the University career, the essential MD examination, which is so rigorous, puts many mental hospital doctors entirely out of the running.

There seems no doubt that Prof. Vogt has had a great influence on the direction psychiatry has been taking in Norway, and that his broad-mindedness, philosophical interests and personality have not only been of general benefit, but have led particularly to a concern with the social and therapeutic side of the subject.

There were several people whom I was unable to see because they were away at a congress - Ödegaard, Monrad-Krohn, Jensen and others. I had also thought of seeing Lingjaerde, but he was away up in the north of Norway at Bødin, and most 
of the people I met had a low opinion of his unusually painstaking investigations into liver-function in schizophrenia. Apparently he interpreted as abnormal much that occurs in normal people, e.g. bile products in the urine.

I saw Prof. Mohr who told me about his Drosophila work. He also introduced me to Keonesland, an assistant of Jensen's, who was working on the effects of carbonmonoxide on the brain, in the manner of Alfred Meyer, and following the tracts in the brain affected by cortical lesions. Prof. Kristine Bonnevie discussed some of the questions arising out of her work on finger prints. I was surprised to find that she did not know of the English work, particularly that of Percy Stocks, on the finger prints of twins, and that she had not used palm prints at all to confirm her diagnosis of monozygosity in twins whom she had reported; on the other hand, it is extraordinary that workers in England have never adopted her method of denoting finger print patterns, so generally used elsewhere now. She also told me how the study of anomalies of digital development in some mice had demonstrated that during a brief stage of development the CSF was forced out under the skin and travelled round, interfering also with eye development. It occurred to me that the mysterious association of polydactylism with eye anomalies in the Lawrence-Meon-Biedl syndrome might be worth looking at from this point of view, though such an explanation would probably be impossible to apply because of the nature of the eye change. She told me of her studies on transplantation and of the work on anencephaly; she also showed me her preparations in celloidin. The relevance of her studies in comparative pathoembryology - as it may be called - to some of the problems of neurology, seemed fairly clear, though not to those of psychiatry.

Professor Langfeld told me of the work being done in his laboratory on calcium metabolism and vitamins, but it appeared that these were mostly limited investigations done by candidates for a doctorate, and that he would have preferred to have had more say in the choice of subject of the investigations, instead of merely advising and superintending these young men, who would leave the laboratory as soon as the investigation was complete.

Prof. Langfeld seemed extremely critical in his outlook, perhaps more critical than productive; his strictures on the physiological work of Lingjaerde and other psychiatrists, who had submitted MD theses - which came under his notice - were no doubt justified, but sharp.

I spent a day at Dikemark with Gjessing. Of his approximately 800 patients belonging to the city of Oslo, the majority were regarded by him as schizophrenics. There were some seniles and arteriosclerotics, but GPIs are lacking because they are filtered off by the General Hospital, and therefore the only ones he gets are those that have been unsuccessfully treated with malaria, etc.; and the recurrent affective conditions are drained off by the psychiatric clinics. He has succeeded in getting much support from the Commune for his research, as well as for building, and his new block for occupational therapy, etc., is admirably arranged for his purpose. The level of general organization was high; treatment was individualised, and, presumably because of good nursing and structural facilities, they have been able to dispense with sedative drugs during the daytime for the last four to five years. It was of interest that in spite of admirable arrangements and the pleasant surroundings of his hospital, Gjessing found 
it difficult to induce his former patients, who had been discharged "recovered", to come back for a few days for further metabolic study, because their relatives or the patients themselves did not like the idea. Consequently, Gjessing was anxious to have a small clinic or separate ward in Oslo for this purpose; evidently it takes much more than general hospital conditions to make people, even in Norway, regard the mental hospital as they would a general hospital. Possibly the difficulty is enhanced in Gjessing's case by his not having a social worker; Lofthuis, I gather, has nurses who act as social workers, and he keeps in touch with the patients, as does Saethre also, in some cases.

Gjessing's senior women nurses had, I was told, done three years general training before they came to him, and the level of nursing attained seemed well up to, or above, the standard of the average English mental hospital. Some of his male nurses were, like his laboratory workers, medical students obliged to mark time. From his point of view it is, of course, a great advantage to be able to pick out men particularly interested and competent in physiology for his work, and it has probably also the advantage of directing able students into the psychiatric field when later on they qualify, but of course the system is hard on the students themselves. It is a pity that, apart from a few women medical students who do psychiatric nursing during the long vacation, no advantage is taken in England, as far as I know, of the briefer opportunity available here during the holidays for encouraging some interest and detailed study in psychiatry.

In spite of his large staff Gjessing finds it impossible to carry out his detailed metabolic researches on more than three cases at once, and in view of the length of time during which he carried on an investigation and the strictness of dietary control, his researches would be impracticable in a psychiatric clinic. It was indeed on the method, rather than on the outcome of the research, that he laid most stress, insisting on the value of continuous observations over a long period. The thoroughness of his initial overhaul of the cases, both for general purposes and in order to determine suitability for the metabolic research, was impressive, and, as growing out from his earlier views as to the toxic origin of much mental disorder, indicated how the thorough prosecution of even a false scent proved, in the long run, more fruitful than dull or halfhearted research along more travelled roads; his combination of a speculative and even imaginative optimism with fairly severe self-criticism and, I gathered, receptiveness to criticism from outside was noteworthy. The two chief difficulties about accepting his work as it stands are presumably (1) the uncertainty as to whether the cases he has studied are mainly schizophrenic, as he suggests, and (2) the possibility that the metabolic changes he observes are dependent on the great change in muscular activity that occurs when the patient passes out of his stupor or into it. As to the former, he told me that he had found a pyknic habit of body among the immediate relatives, and the data I learned about the clinical picture in the patients I saw suggested that there was a large affective component (as witness the predominance of paranoid delusions, the cyclical course, the "facultative" stupor, and the striking manic conduct of a patient who was shown to me as schizophrenic) which fitted in with this view. This is not to dispute that there were also many schizophrenic features in the patients.

As to the dietary point (upon which Prof. Langfeld was inclined to lay much stress) one must accept Gjessing's statement that the food taken remains consistent in both phases, but as it is a diet adequate for resting conditions, it is understandable, as his 


\section{Aubrey Lewis}

critics say, that the nitrogenous output might increase with a catatonic excitement; he said that experts he had recently consulted, while abroad, had agreed with him that it was inadvisable to vary the diet according to the clinical state, but I could not see why he should not make his standard diet bigger. From his point of view the question is not an important one, because he believes there is no evidence that exercise would account for the alteration of nitrogen output, and the fact that the nitrogenous substances are turned out two days before the excitement comes on cannot be explained easily. Langfield's other criticisms e.g. of the view that there can be a storage of toxic nitrogenous substances, during the stuporose phase, in some indeterminate storehouse, probably the liver, and of Gjessing's view that the condition is a toxic diencephalosis, are less important, since Gjessing puts these forward only as speculations.

His earlier interest in focal sepsis leads him to search patients thoroughly for sources of infection, but no longer with the excess of zeal which prevailed during the Cotton phase, as one may call it. Gjessing holds, however, that many of the variations in the clinical picture are complications due to infection, and that with thorough "defocalisation", clear-cut swings in the clinical state are enabled sometimes to appear, where formerly they were muddled. Gjessing had also been using insulin treatment for some of his long-standing patients; he had given heroic doses, the largest I had ever heard of (even up to 800 units), and believed that it effected considerable social improvement in their state; he was proposing to combine it with thyroid treatment afterwards.

It seems a great pity that the researches he has done, which for exactitude and completeness are probably unequalled, could not be carried out on any manic-depressive cases, recognised by him as such. It would clear up some important ambiguities in his work. He has such a remarkable turnover each year that it is difficult to escape the conclusion that a number of manic-depressive patients, or what would be diagnosed as such in other countries, go into his statistics as schizophrenics. If that is not so, then his "defocalisation", and other measures of treatment, make nearly half his schizophrenics capable of returning to ordinary life - a better result than most people with a similar unselected material can report. It was regrettably impossible, the day I was there to get statistics of the frequency of the different disorders in the hospital. Another difficulty is that he cannot, for obvious reasons, demonstrate in the blood of his patients any particular toxic nitrogenous substances, though he believes that of the total nitrogenous substances only a small proportion can be toxic, and that in this sense it may be a quite unmeasurable, qualitative rather than quantitative, effect. There is no evidence that the metabolic happenings he observes are the cause, so to speak, of the stupor or excitement, they may well be concomitants and are, no doubt, none the less valuable for that. If his view that there are toxic nitrogenous substances, as indicated by variations in nitrogen output, is correct, one might ask about the findings in other diseases in which there is nitrogen retention. He also mentioned that he was anxious to find a tolerance test for protein, but had not been able to. I put this point to Theorell in Stockholm, and he considered, as Gjessing had been told by others, that the only thing one could do would be to work through the amino-acids one by one, obviously a huge task. Gjessing did not know of Prof. London's method of studying the changes that occurred in the liver and kidneys, which I thought might throw light on the problem. 


\section{Report}

The doctor who was in charge of the female side of the hospital was working on folliculin, and had a good medical student assisting him. His results showed such close concord of folliculin output, presence or absence of menstruation, and effect of treatment by injecting a Norwegian gonadal hormone, as to be almost too good to be true.

\section{SWEDEN ${ }^{34}$}

\section{Uppsala}

First I went to Prof. Dahlberg's Institute. Unfortunately he was away but Dr Sjövall showed me the work that was going on. The inquiry that was being made into the factors bearing on the course of manic-depressive psychosis was a social, rather than a genetic study, so far as one could judge. The psychiatric problems raised by such an inquiry, which Sjövall was undertaking, had not been thought out; Dahlberg, however, had been there so short a time that the research had not got properly under way. An inquiry into the heredity of mental deficiency was evidently also in its initial stages. Sjövall said they were investigating fertility in the course of the latter investigation, but since still-births were not being included in the recorded number of siblings, there seemed a possibility of error. Later I saw Prof. Dahlberg in Copenhagen; he was good enough to explain to me the limited scope of the proposed investigations, which are only a beginning. He will obviously need the co-operation of an abler psychiatrist than seems available at present, if the psychiatric side of his research is to be done satisfactorily; he is himself (on some points perhaps unduly, and on others insufficiently) aware of the pitfalls.

I visited Prof. Svedberg's Institute, where he and Dr Tiselius kindly showed me the ultracentrifuge, as well as the cataphoresis method, for determining globulin fractions. Apparently the application of the methods to the study of the cerebro-spinal fluid, for example, has not yet come about.

I saw Prof. Jacobowsky at the mental hospital. He is very quick in his mind, but seems more interested in the administrative and vaguer social issues than in the details of psychiatry. Some of his opinions seemed more like impressions than conclusions. His staff did not seem particularly interested in research, except for the woman parasitologist in the laboratory, and the first assistant, Wahlström, who has been investigating for years the toxicity of the blood in schizophrenia, with on the whole negative results. The clinical material was extraordinarily interesting, and the general layout of the hospital good; occupational therapy was, as one nearly always found in Scandinavia, excellent. I was struck here, and at Beckumberga, by the low rate of charge for patients who have private rooms; it scarcely covers the per capita maintenance.

Prof. Jacobowsky was responsible for only a proportion of the beds in the mental hospital; another senior physician, in charge of 450 beds and also of the extra-mural

\footnotetext{
${ }^{34}$ See note 32 above for Scandinavian trends. The Order of the Seraphins was in charge of the hospital system in Sweden until 1876; these psychiatric hospitals were finally administered by medical services from 1877. It was only in 1851 that the State became involved. In 1929 a Swedish law included regulation for the admission and release of patients from psychiatric establishments.
} 
arrangements, took me on his round among the 70 patients placed out in family care. They are visited by a nurse once a week, and come to the hospital for their baths, etc. The cost of upkeep is approximately 2 kronor a day, i.e. heavier, I gathered, than it would be in Belgium or Switzerland. If, however, the patients work for the people in whose houses they live, less may be paid. Some of the patients who were regarded as incapable of work in family care would almost certainly have been working if still in the mental hospital. A high proportion of the people placed out seemed to be defectives; this was in keeping with the Gheel experience, and should probably modify some of the opinions expressed by Pollock and others about the wide scope of colony and familycare treatment. In the Uppsala arrangement, it looked as though the number of people in family care, and the people selected for it, depended a good deal upon how much pressure there was on the mental hospital beds. Family care is regarded more as the intermediate stage between the mental hospital and ordinary life, than as a permanent arrangement for the patient. The system was fairly recent and was being built up slowly, so that in the Uppsala district they have not as yet had difficulty in getting enough guardians, apart from the initial prejudice - now somewhat overcome. In one house where the house-wife was a young woman of the urban type with children of her own, and two difficult patients (a suicidal involutional and an aggressive senile), I asked why she stood it, and learned that she was in fact just going to give up looking after patients. Dr Hojer, however, told me that one of the reasons why guardians can be found is that there are so many childless people who care to earn a little more money thus.

Prof. Bergmark showed me the medical clinic, including some interesting neurological cases. I also met Dr Waldenstrom who told me of his study in porphyria; it occurred to me that the different responses of people to large doses of sulphonal might be attributable to there being always a particular metabolic disturbance in those who develop pellagra-like symptoms and methaemoglobinaemia, and that this metabolic disturbance might be characteristic of their illness, so far as the mental hospital cases are concerned. I also met Dr Lindquist, who mentioned his work on vitamin deficiency. Dr Waldenstrom showed me a striking case of alcaptonuria.

\section{Stockholm}

Prof. Wigert was apologetic about the structural arrangements of his clinic, which is, as he says, an old mental hospital, but it has plenty of ground and did not strike me as deplorable, though the laboratory space is small. There are 260 patients, of whom the majority are "under voluntary treatment", but this is different from what passes by the same name in England, in as much as these Swedish patients cannot leave until the doctor consents; if they protest, they may, I gathered, write to a board composed of two psychiatrists, as well as a lawyer and a layman, on which Prof. Wigert sits. A small group of patients had been admitted without any formalities, i.e. they were comparable to English voluntary patients, but they were exceptional cases. Prof. Wigert has the inconvenience of being unable to get rid of some chronic cases already in the clinic; he has only a small turnover of cases, with a hundred or so beds which he may do what he likes with. There is much pressure on his beds, but the new arrangements proposed will probably enable him to run the clinic on more satisfactory lines. Prof. Wigert was enthusiastic, in his jovial volatile way, about the 


\section{Report}

apparatus for doing electro-encephalograms, which had just been installed. It seemed an excellent set-up, and Dr Frey and the non-psychiatrist, specially responsible for it, were both very keen. I gathered that Zoltermann, who worked with Adrian, had had nothing to do with the arrangement, which had been put almost entirely in the hands of Ehrenswert.

They are also doing insulin and cardiazol treatment, though they cannot do more than about four cases at a time. The clinic is mainly an inpatient one; little psychotherapy is practised. The polyclinic is open two nights a week, and deals with about 30 patients each time; clearly when there are 10 or 15 new cases at a session, they cannot receive much individual attention. The new scheme provides for separate doctors to deal with the out-patients, so that the continuity now ensured by Rylander and Frey will be impossible.

In Hammerstein's laboratory (who was himself in hospital with a gastric ulcer) I saw Hugo Theorell. He told me of the work going on into the effectiveness of anti-anaemic principle; he and his associates were not working, however, on the changes that particularly affect the central nervous system. His chief interest, viz. the determination of the chemical structure of cytochromes, did not seem in any way applicable to clinical problems at present. He had, however, given much advice and help to Izikowitz whom I saw later. Theorell said, when we were discussing Gjessing's work and allied matters, that he supposed it might be better to try producing psychotic pictures by amino-acids, etc., than to attempt an analytical study of psychotics' metabolism. He also mentioned his grounds for being dubious about Verzar's views.

Prof. Antoni has some interesting neurological material in his wards, and it seemed that the cooperation between him and Dr Lyssolm, and probably also with Prof. Olivecrona, made for a very thorough organisation. He had several cases of aphasia, due to areas of softening, in people under 45 without syphilitic or vascular changes. Rather surprisingly, in his GPI ward he was not using tryparsamide because he thought it too dangerous. I saw him do two cisternal punctures for encephalography, and a combined cisternal and lumbar puncture for the photographic registration of the two pressures and the respiration by his assistant Lagergren. The latter had devised an ingenious and accurate method. Another assistant was about to study the oscillation arterial blood pressure in conditions of neuralgia and other disturbances. I was also told of the work that was being done on chronaxy in relation to Peer Wolfahrt's finding that one kind of muscle fibre predominated in the embryos of young people and was to be found in increased proportion in dystrophies.

Dr Höjer explained to me the administrative plans. I gathered that he had spent three or four years in psychiatry and was, therefore, well acquainted with the problems. Evidently the big towns - Stockholm, Gothenburg, and Malmö and one other - were being treated somewhat differently from the country districts, where more responsibility for mental care is to be put upon the county authorities. There were also the four institutions (including the one at Malmö) in which neurotic and psychotic patients remain, for roughly two months, in charge of physicians who are mainly internists with a few years' psychiatric training, the treatments being more along medical, occupational, and social than psychological lines. The purpose of the institutions was not so much to supply psychotherapy, as to be a means of ensuring that those receiving 


\section{Aubrey Lewis}

health insurance because of neurosis should be observed and treated. Apparently alcoholic cases are becoming less common in the big towns; Prof. Antoni said the same. In as much as the patient who is ordered to go to one of these places ceases to receive his insurance if he refuses, they differ from anything that exists in England. There is of course a fairly high proportion of relapses, though, I gathered, few patients are re-admitted more than three or four times.

Outside the town, which contains only a minority of the population of Sweden, the doctors are largely socialised, i.e. public officials. From what Dr Höjer said, it seemed that the private practitioners in those parts were rather less competent than the district doctor; in essentials the position was rather like what Bela Johan had described in Hungary, though presumably the standard is very different. These doctors correspond to medical officers of health, and have a trained nurse-social worker, who reports the cases requiring investigation; it is for these specialised investigations that physicians with three years training in a specialty, e.g. psychiatry, are recognised. Some of these are, at present, the doctors in local mental hospitals, as was the case, I suppose, with the doctor at Uppsala who had shown me the family care. On the whole Höjer did not seem disposed to staff the public psychiatric services in question with people engaged in mental hospital work, but said that a lot of these matters had not yet been decided, and were affected by the customary claims and dissensions, e.g. between paediatricians and psychiatrists in regard to children. He did not contemplate their embarking on any particular scheme of psychotherapy because of the obvious economic objections and the present uncertainty as to results. I surmised that there was not the same demand by the public for psychological treatment as has been aroused in some other countries in Western Europe or in America.

In Sweden, as in the other Scandinavian countries, none of the people holding authoritative positions had much esteem for psycho-analysis. Certainly the psychoanalysts have not gained any footing in the University clinics or in the public services. I was able to discuss with two of Dr Höjer's assistants, legal and administrative aspects, corresponding to the activities of the Board of Control in England, and the working of their law concerning sterilisation and alcoholism. There is also a department for the supervision of defectives, but attempts are being made to unify the two departments. Everyone emphasised the pressure on the mental hospital beds in Sweden.

I also saw Dr Izikowitz, who still works at the laboratory in Wigert's clinic, although now without any post there. Apparently he is hampered somewhat by lack of facilities and monetary support, having to provide some of this himself, but his investigations seemed extraordinarily painstaking and thorough. He had not been able to confirm Georgi's findings about cholesterine in manic-depressive psychosis. His chief interest for the last nine years has, however, been in estimating the albumin and globulin proportions in the cerebro-spinal fluid, in GPI. He had been studying the differences in this respect between pre- and post-malaria cases for their prognostic significance, and thought that a relationship had been established. Among his other interesting ideas was his attempt at providing prophylaxis against malaria, for those going to the tropics, by inoculating them artificially, as one would a GPI, and then giving sufficient quinine to kill the infection. His association with Theorell has clearly been to his advantage 


\section{Report}

in working out reliable methods. I did not get the impression that he had any close contact with Prof. Wigert.

I visited Prof. Kinberg in the prison and saw him with his chief assistant. His department is quite independent of the Public Health Department, and is a section of the Department of Justice. He is enthusiastic rather than critical. The patients who are referred to him are persons not allowed out on bail, i.e. mainly criminal cases; the people with minor offences are referred to one of a group of approved psychiatrists. Prof. Kinberg has assistants whom he calls social workers, but they do no visiting; their training has been in general, not in psychiatric, social work in Stockholm. The psychological testing is done by these social workers. The histories, moreover, are not got by a questionnaire circulated to the relations; it may be amplified later by the social workers. The forensic side of the psychiatric work is emphasised in the fact that all the psychiatrist's interviews with patients and their relatives are recorded by a stenographer, sometimes through the medium of a small microphone, of which the patient is unaware. Psychological tests are detailed and include some from van Lennep in Utrecht. Crime seems to be on a small scale in Sweden, judging by the number of people in prison; the number of women seemed especially small. Prof. Kinberg, however, sees two or three new cases there a week, and his reports are usually acted upon by the judge according to the recommendations included in them.

I also saw Dr Ramer, who is in charge of the child guidance clinic. It is run by the state, and is held in the building in which orphans and other children for whom the state becomes responsible are dealt with. The clinic is held daily and is conducted by two almost full-time doctors; it has been in existence for four years, and all children in the state schools, who show either abnormalities of conduct, learning difficulties, or delinquency are referred to it. The two psychiatrists have trained social workers and psychologists, and much of the work is done on general child guidance lines, the case sheet being prepared by social workers who visit the home, and psychological tests being done before the child is seen by the doctor. The treatment is mainly social and educational, little time being given to direct or intensive psychotherapy. There is no psychoanalysis. As it is a state clinic they are not able to select their material, the greater part of which consists of behaviour problems. I gathered that the arrangements for defective and backward children are - for the severer defects - residential schools; for those with mild deficiency, special non-residential schools of which there are ten in Stockholm; special classes for intellectually handicapped children, held in certain of the ordinary state schools, but conducted by specially trained teachers; and finally, children with such defects as word blindness or high frequency deafness are referred to a psychological institute.

I did not discover that there was any active work in neuro-pathology going on, apart from that done by a somewhat junior pathologist (Dr Ringert) whom I met, who is engaged on a study of the minute structure of cerebral tumours. I visited Prof. Liljestrand who discussed the difficulties of applying pharmacological methods of research to psychiatry. I gathered that he was less interested in the synthetic or analytic-chemical side of pharmacology than in what might be termed its physiology. He told me of the work he had been doing on the effects of alcoholism, and I was able also to discuss with Dr Bernhard the special investigations the latter was making 


\section{Aubrey Lewis}

into this problem. Dr Bernhard showed me his conditioned reflex chamber in which he had just been beginning some work designed to have a bearing on problems of child psychology. Although he is located in the children's clinic, and had spent some time with Prof. Krasnogorsky, I gathered that he would prefer to work mainly with dogs, for the customary reasons. As had been the case with Prof. Pick and Prof. Supniewski, Prof. Liljestrand had very little that was precise or of immediate applicability to say about the possibilities of pharmacological research in psychiatry; but like them, he believed the field would be large and promising.

Dr Lyssolm showed me his X-ray department, which seemed extraordinarily good. The care with which he traced out the outlines and located the abnormalities visible in his diagrams of the brain, together with his careful recording system, indicated how far he combined technical excellence with a research thoroughness and caution. He told me of the investigation that he was now making into the abnormalities to be demonstrated by encephalogram in the patients at the nearby mental hospital, Beckumberga, and added that he proposed to have the results analysed with Dahlberg's co-operation. I was shown round Beckumberga by one of the assistant physicians. The buildings, which are new, seemed well designed, but in the disturbed ward, in spite of the various improvements introduced into the building, the noisy patient, who tears off her clothes and rushes about, seemed as much in evidence as elsewhere. The relatively low rate of charge for the pleasant private rooms was again striking. Although the hospital is well staffed, I did not gather that the neurotic patients received much individual treatment of a psychological kind. I was told of the routine investigation Dr S W Wolfahrt had been making into the physical anomalies of the patients admitted; its excellence seemed to lie in its thoroughness and regularity rather than in a wide range of anomalies looked for.

\section{DENMARK $^{35}$}

\section{Copenhagen}

I first visited Tage Kemp: Prof. Thomsen, who is in the same building, was ill when I was there. Dr Kemp told me of his endocrine work, but indicated that he was rather marking time until his new laboratories were available. He told me of the limited genetic investigations he had been engaged on, but I gathered that he had not gone any further with social investigations, such as that reported in his monograph on prostitution. He seemed in touch with psychiatric activities in Sweden and Denmark, though not at the moment personally engaged in any co-operative work on psychiatry.

I visited Dr Sturup at the Psychiatric Clinic. Prof. Helweg had not then been appointed to the chair. Dr Sturup's interests, on the research side, seemed in the field of neuro-physiology and pathology rather than in psychiatry, he was, however, arranging to go to Switzerland so that he might introduce into the clinic insulin treatment, having already been working a little with cardiazol. Later on I met Dr Erik

\footnotetext{
${ }^{35}$ See note 32 above for Scandinavian trends. The first psychiatric hospital of the State of Denmark opened in 1820; during the remainder of the nineteenth century other psychiatric hospitals were built: Aarhus (1852), Oringe (1857), Saint-Jean (1860), Viborg (1977) and Middalfort (1888). A department of nervous illness was established at the municipal hospital in Copenhagen in 1875. Denmark was a pioneer in the treatment of "mental defectives", with a law adopted in 1934.
} 
Stromgren several times. He told me about his genetic and anthropometric inquiries on the island of Bornholm. I was impressed with the critical thoroughness with which he had been taking advantage of such an extraordinarily good opportunity for studying the incidence and genetic relationships of mental disorder in a limited population. $\mathrm{He}$ seemed to have an all round interest in medical psychiatry, including that of children, which is not always found in people who can pursue an exact investigation such as he had made, at so early a stage in their psychiatric education. I gathered that he will for another year be engaged in completing his training in general medicine. The requirements for specialising in psychiatry, as in other subjects in Denmark, seemed to be well adapted towards getting men who would not be one-sided or likely to make psychological medicine remote from general medicine. On the other hand, the impossibility of the senior assistant of the professor remaining for more than two to three years in this position, would appear to damage the continuity of teaching and research in the clinic; although it is to the advantage of the mental hospitals that their superintendents should be recruited in this way, it does not conduce to the university psychiatric clinic being as prolific as it might be in research. Presumably the matter turns on whether in the mental hospitals there are adequate facilities for a superintendent, who is keen to do research and not to be swamped by administrative routine.

I spent one afternoon with Dr Mogens Fog. He showed me his apparatus for studying the factors determining change in the size of the cerebral vessels. The investigations are obviously well devised and controlled, so that the results would be very reliable. It was arranged that I should go again, but my illness prevented this. Dr Fog also took me to his other laboratory where he was studying, with a dermatologist (Dr Christiansen), the variations of the skin temperature in the hand. In this, as in his other research, the technical and physiological pitfalls in what might superficially be regarded as a straightforward problem, came out clearly in his discussion with me on the precautions that had to be taken in working out and interpreting the experiments. He also introduced me to Dr Busch, the manifestly energetic neuro-surgeon, whose interest in histopathological problems Fog had managed to revive, with happy results for collaboration. Dr Busch showed me a number of his preparations.

During my illness there I also met a number of the physicians of the Rigshospital, who told me of their work, e.g. Prof. Warburg, Dr Preben Plum who had been making an extremely thorough investigation into agranulocytosis, Dr Kirk, who works on liverfunction, Dr Nielsen who has been studying digitalis effects (in conjunction with the physiologist at Lund) and others.

\section{GENERAL IMPRESSIONS}

There are some very general impressions (especially as regards psychiatry), which can be gathered together at the end. It is not possible to summarise the good things I saw and learnt: they were, of course, the best part of my journey, but they were spread over many fields, and were mostly connected with individuals rather than with systems and organisations; moreover, they were on the whole more often in other branches than in psychiatric research or practice, which did not seem in a rapidly progressive stage of development anywhere. My general impressions may therefore 


\section{Aubrey Lewis}

seem rather misleadingly weighted towards the side of depreciation. Most of the good things will have been mentioned in the earlier, more detailed part of the report.

Psychiatry seemed everywhere rather a stagnant subject: there is much research activity but this does not advance practice or understanding, because of either conflicting results, weak technique, idea-less repetition, excess of speculation, or - probably most important of all - failure to see problems that are at once fruitful and attackable. Certainly the fruits of psychiatric research seem very meagre in relation to its volume; it is depressingly less alive and (intellectually, if not practically,) less exciting than research in some other branches of medicine and in the restricted biological sciences such as animal genetics. It was very rare to find any worker on psychiatric problems - Gjessing was one of the few exceptions - who was enthusiastic and absorbed in his investigation because of the unexpected or unknown details he was finding out: yet there were many such people to be found in physiology, say, or even in internal medicine (e.g. Snapper). Insulin and cardiazol had, in consequence, a rather disproportionate value given them in most clinics: they stirred the waters dramatically, and were esteemed for that.

Nowhere was there evidence of any characteristic psychiatric method of research developing. This or that method, worked out in other disciplines, was applied with little modification to psychiatric problems: often this was done with only superficial knowledge of the limitations of the method, by a psychiatrist who "wanted to try it". But even where the investigation was carried out competently by a man well trained in the subject from which it was borrowed, the application of the method seldom led to its being transformed in order to cope with the problems peculiar to psychiatry. This borrowing of methods is of course what happens in all branches of medicine, but it seems that generally, and apart from empirical research, each such study has, when it is fruitful, led to the development of some peculiar features in the method, adapted to the new problem. In psychiatry psycho-analysis would seem to be the only such characteristic mode of attack devised during this century; and perhaps malarial treatment of GPI, though this might equally well, I suppose, have been introduced in the treatment of a somatic disorder without any mental features. Insulin (and cardiazol) represent another of these half-empirical somatic procedures: providing an impetus to research and therapeutic effort which was everywhere needed, but probably more so in European than in the English-speaking countries, where schizophrenia had not latterly been regarded with such fatalistic resignation as in the German school of psychiatry, still influenced by Kraepelin's conception of dementia praecox. It did not seem either that in psychiatry, even in Russia, there was that pushing of an idea to extremes which, whether the idea be partly right or mainly wrong, generally leads to the discovery of something new; that is, so long as it is done with the usual accompaniment of opposition, criticism and enforced modification by experience.

Most of the research, as far as it consists in fructifying psychiatry from outside, is unfortunately separated from the centres where the original studies "outside" are being actively pursued: quite often it is begun by the psychiatrist with only a reading knowledge of what it is about and how it is done. There is extraordinarily little evidence of the "outsiders", at work in some growing science, asking or managing to get to grips themselves with the problem of psychiatry, which their research might elucidate. 
Many of the people of this sort whom I met professed an interest in research into mental disorder, and even a keen desire to look at its problems and see what they could make of it, but ignorance of clinical psychiatry, limited time, administrative and other factors seemed almost always to be in the way. No doubt psychiatry, even where it was located in a general hospital as in Amsterdam, often remained rather out of the main stream of medicine, a division apart from the rest. Nevertheless, it looked as though in this and most of the other respects which entailed collaboration or fertilisation from without, conditions were appreciably better now than they had been and were improving steadily. Interest in the problems of psychiatry on the part of other physicians of ability seemed to be more hindered now by distrust of its vagueness, and of the excessive claims and obscure speculations of the psychopathologists and psycho-analysts than by any traditional prejudice.

Research in psychiatry seemed in most places poorly organised, when compared with neurology or physiology. It was bad when directed by a clinical psychiatrist who spent half his time in private practice, as nearly all the professors do, and much worse when directed by a laboratory man (even though full-time) who was not in daily contact with clinical psychiatric work. In the former instance it tended to be handto-mouth, slapdash or uncritical, short-sighted and excessively influenced by fashions and practical exigencies, bulky rather than valuable: in the latter (which was much less common) it commonly seemed to be departing from rather than approaching the problems of psychiatry; sometimes confusing the issues or leaving them in deeper shade, through ignorance of the many-sided phenomena of mental disorder and the fallacies and real questions they may give rise to.

In nearly all countries, moreover, the financial deterrents to entering on a career of research seemed harmful to the development of psychiatry. Those who go into private practice, as the majority must, are forced in the richer countries to direct their interests into psychotherapy, without being able to study its problems dispassionately, and in the poorer ones to aim at some prestige-giving academic status which is less a by-product of ability and enthusiasm than a means towards earning a living. Nevertheless, academic status and a record of having done some research have so much more to do with any advancement in a psychiatric or other medical career abroad than they have in England that the general level of training and experience in what may be called the hack-work of research - making a prescribed investigation painstakingly or at any rate industriously, working through the literature of a problem and summarising it with discrimination, using advice and criticism and learning one's limitations - was higher among the general run of psychiatric aspirants than it is with us. Particularly in the Scandinavian countries the rigorous demands of the MD qualification raised the standard of work in the university clinics and institutes, and indirectly throughout the country. I find it difficult to generalise, however, because of the enormous differences between countries, e.g. between Hungary and Holland; Sweden and Czechoslovakia; or even adjacent ones like Russia, Poland and Finland. Political factors and jobbery were, however, rapidly altering the state of affairs in the dictator or semi-dictator ruled countries: clearly the future professors and hospital directors were going to "get by" with less to their scientific credit than their predecessors had to show. 


\section{Aubrey Lewis}

Almost everywhere I found a greater interest and activity on the physical than on the psychological or sociological side of psychiatric inquiry. This was, of course, less noticeable in Switzerland and the Scandinavian countries, but even in them psychological investigations tended to be rigorously kept in hand and to follow safe rather than speculative lines: (psychotherapy, moreover, was either for the most part reserved for private practice or was a matter of common-sense adjustment of social and emotional problems). Social work was very much a practical matter (deliberate sociological research was very exceptional, though the need and opportunities cried out) and got worse as one went further East and the countries were poorer. There was, however, in some countries a contrast between their impressive buildings and laboratory equipment on the one hand, and, on the other, the low standard of hospital care and of social concern or provision for the patients who were outside an institution. In short, all that in England or the USA is linked up with the psychiatric nurse and the social worker seemed to call for much improvement in most of the countries I visited - in all indeed but a few western ones. The neglect was not so often due to economic stringency, I believe, as they made out.

In some places the predominance of neurology and the extravagances of some psychotherapists seemed to have had almost an equal share in delaying the development of the social and psychological side of psychiatry. On the other hand there were few places where the social side was wholly neglected: certainly the influence of current modes of thought in the world, or in individual countries, was strongly evident in the practical development of social psychiatry (on broad rather than individual lines) and the study of inheritance, whereas individualised psychological work was on the whole little regarded, whether as research or treatment. Other factors were of course also responsible for the shift of emphasis.

The wave of therapeutic interest, which followed the introduction of insulin and cardiazol, was working out less well in many places than one would have hoped: certainly in a few countries the work was being well done and its range extended, but, in many, little clinical acumen was displayed in assessing the outcome of treatment, the research possibilities were ignored, and there was the risk that, as with psychotherapy, over-enthusiasm might in time provoke an excessive disillusionment. The standard of clinical work and knowledge was perceptibly lower in psychiatry than in neurology: people had often a very detailed knowledge of the literature and difficulties of some tiny problem they had worked on for a dissertation or article, but had a poor grasp of clinical psychiatry as a whole; partly, I think, because they had not time to examine all their cases thoroughly, and because they were unduly satisfied with text-book accounts and needlessly conversant with bygone controversies, in which, let us say, Kraepelin's error, and still another had shown three years later that they were all a little right and a little wrong: names of people and of categories and quarrels usurped the place of immediate experience. All the schools of psychiatry except the French seemed to have been derivative, looking to Germany for their nourishment. Now, however, mainly for political reasons, and because of the great drop in the standard of German scientific work, this seemed to have changed: and there was no country that I visited (even including Italy and Russia), where it did not occur that many of the people I met were eager to establish or strengthen their contacts with corresponding workers in the 


\section{Report}

English-speaking countries: they would spontaneously raise this matter (at first, and again in Russia, rather to my surprise), ask about the opportunities of getting their articles published in the journals, even beg for lists of people here interested in their line of work, with whom they could get in touch, and often wanted advice about English and American books and journals which they might get for their libraries: I do not think that this was only from politeness, or in hopes of a nearer approach to the countries in which more money is provided for the endowment of research than in their own. Whereas for physiology and clinical neurology in England and North America their respect is of long standing, in psychiatry there had been an evident contempt or indifference towards all but German, Austrian and Swiss work: this attitude seems to be changing fairly rapidly. The attitude of other doctors towards psychiatry is changing too.

The level of the general practice of psychiatry in hospitals and out-patient work was, of course, closely dependent in each country on the moral and economic position. There were also the political factors, already alluded to, and particularised in the earlier passages dealing with some countries, e.g. Russia and Austria. There was the tendency in "totalitarian" countries to reward spectacular work, whether sound or not, and to favour lavish building and equipment; also to promote party-men, to damp down scientific criticism, and to hamper or exclude some able people who should have had influential positions and good opportunities to work; even sometimes, to modify theory for irrelevant reasons, (e.g. in genetics of insanity and defect, aetiology of neuroses). An indirect and less obvious effect, which will possibly through propaganda and onesided education be eliminated in the next generation, is the personal distress and unhappiness, apart from any material difficulties of their own, which some of the best productive workers feel while living under a tyranny or a threat, so that they cannot pursue their work with a free and single mind: I did not get the impression that those who told me they fret thus were neurotics or seeming to rationalise laziness and scientific sterility. In all countries individual economic problems of course troubled research workers and practitioners.

As I have said, psychiatry was not among the more stimulating and active branches of medical or biological work that I had the opportunity of learning about abroad. Although many countries have still much obvious leeway to make up in psychiatry, if they are to attain the standard that now prevails in a few, there are no immediate signs that I could see of a great advance in the subject, in any of its aspects, having yet got under way anywhere: nothing comparable to what has happened in pure genetics, biochemistry or even internal medicine during this century. But there is certainly an attack along a wide front, made with very widely varying enterprise and vigour in different places: and the results obtained in research so far correspond to the skill shown in using and adapting borrowed weapons; those achieved in clinical practice are more intrinsic, as it were - more dependent on what are as yet peculiarly psychiatric points of view (as has, I suppose, been evident in the advance of psychiatry, especially on the therapeutic and social side, in the USA for instance), and of course also on the opportunities of demands that come from the community and depend largely on its general cultural and economic level. 